Florida International University FIU Digital Commons

$8-25-2017$

\title{
Essays on Emerging Multinational Enterprises' Acquisitions in Developed Economies
}

Faisal R. Harahap

Florida International University, fhara001@fiu.edu

DOI: 10.25148 /etd.FIDC004026

Follow this and additional works at: https:// digitalcommons.fiu.edu/etd

Part of the International Business Commons, and the Strategic Management Policy Commons

\section{Recommended Citation}

Harahap, Faisal R., "Essays on Emerging Multinational Enterprises' Acquisitions in Developed Economies" (2017). FIU Electronic Theses and Dissertations. 3540.

https://digitalcommons.fiu.edu/etd/3540 


\section{)/ 25,' \$ \$,1 7( $51 \$ 7,21 \$ /[81,9(56,7<$ \\ 0 IIP II) QRUGD}

ESSAYS ON EMERGING MULTINATIONAL ENTERPRISES’ ACQUISITIONS ,1

' ( 9 ( / 23 ( ' ‘) \&2120, (6

\$ LGWHUWARQWXEP LWKCIQQSDWNOTXOICOP HQWRI

WHIUTXIUP HQWIRUMXHGH UHIRI

' $2 \& 725 \square 2$ ) $3+, / 2623+<$

IQ

\%8 6,1 ( 66ロ\$ ' $0,1,675 \$ 7,21$

El

) DMDO5 $1+$ DNKDS 
$\begin{array}{ll}\text { 7R] } & \mathrm{HO}-\mathrm{RDOQH} / \mathrm{L} \\ \text { \&RCOJ HIRI\%XVQHW }\end{array}$

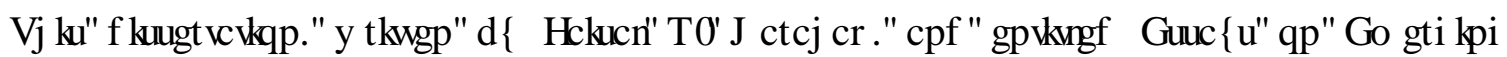

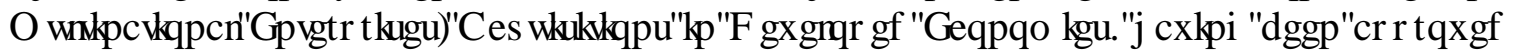

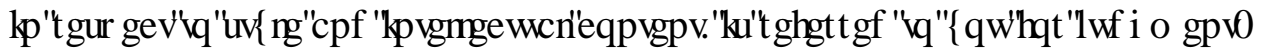

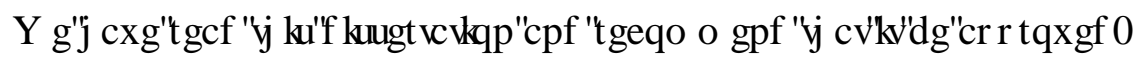

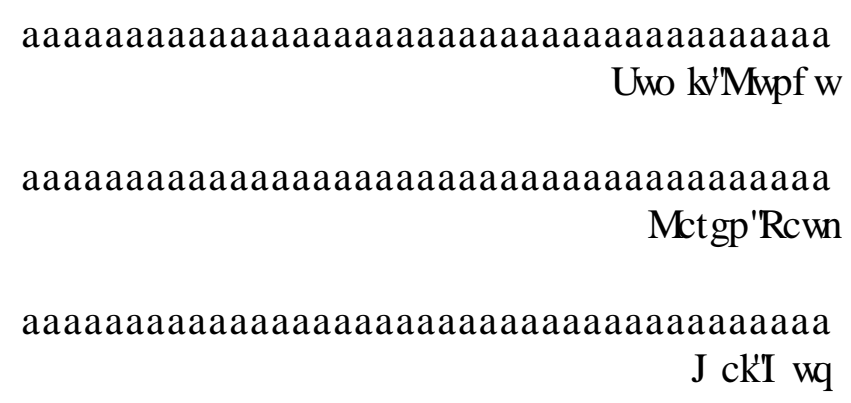

BBBBBBBBBBBBBBBBBBBBBBBBBBBBBBBBBBBBBBBBBBB

0 DU L\$ QQ9 RQ* OCRZ प0 DKU3LRIHMRU

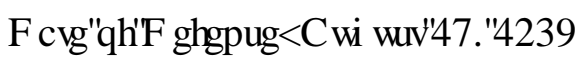

7 KHCWHUWRQRI ) DUDO5 W+ DOKDS LVIDSSLRYHG

BBBBBBBBBBBBBBBBBBBBBBBBBBBBBBBBBBBBBBBBB

' $\mathrm{HDQ}-\mathrm{RDOQH} / \mathrm{L}$ \&RCOH HRIT\%XYQHW

BBBBBBBBBBBBBBBBBBBBBBBBBBBBBBBBBBBBBBBBBB

$\$$ QO $\phi \mathrm{V} * \mathrm{~W}^{*} \mathrm{IO}$

9 IFHB HMGHQWRUL5 HHDFKIDOCF( FRQRP IFU HMHRSP HQW

DQG HDQRIIKH8 QYYHULM" UCXDM6FRRO

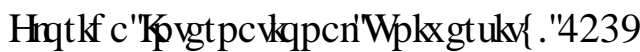

L 


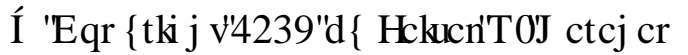

\$ QU KWLHMHYHG

III 
' ( ' , \&\$ 7,2 1

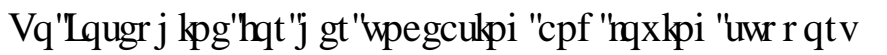


\$\&. $12: /(' * 0(176$

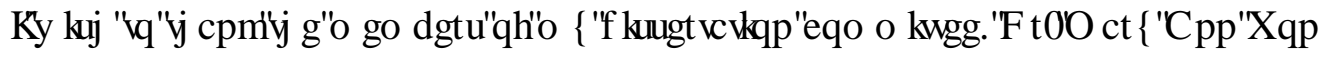

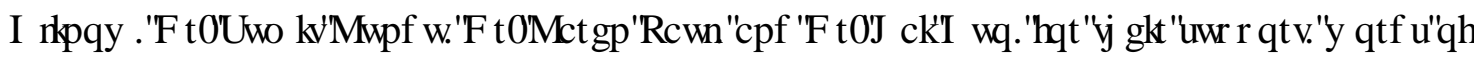

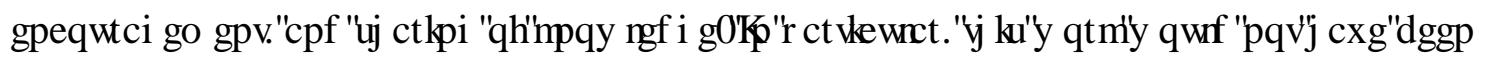

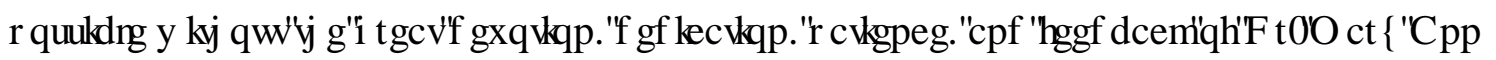

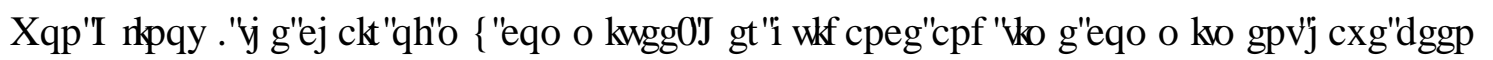

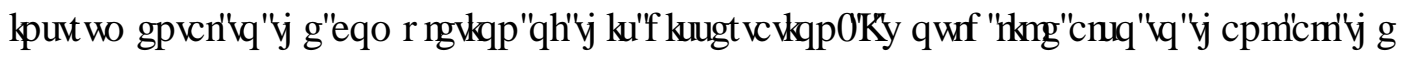

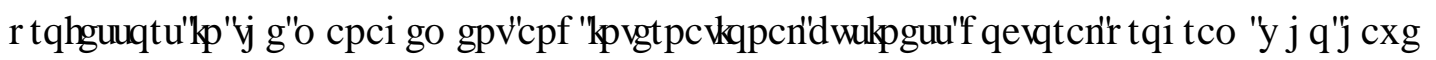
EHQYHU TIXSSRLUAH

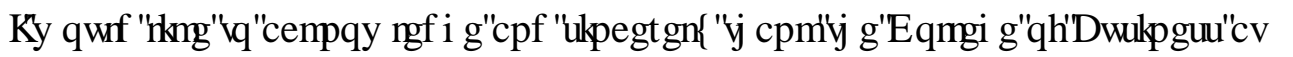

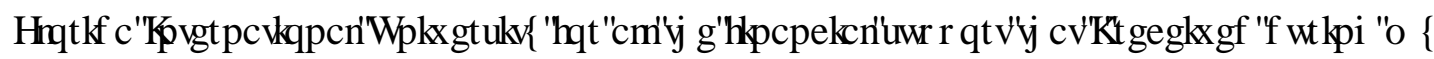

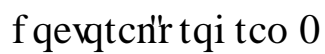




$$
\$ \% 675 \$ \& 7 \square 2) \square 7+(\square, 66(57 \$ 7,21
$$

ESSAYS ON EMERGING MULTINATIONAL ENTERPRISES’ ACQUISITIONS ,1

$$
\begin{aligned}
& \text { ' ( } 9 \text { ( / } 23 \text { 3) ' प) \&212 ), } 6 \\
& \text { El } \\
& \text { ) DWOO5 प+ DUKDS } \\
& \text { ) RLUAD, QMADNRQDOB QYHHUWMITI } \\
& 0 \text { IIP II) (RUTD }
\end{aligned}
$$

3LRIHMRU0 DUI\$ QQ9 RQ* OQRZ 0 DKUBLRIHMU

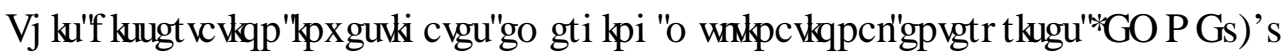

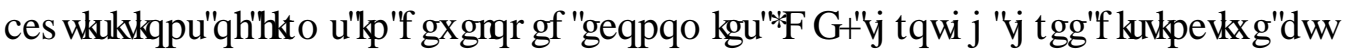

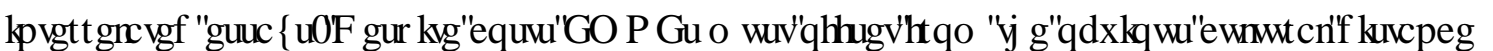

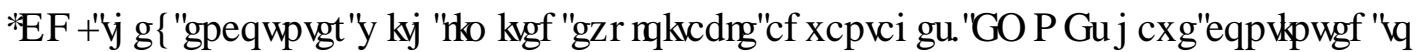

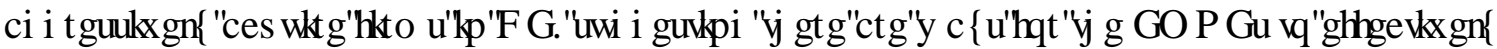

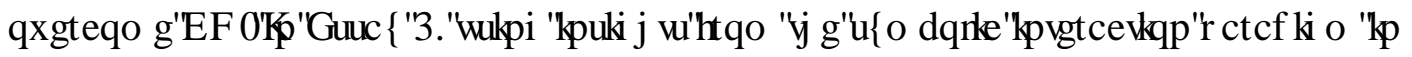

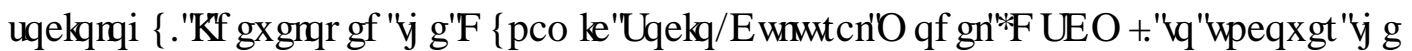

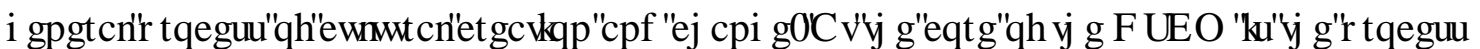

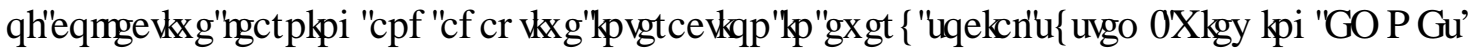

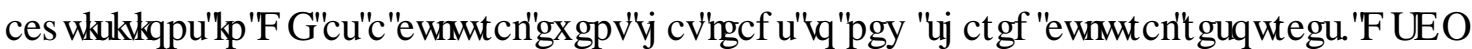

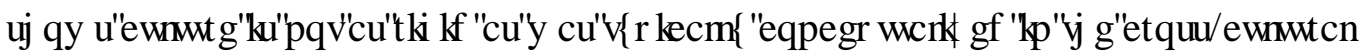

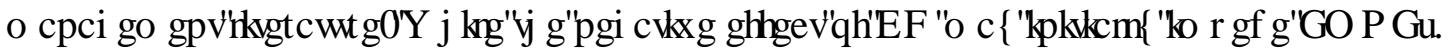

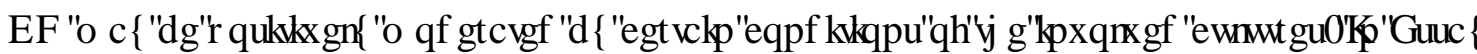

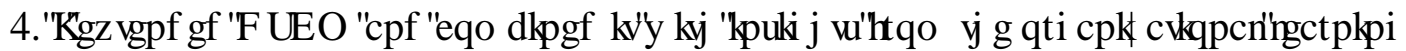
literature to focus on EMNE's choices of con WROP RGHDOGMXHUSHIRLP DQFH 


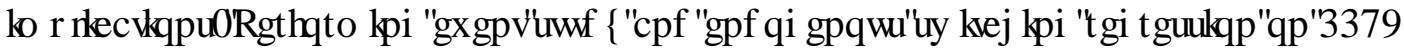

EMNE's acquisitions in 21 advanced economies, I found EMNE VKDYHIRQQDYHD HID

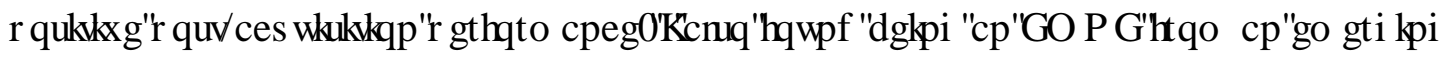

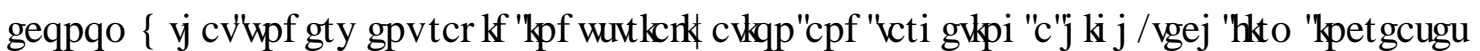

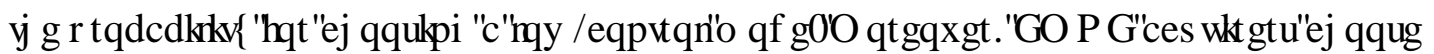

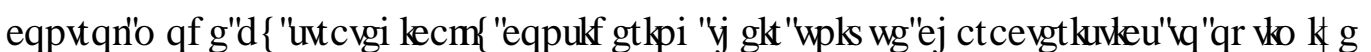

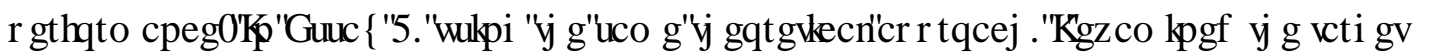

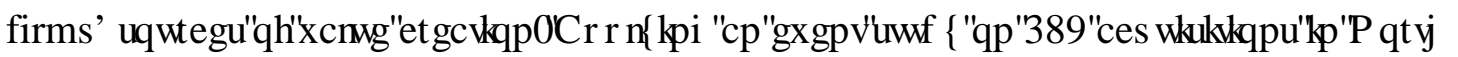

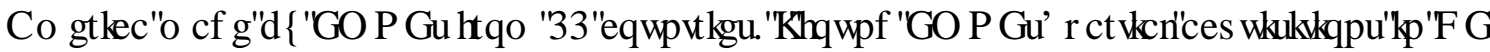
generate, on average, a positive target's cumulative abnormal returns (CAR). There is also empirical support for several determinants of target's value creation and moderation effects. In particular, I found target's international experience DWDXDMULHQH DUXH effect of CD on target CAR, while acquirer's state[RZ QHFWMVH DFHFDMNIWW2 YHDO

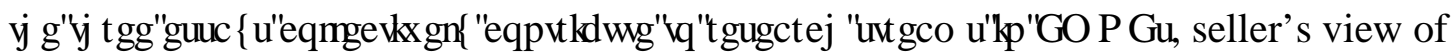

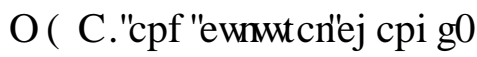

YL 


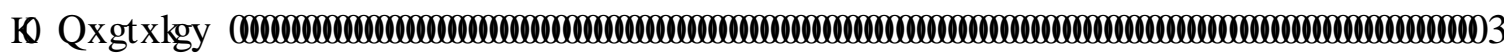

„, Essay 1. Managing Cultural Distance in Emerging Multinationals’ Acquisitions in

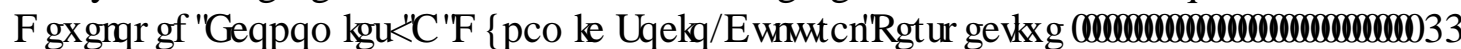

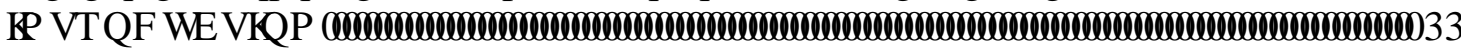

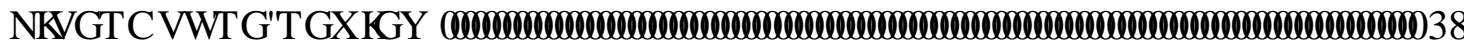

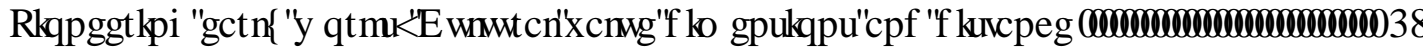
\&UWFLP VIRIMAHGP HQMRQVDSSLRDFK

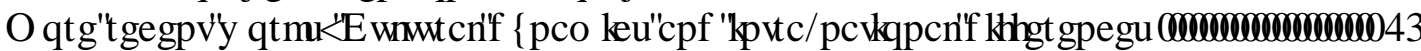

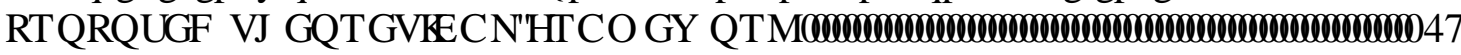

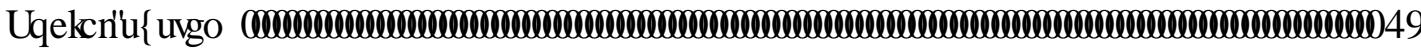
\&XOxL H

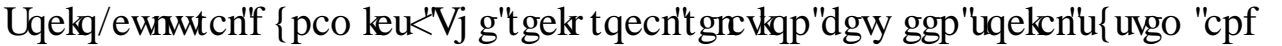

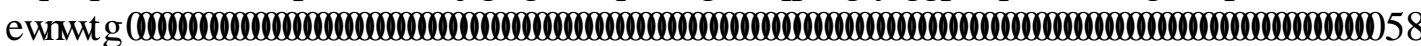

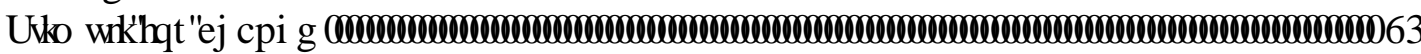

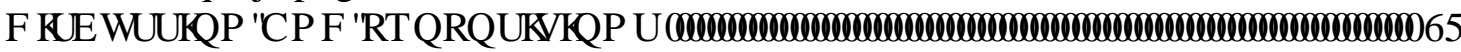

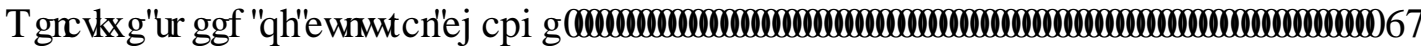

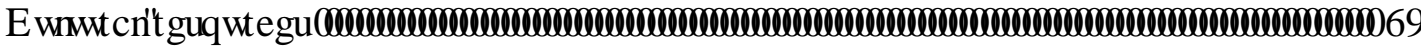

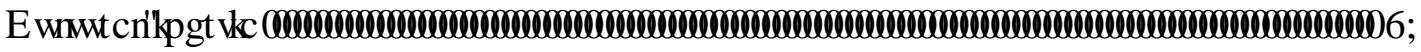

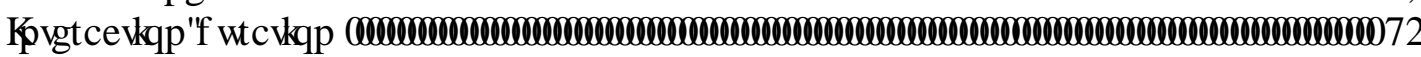

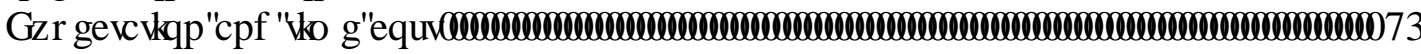

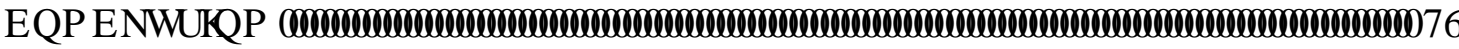

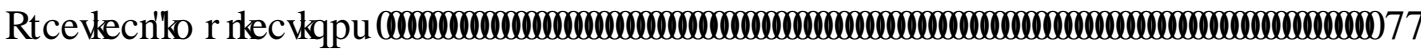

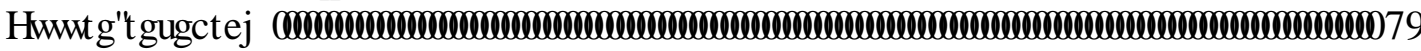

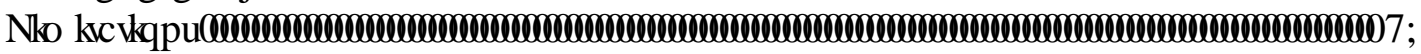

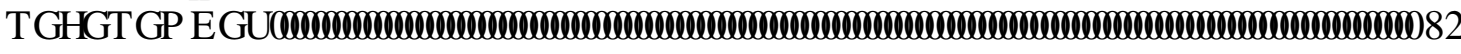

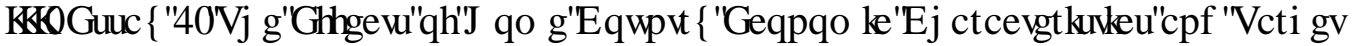

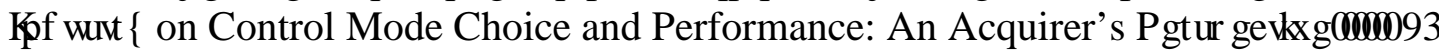

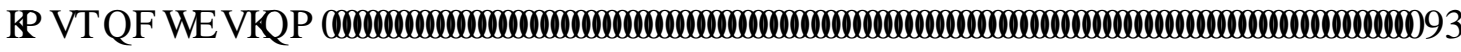

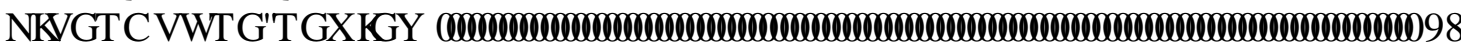

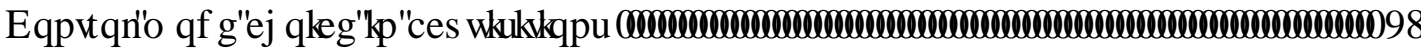

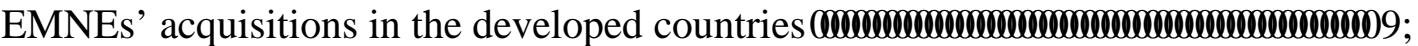

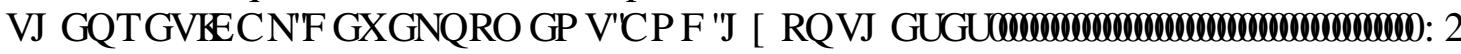

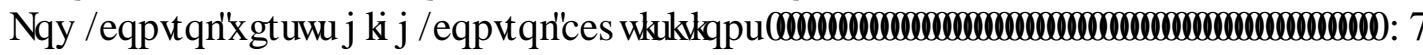

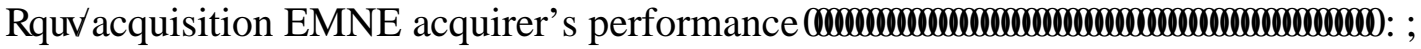

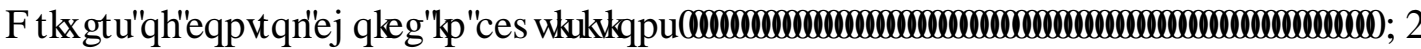

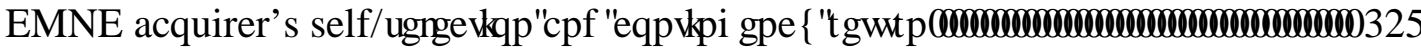

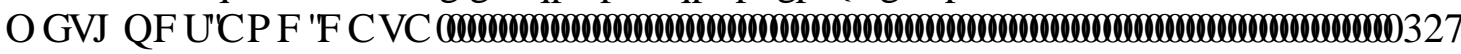

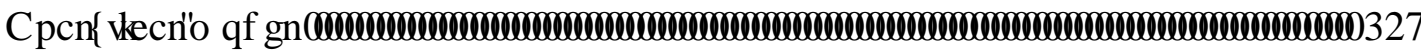

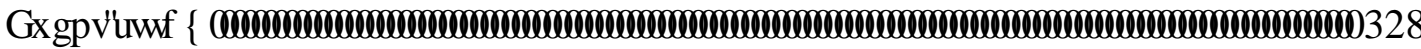




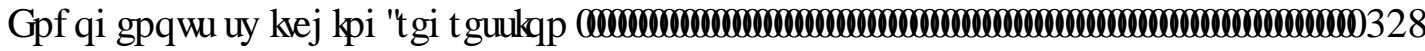

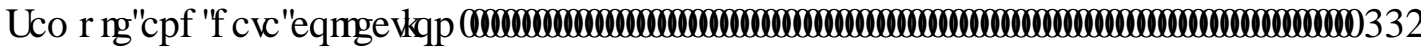

0 HDXLHMnس

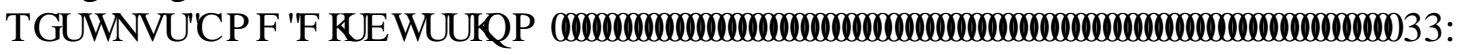

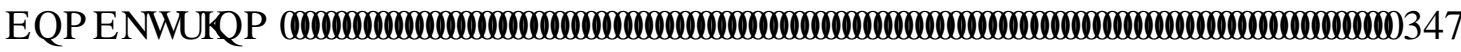

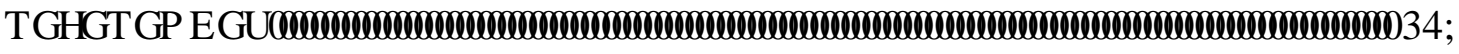

,9 9 Essay 3. Sources of Value Creation in Emerging Multinational Enterprises’

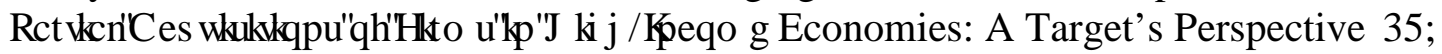

,1 752 ' 8 \&7,2 1 ए

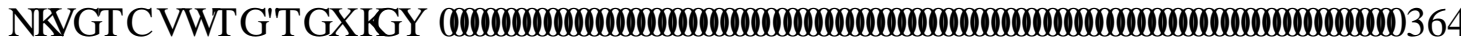
EMNEs’ crossロERLHUDFTXLMRQVDOG1 RUIXS P HUFDQP DUHWIRUFRLSRUM

FRQAROM

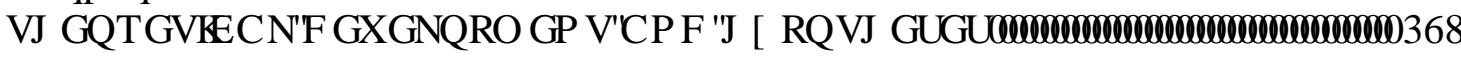
3RWLLTXLMRQWWJ HMSHURW DQFH

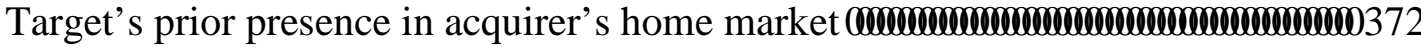

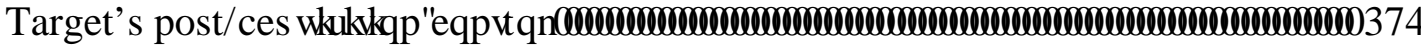

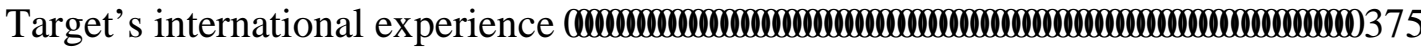

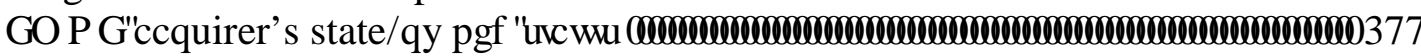

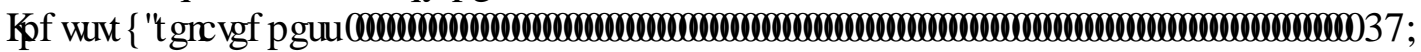
0 RGHONRQHIHFWm

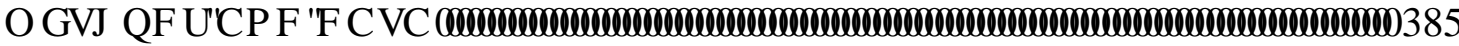
\$ QDOWFDOP RGHOسயm

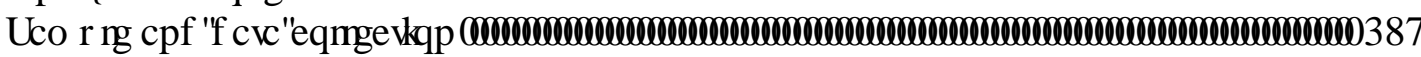
0 HDXXHMn

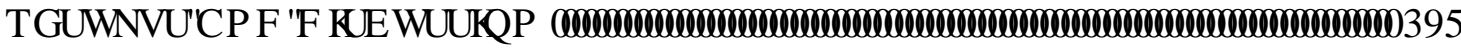
\&2 1 \&/ 8 6,2 1 ए

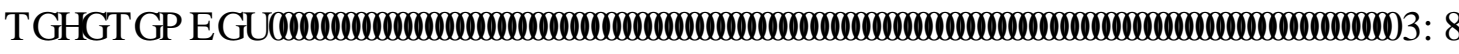

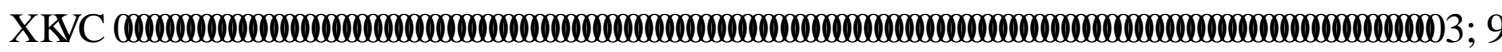




$$
\text { / ,67ロ ) प7\$\%( } 6
$$

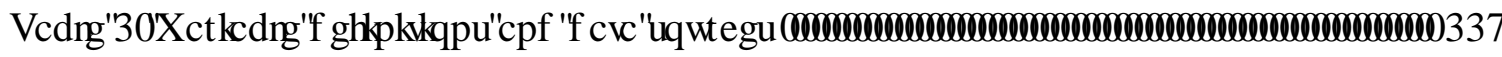

Table 2. EMNE acquirers' CAR around the acquisition announcement days

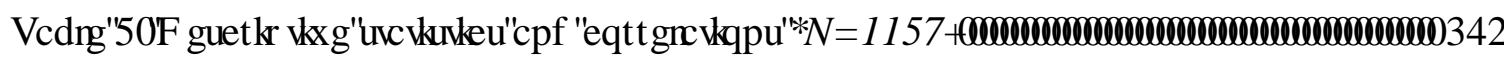

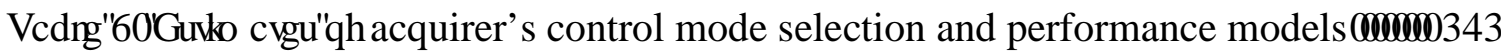
Table 5. Acquirer's predicted returns: observed versus counterfactual control mode प⿴囗十े

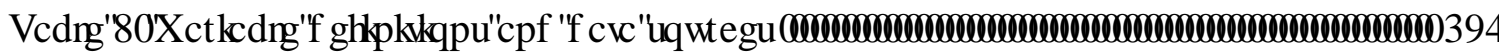

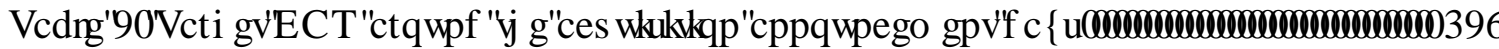

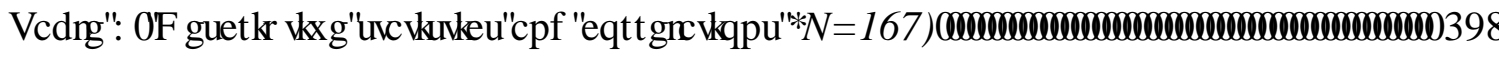

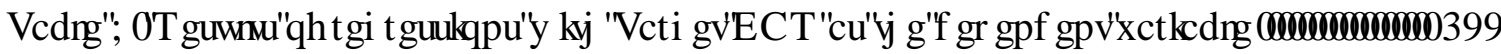




$$
/, 67 \square) \square), * 85(6
$$

),$* 85($

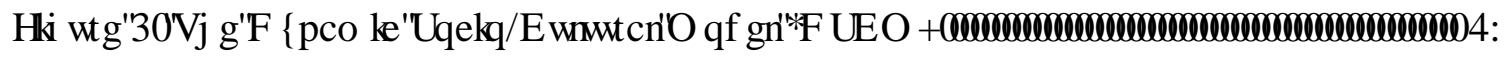

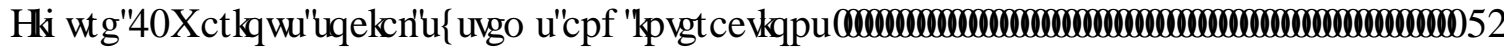

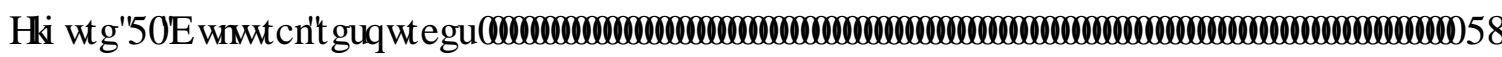

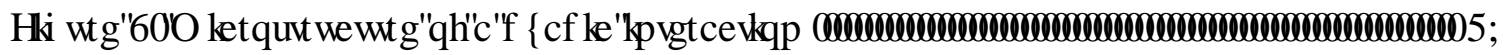

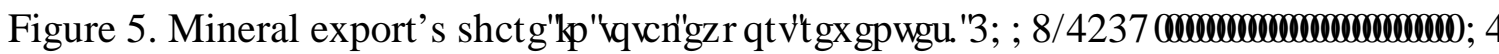

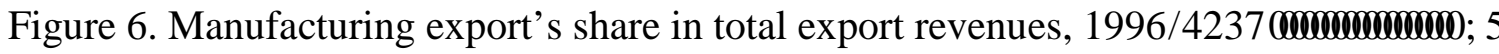

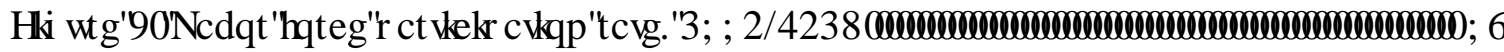

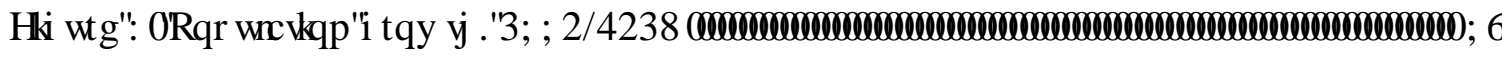

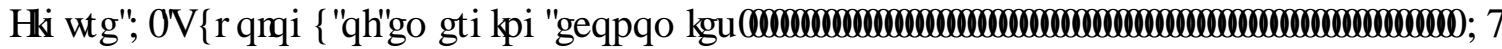

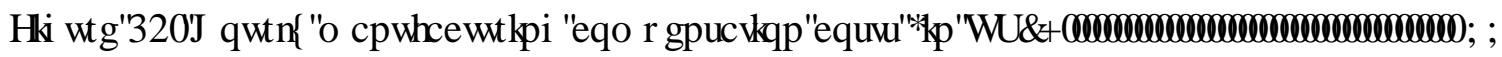

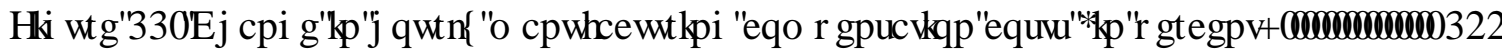

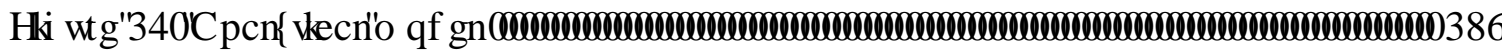




\section{Overview}

Foreign direct investment (FDI) from developing economies to developed economies has increased steadily since the beginning of the new millennium. Although historically FDI flows have been mainly traditional multinational enterprises (MNE) from developed countries investing in other developed countries (a.k.a. “North-to-North” FDI), or developing countries (a.k.a. “North-to- South” FDI), FDI now also flows increasingly from South to North and South to South, as the so-called emerging multinational enterprises (EMNEs) from developing economies invest both in the rich world and less developed countries (Economist, 2008). Decades of trade reform and liberalization in many developing economies have led to a rapid economic transformation characterized by unprecedented growth of net exports and inward foreign direct investment. At the same time, increased international experience, higher foreign currency reserves from the export-led growth, and more open global economies have encouraged the emerging economies to become outward foreign direct investors themselves (Wright, Filatochev, Hoskisson, \& Peng, 2005). In 2016, 28.1 percent of about \$1.5 trillion world’s foreign direct investment (FDI) was FDI outflows made by EMNEs, a significant increase from merely 5.4 percent in 1990 (UNCTAD, 2017). The overall number of EMNEs has also risen in line with their total FDI outflows (Sauvant, McAllister, \& Maschek, 2010). In 2011, 22.4 percent of the world's 5,000 largest firms had headquarters located in developing economies (UNCTAD, 2011). A significant share of the total FDI outflows from developing economies is "South-North" and uses acquisitions as their entry mode. 
Of the $\$ 408.6$ billion FDI outflows from developing economies in 2016 (UNCTAD, 2017), 48.9 percent were in the form of acquisitions of firms in developed economies ${ }^{1}$. Multinational enterprises from the emerging markets (EMNE) have been indeed engaging in aggressive acquisitions of firms in developed economies for almost two decades $^{2}$. The value of cross-border acquisition made by the EMNEs in developed economies rose almost twentyfold from $\$ 10.1$ billion in 1990 to around $\$ 200$ billion in 2016, increasing its share from 7.1 percent to 27.6 percent of the total cross-border acquisitions in developed economies during the same period. The number of deals completed also increased by more than five times from 468 deals in 1990 to 2,156 deals in 2016. Cumulatively, between 1990 and 2016 EMNE's acquisitions in developed economies reached $\$ 1.9$ trillion in 28,073 deals. About one-third of these acquisition deals were made by EMNEs whose ultimate parents were headquartered in China, Singapore, India, South Africa, and Russia, which were the top five developing nations that had been acquiring firms in developed economies during the 1990-2016 period. The U.S., Canada, Australia, the U.K. and Germany are EMNE's top five target country destinations, together absorbing about 71.9 percent of EMNE's total acquisition value in developed economies for the same period in industries as diverse as natural resources, manufacturing, high technology, telecommunication, real estate, media and entertainment, financial and other service industries. Moreover, about 87.3 percent of the 28.073 EMNE's acquisitions deals in developed economies between 1990 and 2016 were directed toward non-publicly listed (or private) targets, while about 26.8 percent of the

\footnotetext{
${ }^{1}$ Data were retrieved from Thomson One Database on June 14, 2017

${ }^{2}$ These are countries classified by UNCTAD as developed economies.
} 
deals were partial acquisitions where the original target shareholders retain controlling majority or non-controlling minority interests in the target firms after the acquisitions ${ }^{3}$.

This dissertation focuses on acquisition activities of firms from the emerging markets (EMNE) in developed countries. The terms “emerging markets” or "emerging economies” are often used to represent economies whose living standards have risen dramatically in the last two decades, and are characterized by large domestic markets, pro-market domestic reforms, integration with the global economy through rapid increase in international trade and foreign direct investment, expanding middle classes, political stability, and increased cooperation with multilateral institutions (Kvint, 2009). In the rest of this dissertation, I will use the term “emerging economies”, “emerging markets”, and “developing economies” interchangeably.

EMNE's cross-border acquisitions of firms in developed countries are an interesting phenomenon. Theories of economic development suggest poor developing countries are expected to be recipients of capital from rich, developed countries. Constrained by limited technological capability, developing countries’ FDI in rich countries would hardly make any economic sense, given the extremely competitive environment and quality-demanding customers in the developed economies. The fact that EMNEs now become significant exporters of capital to the developed world is somewhat counter-intuitive. Moreover, classical theories of MNE and FDI, such as the Hymer model, the eclectic paradigm, and the product life cycle hypothesis, seem to suggest that a firm invests abroad to exploit its (monopolistic) ownership advantage, which implies the possession of firm-specific advantages is a necessary condition before any firm can

\footnotetext{
${ }^{3}$ All acquisition data were retrieved from Thomson One Database on June 14, 2017.
} 
offset the extra costs from doing business abroad, "liabilities of foreignness", or cultural distance (Dunning, 1988; Hymer, 1976; Kogut \& Singh, 1988; Vernon, 1966; Zaheer, 1995 ). Recent studies have attempted to explain EMNE's objectives in their international acquisitions. The explanations range from EMNEs have no reasonable motive at all (Rugman, 2009); EMNEs are exploiting their ownership advantages in the ability to succeed in a business environment with weak institutions, and ability to operate and survive in a low-cost-and-profit-margin environment (Cuervo-Cazurra \& Genc, 2008; Govindarajan \& Ramamurti, 2011; Guillen \& Garcia-Canal, 2009; Ramamurti, 2009); EMNEs are acquiring ownership advantages such as technologies and brands for exploitation in their home markets (Ramamurti, 2012); to EMNEs are exploring and learning about the developed markets in an accelerated manner (Luo \& Tung, 2007; Madhok \& Keyhani, 2012; Mathews, 2006). Yet, it remains theoretically enigmatic that EMNE can operate in culturally distant high-income markets with very limited exploitable advantages, compared to their local competitors in the host countries.

The fact that EMNEs have continued to aggressively acquire firms in developed economies, notwithstanding the obvious cultural distance (Kogut \& Singh, 1988) or "liabilities of foreignness" (Zaheer, 1995) the EMNEs have to encounter, raises at least two important issues. First, there are apparently ways for the EMNE to effectively overcome the extra costs imposed by the cultural distance they must face when they enter high-income markets. Second, there may be a need for a refined conceptualization of culture beyond the traditional dimensions approach where culture is equated to stable cultural values (e.g. , Hofstede, 1980, 1991, 2001; House, Hanges, Javidan, Dorfman, \& Gupta, 2004; Schwartz, 1992); and cultural distance is perceived merely as negative in 
international business (IB) activities (Ambos \& Hakanson, 2014), because it is associated with limited insights of the local culture and business practices (Luo, 2002) and creates impediments to communication (Reus \&Lamont, 2009). This dissertation is aimed at better understanding EMNE’s acquisition activities in developed economies. I focus on several research inquiries and respond in three distinctive but interrelated essays.

In the first essay, I develop a generalized perspective culture, the Dynamic SocioCultural Model (DSCM), to better account for the dynamic influence of the ever changing IB environment as well as the complexities of cultural elements beyond cultural values, which hopefully will lead to a richer and more realistic description of culture. I take a broader view of culture and inquire how culture is created and evolves; why it evolves; and how should IB researchers treat the evolving culture as they are theorizing the interaction between emerging multinational enterprises (EMNEs) and people, organizations, and governments in societies with different cultures, particularly in culturally-distance advanced countries. I integrate ideas from the symbolic interaction paradigm in sociology (Blumer, 1969), combined with insights from economics and anthropology, to develop a new conceptual framework with a central feature on collective learning that occurs among interacting individuals and leads to new shared cultural resources. Collective learning is an adaptive mechanism that takes place not only in interpersonal interactions, but also inter-group, inter-organizational and inter-national interactions. The DSCM suggests new culture is being created because of continuous collective learning, as individuals, groups, organizations, and nations learn from each other ways to survive continual changes. It views culture as fluid and cultural differences 
as context-specific, and their effects on IB are therefore dynamically context-dependent, as people and organizations from different cultures interact with one another.

In the second essay, I again extend ideas from the DSCM in Essay 1 to the context of EMNE's cross-border acquisitions in developed economies, where collective learning occurs between two organizations (i.e., the acquirer and the target) with different national cultures as well as organizational cultures. Aided by additional insights from the organizational learning literature, particularly the concepts of ambidexterity, exploration and exploitation (March, 1991), I focus on how acquiring EMNEs choose their control mode choice in their acquisition of targets in developed economies to optimize postacquisition learning and maximize post-acquisition value creation. Using a sample from acquisitions made by EMNEs from Brazil, Russia, India, China and South Africa (BRICS) in twenty-one high-income economies that are members of the Organization for Economic Co-operation and Development (OECD), I empirically investigate the determinants of the acquirers' choice of control mode (i.e., non-controlling minority acquisition versus controlling majority acquisition). Specifically, I examine how acquirer's home country characteristics and target industry affect EMNE's choice of control mode. The need for collective learning is arguably more intense when the acquirer's home country is a rapidly industrializing emerging economy, such as China, and when the target is a high-technology firm. Moreover, using the endogenous switching regression model (Lokshin \& Sajaia, 2004), I look into the performance implication of the acquirer's control mode choice.

In the third essay, I switch my attention to the perspective of the target firms in developed countries which engaged in a partial sale of shares to EMNEs. I again extend 
the idea of collective learning from DSCM in Essay 1 and complement it with insights from organizational learning (March, 1991) and the seller's view (Graebner \& Eisenhardt, 2004) literature to develop my testable hypotheses. When an acquirer interacts with an acquired target firm, learning occurs not only within the acquiring firm, but also within the target firm. This is especially true when cultural resources of the acquiring firm and the target firm are distinctively different such as when an EMNE acquires a firm in a developed economy. I examine whether being partially acquired by an EMNE optimizes post-acquisition learning and creates value for targets in developed economies, in light of targets' interest in accessing their EMNE acquirer's lucrative home and regional markets. I also investigate what drives target's value creation in such crossborder partial acquisitions. Using a sample from partial acquisitions made by EMNEs in the United States and Canada, I explore the relationship between post-acquisition target value creation and target's prior presence in acquirer's home market, target's postacquisition control, target's international experience, target-acquirer industry relatedness, acquirer's state-owned status, and cultural distance between home and host countries. I also look into the moderation effects of international experience and EMNE acquirer's state-owned status on the effect of cultural distance on post-acquisition target value creation.

These three essays collectively contribute to the growing literature of emerging multinational enterprises in general, and more specifically to multiple other research streams in IB including cross-border M\&As, global strategy of the EMNEs, cultural change, cultural distance and FDI, liabilities of foreignness, equity ownership choice, 
partial acquisitions, and seller's view of acquisitions. Essays 1, 2 and 3 are presented in the next three chapters.

\section{REFERENCES}

Ambos, B., \& Håkanson, L. 2014. The concept of distance in international management research. Journal of International Management, 20: 1-7.

Blumer, H. 1969. Symbolic interactionism: Perspective and method. Englewood Cliffs, NJ: Prentice Hall.

Cuervo-Cazurra, A., \& Genc, M. 2008. Transforming disadvantages into advantages: developing-country MNEs in the least developed countries. Journal of International Business Studies, 39(6): 957-979.

Dunning, J. 1988. The eclectic paradigm of international production: A restatement and some possible extensions. Journal of International Business Studies, 19(1): 1-31.

Economist 2008. The challengers - emerging-market multinationals. 12 January: 61.

Govindarajan, V., \& Ramamurti, R. 2011. Reverse innovation, emerging markets, and global strategy. Global Strategy Journal, 1(3-4): 191-205.

Graebner, M. E., \& Eisenhardt, K. M. 2004. The seller's side of the story: Acquisition as courtship and governance as syndicate in entrepreneurial firms. Administrative Science Quarterly, 49(3): 366-403.

Guillén, M. F., \& García-Canal, E. 2009. The American model of the multinational firm and the "new" multinationals from emerging economies. The Academy of Management Perspectives, 23(2): 23-35.

Hofstede, G. 1980. Culture's consequences: International differences in work-related values. London: Sage.

Hofstede, G. 1991. Cultures and organizations: Software of the mind. London: McGrawHill.

Hofstede, G. 2001. Culture's consequences: Comparing values, behaviors, institutions and organizations across nations. Thousand Oaks, CA: Sage. 
House, R.J., Hanges, P.J., Javidan, M., Dorfman, P., \& Gupta, V. 2004. Culture, leadership, and organizations: The GLOBE study of 62 societies. Thousand Oaks, CA: Sage Publications.

Hymer, S. 1976. The international operations of national firms: A study of direct foreign investment. Cambridge, MA: MIT press.

Kogut, B., \& Singh, H. 1988. The effect of national culture on the choice of entry mode. Journal of International Business Studies, 19(3): 411-432.

Kvint, V. 2009. The global emerging market. New York, NY.

Lokshin, M., \& Sajaia, Z. 2004. Maximum likelihood estimation of endogenous switching regression models. Stata Journal, 4, 282-289.

Luo, Y. 2002. Contract, cooperation, and performance in international joint ventures. Strategic Management Journal, 23: 903-919.

Luo, Y., \& Tung, R. L. 2007. International expansion of emerging market enterprises: A springboard perspective. Journal of International Business Studies, 38(4): 481498.

Madhok, A., \& Keyhani, M. 2012. Acquisitions as entrepreneurship: asymmetries, opportunities, and the internationalization of multinationals from emerging economies. Global Strategy Journal, 2(1): 26-40.

March, J. G. 1991. Exploration and exploitation in organizational learning. Organization Science, 2(1): 71-87.

Mathews, J. A. 2006. Dragon multinationals: New players in 21 st century globalization. Asia Pacific Journal of Management, 23(1): 5-27.

Reus, T. H., \& Lamont, B. T. 2009. The double-edged sword of cultural distance in international acquisitions. Journal of International Business Studies, 40(8): 12981316.

Rugman, A. M. 2009. Theoretical aspects of MNEs from emerging economies. In R. Ramamurti (Ed.), Emerging multinationals in emerging markets: 42-63. Cambridge, UK: Cambridge University Press.

Ramamurti, R. 2012. What is really different about emerging market multinationals? Global Strategy Journal, 2(1): 41-47.

Sauvant, K. P., Maschek, W. A., \& McAllister, G. 2010. Foreign direct investment by emerging market multinational enterprises, the impact of the financial crisis and 
recession, and challenges ahead. In Foreign direct investments from emerging markets. 3-29. Palgrave Macmillan US.

Schwartz, S.H. 1992. Universals in the content and structure of values: Theoretical advances and empirical tests in 20 countries. In M.P. Zanna (Ed.), Advances in experimental social psychology: 1-65. New York: Academic Press.

UNCTAD 2011. World investment prospect survey 2009-2011. New York: United Nations.

UNCTAD. 2017. World investment report 2017: Investment and the digital economy. New York: United Nations.

Vernon, R. 1966. International Investment and International Trade in the Product Cycle. The Quarterly Journal of Economics, 80(2): 190-207.

Wright, M., Filatotchev, I., Hoskisson, R. E., \& Peng, M. W. 2005. Strategy research in emerging economies: Challenging the conventional wisdom. Journal of Management Studies, 42(1): 1-33.

Zaheer, S. 1995. Overcoming the liability of foreignness. Academy of Management Journal, 38(2): 341-363. 


\section{Essay 1. Managing Cultural Distance in Emerging Multinationals' Acquisitions in Developed Economies: A Dynamic Socio-Cultural Perspective}

\section{INTRODUCTION}

International Business (IB) literature suggest firms going international encounter the socalled "costs of doing business abroad" (Hymer, 1960) from their liabilities of foreignness (LOF) (e.g., Nachum, 2003; Zaheer, 1995), which originates from sociocultural differences between the host and home countries, often operationalized as cultural distance (CD) in various empirical works in IB (Kirkman, Lowe, \& Gibson, 2006). First introduced by Kogut and Singh (1988), Cultural distance is a single numerical index that measures country-level cultural differences between pairs of countries, derived from applying Euclidean distance formula to numerical scores from each of Hofstede’s four dimension of culture (1980). Moreover, the classical multinational enterprise (MNE) theory suggests that for firms to go abroad, they must possess competitive advantages that they can exploit in the foreign markets, and these monopolistic firm-specific ownership advantages (FSAs) must be more than sufficient to offset any additional costs from the cultural distance that their local competitors in the host market do not encounter (Hymer, 1976; Dunning, 1988). CD indeed has traditionally been perceived as negative (Ambos \& Hakanson, 2014) and is associated specifically with limited insights of the local culture and business practices in culturally-distant markets (Luo, 2002) and impediments to communication, which eventually leads to MNE’s suboptimal performance (Reus \&Lamont, 2009). From the transaction cost perspective, $\mathrm{CD}$, as other cross-national differences in $\mathrm{IB}$, constitutes additional costs for 
the involved parties, because they increase uncertainty in the flow of information or knowledge between countries (Berry, Guillen, \& Zhou, 2010; Hennart \&Larimo, 1998). Nonetheless, the last decade has seen the rise of firms from emerging economies (e.g., China, India, Brazil, Russia, etc.) in the international arena, where emerging multinational enterprises (EMNEs) actively engaged in foreign direct investment (FDI) not only in other emerging markets, but also high-income markets such as those of the United States, European Union, and Japan, primarily through aggressive acquisitions of existing firms (Sauvant, McAllister, \& Maschek, 2010). From a theoretical IB perspective, the EMNE's acquisitions in developed countries are an interesting phenomenon, because EMNEs enter these often culturally and institutionally distant markets essentially with no distinctive FSAs to exploit (e.g., technologies, brand, and managerial know-how), compared to their local competitors in the host markets (Ramamurti, 2012).

Several studies have provided views on whether EMNEs possess sustainable competitive advantage and the kinds of competitive advantage they may have. Some studies argue EMNEs possess unconventional FSAs in their ability to succeed in a business environment with weak institutions, and their ability to operate and survive in a low-cost-and-profit-margin environment (Cuervo-Cazurra \& Genc, 2008; Govindarajan \& Ramamurti, 2011; Guillen \& Garcia-Canal, 2009; Ramamurti, 2009). By contrast, Rugman (2009) contends EMNEs have no FSAs to leverage and hence their ventures to advanced economies are destined to fail. Similarly, Luo and Tung's "springboard perspective" argues that EMNEs have no distinctive FSAs to exploit in the advanced host markets, but they enter these markets for a different motive, which is to acquire strategic 
assets such as technologies, brand and managerial know-how, for immediate exploitation in their own fast growing and sizable home as well as other emerging markets. It is argued that EMNE's previous experience in inward FDI and the advantage generated by the acquired strategic assets are more than sufficient to attenuate risks and costs from the cultural distance they face abroad (2007). In addition, the Linkage-Leverage-Learning (LLL) perspective (Matthew 2006) argues that EMNEs have "potential advantages" (Madhok \& Keyhani, 2012) which, when combined with strategic assets the EMNEs obtain from their venture in developed economies, may become sustainable FSAs that are exploitable in both home and host markets.

In this essay, instead of identifying another source of EMNE's sustainable competitive advantage, I step back to explain how EMNEs offset the cultural distance they encounter in developed economies by broadening the view of culture to encompass all aspects of cross-national differences, uncovering the process of cultural creation (and change) and showing that overcoming or bridging cultural distance in the FDI context may not be as costly as often suggested in classical IB/MNE theories. To achieve this, I challenge the predominant conceptualization of culture in IB in which culture is usually viewed as stable, and cultural distance between host and home countries is typically perceived as negative for IB operations. I then offer a more dynamic conceptualization of culture based on insights from the symbolic interaction paradigm in sociology and ideas from anthropology and economics. Through the lens of my Dynamic Socio-Cultural Model (DSCM), I argue that culture is not as rigid as the traditional conceptualization of culture suggests; while cultural distance between home-host countries may initially impede EMNE's acquisitions in developed markets, the actual or "effective” CD 
encountered by EMNE in its host markets may be positively moderated by certain conditions of the involved cultures and significantly reduced over time. As a generalized model of culture, the DSCM provides a more realistic understanding on the effect of cultural differences on not only EMNE's acquisitions performance in developed economies, but also various IB operations and contexts.

I begin the next section with a short review and critique of major theories of culture in international business (IB) and international management (IM). By identifying limits and weaknesses of various existing conceptualizations of culture, I then redress them in my proposed theoretical framework. I aim for integration and construction rather than destruction and argue for a more dynamic conceptualization of culture. I then describe my proposed theoretical perspective of culture which I believe holds great promise for a better understanding of culture in an ever changing IB environment. In the subsequent section, I develop several research propositions based on the new theoretical perspective of culture, describing various aspects of culture and cultural change that may dynamically moderate the initial negative relationship between CD and EMNE’s performance in their acquisitions in developed economies, along with how "effective" cultural distance between the acquiring EMNE and the host market may change over time. Finally, the concluding section provides a summary and discussion of research and practical implications of the proposed perspective of culture along with challenges that need to be addressed in future research.

This paper makes several contributions. First, it addresses the call from Ramamurti (2012) for a more generalized framework of analysis that can better explain the EMNE phenomenon, particularly in their aggressive acquisitions in developed 
economies. The paper also responds to Stahl and Tung (2015)'s call for a new theoretical framework of culture in IB that pays more attention to context and process, for which both positive and negative aspects of cultural differences are accounted. It also extends Reus and Lamont (2009)'s attempt to resolve the seemingly contradictory role of cultural distance in international acquisitions in empirical findings by systematizing and explicating the process of cultural creation, which allows for a more dynamic and flexible conceptualization of culture in IB beyond what has been proposed by more recent works in cross-cultural management.

Responding to calls from Caprar, Devinney, Kirkman, and Caligiuri (2015) for considering culture as a dependent variable to better understand the true influence of culture, this paper endogenizes institutional elements that shape the process of cultural production by proposing continuous interdependence between culture and the social systems in which the institutional factors are embedded, rendering a theoretical perspective that can be applied not only at a group or organizational level, but also at a societal level. Additionally, the proposed new perspective of culture expands the theoretical frontier particularly away from the dimensions approach so commonly used in IB (e.g., Hofstede 1980, 1991, 2001; House, Hanges, Javidan, Dorfman, \& Gupta, 2004; Schwartz, 1992; Trompenaars, 1994) and empowers scholars to build more realistic and predictive models that dynamically capture the relationships between culture and managerial outcomes, and linkages among elements within culture. As such, the paper opens a new avenue for international managers to reexamine the interplay between their firms and the environment in a much more realistic way, which ultimately will help them devise more effective corporate strategies and managerial decisions, particularly in the 
context of managing cultural distance in EMNE's acquisitions of firms in developed economies.

\section{LITERATURE REVIEW}

This section highlights the predominantly influential major studies of culture in IB for limits and weaknesses in the hope that I can rectify them in my proposed theoretical framework in an integrative and constructive fashion. This section by no means attempts to exhaustively review all theories of culture in IB. For a more comprehensive account, readers are referred to an excellent work by Nardon and Steers (2009).

\section{Pioneering early works: Cultural value dimensions and distance}

The dimensions approach to culture in IB was popularized by Hofstede with the publication of Culture's Consequences almost four decades ago (1980). This influential dimensions approach since then has inspired thousands of empirical studies in IB/IM. Hofstede proposed the “onion” metaphor to illustrate culture’s four complex layers, namely, symbols, heroes, rituals (or practices), and values (1980). His model focuses on national cultural values, which unidirectionally determine individual behavior, and are very stable inter-temporally (Hofstede, 1980, 1991, 2001). Hofstede’s pioneering work focuses on differences in cultural values across countries and their measurability, and with the aid of factor analyses employed on individual-level survey responses from IBM employees worldwide, four (or later five) bi-polar dimensions of cultural values were derived to describe complex national cultures (Hofstede, 1995). The dimensions have been widely used in empirical investigations of the effects of culture on IB practices 
(Kirkman et al., 2006; Sivakumar \& Nakata, 2001). Anecdotal evidence also suggests the practical framework provided by Hofstede’s cultural dimensions has extensive usage among managers worldwide.

Other authors have proposed other models of culture, often with rigorous underlying theoretical constructs and more complex typologies. Most notably Schein (1992) generalized the conceptualization of culture beyond Hofstede’s strictly national culture to other levels including organization, and offered an alternative "onion" metaphor. Unlike the four-layer Hofstede’s onion, Schein’s onion has three layers, namely (from the most visible to the least visible), artifacts and behaviors, espoused values, and basic assumptions and beliefs, and culture is defined as what a group learns over a period of time as that group solves its problems of survival and international integration in an external environment.

Building on Schein’s “onion” metaphor and inspired by Hofstede’s works, House et al. (2004) proposed another dimensions approach to culture, known as GLOBE. They define culture as shared motives, values, beliefs, identities, and interpretations or meanings of significant events that result from common experiences of members of collectives and are transmitted across age and generations (House et al., 2004). The GLOBE dimensions do not make any distinction between national culture and organizational culture, and they focused on cultural values and behavior using nine dimensions of cultural values based on a wider, heterogeneous sample of 951 firms in three manufacturing and service industries across 62 countries, compared to Hofstede’s original sample of IBM employees from 50 countries. 
Several important studies have been based on Schein's conceptualization of culture. First, Schwartz (1992) focused on the values layer of Schein’s “onion”, and offered ten cultural core values. Unlike GLOBE’ s nine dimensions that largely overlap with Hofstede’s five dimensions, Schwartz's ten dimensions are rather distinctive, which include self-direction, stimulation, hedonism, achievement, power, security, conformity, tradition, benevolence, and universalism. Moreover, Trompenaars (1994) focused on the behavior layer of Schein’s “onion” and derived cultural values indirectly from observed behavior to develop seven dimensions of cultural values. Leung et al. (2002) focused on the most inner and least visible layer of Schein’s “onion” metaphor: basic beliefs and assumptions. They argued for five theoretical factors, or social axioms, namely, social cynicism, social flexibility, reward application, spiritual consequence, and fate control, which they viewed as universal across cultures.

Perhaps, the most important extension of Hofstede's work in IB research in nearly three decades is the cultural distance (CD) construct (Kogut \& Singh, 1988). Derived from applying Euclidean distance formula to Hofstede's quantitative measures of cultural value dimensions, $\mathrm{CD}$ is a single numerical index that measures national cultural differences between pairs of countries. The introduction of $\mathrm{CD}$ was an important step toward further operationalization of culture in IB research, as CD offers an even more concrete and convenient tool for further simplifying the complexities of culture and cultural differences across countries despite myriad criticisms. Cultural distance has been specified as a main effect or moderator in various IB research areas (Kirkman et al., 2006). 


\section{Criticisms of the dimensions approach}

Several concerns have been raised over Hofstede's model of culture and more generally of the cultural dimensions approach. First, the dimension-based models are viewed as a rather traditional approach to culture ingrained in the anthropological literature (Earley, 2006). Specifically, Hofstede's strict conceptualization of culture at the national level is thought to be troublesome, as it is hard to imagine national culture is the same for all within a nation (McSweeney, 2002). Culture can be imperfectly shared across individuals and/or subgroups within the same nation, rendering the possibility of intra-national cultural differences (Earley, 2006; Chen, Leung, \& Chen, 2009; Tung, 2008), or paradoxes within a national culture (Fang, 2005).

Second, the "onion” metaphor suggests an overly stable culture (Leung et al., 2005), implying core cultural differences are hard to overcome, such that when two different cultures come into contact, the cultural differences between the two will be amplified, and cross-cultural conflicts will naturally occur (Fang, 2005; Tung, 2008). Yet, this prediction seems counter-intuitive to realities in IB, where people and organizations from very different cultures have surmounted problems working together for a greater common purpose (Leung \& Morris, 2015). Ailon (2008) criticized Hofstede’s definition of culture for giving little credit to the individual as a potential agent of social change, thus describing the individual as a passive carrier of a stable cultural template of his or her nationality. Indeed, Hofstede’s or GLOBE's theoretical frameworks lack recognition

of this dynamic nature of culture (Chen et al., 2009). Erez and Gati (2004) even call for a shift in the research focus on culture as a stable entity to culture as a dynamic entity, 
which implies a greater focus on the interplay between different levels of culture such as between organizational culture and national culture.

Another concern about GLOBE and Hofstede's models of culture is the emphasis on cultural values, and yet, values are only one contributor to meanings that a group or individuals might attribute to a given phenomenon (Earley, 2006). Moreover, relationships among cultural elements (e.g., values, behaviors, beliefs, knowledge, etc.) are more likely to be dynamic and non-linear. For example, not only are behaviors shaped by beliefs and values, but they can also proactively shape new beliefs and values, through cognitive mechanisms, creating the process of cultural change (Fang, 2005).

In addition, the $\mathrm{CD}$ measures have been subject to several criticisms. A single distance measure such as $\mathrm{CD}$ is thought to be conceptually inadequate (Tung \& Verbeke, 2010). Five problems with its conceptual properties have been identified, namely, the illusions of symmetry, stability, linearity, causality and discordance (Shenkar, 2001). Another serious problem of the $\mathrm{CD}$ construct is its implicit assumption that similarity is beneficial, and differences are not. However, there are contexts in which CD can be considered an opportunity for arbitrage, complementarity, or creative diversity, making it a more variable construct, rather than a fixed one, especially since societies evolve and CD can change over time (Zaheer, Schomaker, \& Nachum, 2012). Moreover, Shenkar, Luo, and Yeheskel (2008) and Shenkar (2012) explored the idea of replacing CD with the "cultural friction" construct, which focuses on the actual encounter of cultures within a context of power relations and potential conflict between the MNE and its host country constituencies. 


\section{More recent works: Cultural dynamics and intra-national differences}

Responding to the concerns over the dimensions approach to culture, several studies introduced alternative models of culture (e.g., Erez \& Gati, 2004; Fang, 2005; Gould \& Grein, 2009; Leung et al., 2005; Leung \& Morris, 2015; Ralston, Gustafson, Cheung, \& Terpstra, 1993; Stahl \& Tung, 2015). Ralston et al. (1993) introduced the crossvergence theory of evolution in national cultural values to resolve the "divergence-convergence" debate (McGaughey \& Cieri, 1999). Convergence suggests that cultural values, attitudes and behaviors across nations will over time become similar to those in the industrialized Western capitalist countries. By contrast, Divergence predicts that despite the increasingly economic and social similarities among nations, each nation will retain its unique cultural values over time. Ralston et al.’s crossvergence theory proposed a synergistic perspective of cultural value formation and evolution, in which the dynamic interaction of the sociocultural influences with the business ideology (i.e., economic, political, and technological) provides the driving force to precipitate the development of new and unique cultural values systems in societies (1993). While their work is a significant breakthrough toward a more dynamic conceptualization of culture, Tung (2008) criticized the single focus of crossvergence on the value element of culture, and the implicit assumption that cultural values are uniformly similar within a nation.

Another alternative model aimed at remedying the weaknesses of the static traditional view of culture was advanced by Erez and Gati (2004). Still rooted in Schein's “onion”, the model assumes that cultures change. Indeed, environmental changes can provoke adaptation and cultural change. In their model, culture is no longer confined to national culture, as it can reside in many other contexts including global society, 
communities, organizations, groups, and families. A multi-level, multi-layer approach was adopted in the model to capture dynamic relationships across various levels of culture, where each cultural level serves as the context for the many cultural levels below it. Thus, there is an interspatial dynamic relationship across various levels of culture, creating reciprocal influence processes between the nested levels and the macro-levels of culture.

Leung et al. (2005) used a similar multi-layer, multi-level model of culture, and further argued that within each level change first occurs at the most external layer of the “onion" (i.e., behavior), and then, when shared by individuals who belong to the same cultural level, it becomes a shared value that characterizes the aggregated unit (e.g., group, organizations, or nations). Clearly, as in most of the traditional approaches, their model still focuses on cultural values.

As with Ralston et al.'s crossvergence model (1993), the multi-layer, multi-level model of culture implicitly assumes homogeneous non-fragmented culture, disallowing the possibility of intra-culture variation. Yet, there can be more than one context at the same level. For example, firms engaging in foreign direct investment can have more than one higher-level cultural context (i.e., the culture of the host country and the culture of the home country), as discussed by Wind, Douglas, and Perlmutter (1973). Moreover, the multi-level, multi-layer model lacks clarity explaining how higher-level cultures affect lower-level cultures without considering individuals, which is viewed as another level in the model. It also unrealistically implies that national culture can only change when all organizations within it share the change. Additionally, the model is counter-intuitive, as it does not allow a direct lateral change process across groups within the same level. For 
instance, a cultural change may occur simply because a group of individuals in some developing countries is constantly exposed to foreign culture through watching social media. Individuals may also think of their communities less in terms of hierarchical levels than as a salient community among the many with which they are involved (Gould \& Grein, 2009), reflecting Friedman's flattening of the world (2005).

Another model offered by Fang (2005) proposed the “Ocean” metaphor to capture the dynamic and paradoxical nature of values inherent in a national culture. Although the focus of the model is still on cultural values, it removes the assumption of stable value by allowing both old and new values to coexist within a society. Similar to the ebbs and flows of an ocean, at any given time some cultural values may be suppressed or dampened; but external events could trigger or re-ignite these dormant values. Based on the yin-yang dialectical process, Fang (2005) posits that these paradoxical values cannot survive without each other, and they complement each other, and succeed each other at different points in time. While this model shifts the focus from stable cultural values to dynamic cultural values, it is still largely deterministic, since changes are still linear, conforming to the "bi-polar" paradigm of the dimensions approach to culture.

Responding to the call for a more generalized model with a focus beyond national culture (Fang, 2005), Gould and Grein (2009) offered the Glocalized Community Culture Model (GCCM), as an alternative to the multi-layer, multi-level model of culture, which they thought was less flexible and limited researchers' tools of analysis. The GCCM is a flatter, community-based model. Communities are defined as sites where culture is produced, and national culture is just one among a number of community cultures in a more open system with non-hierarchical contexts. Far from being a static phenomenon, 
culture is dynamic in its continual creation. Individual cultural membership in the GCCM is fluid. For example, a person working for an MNE subsidiary may be a member of a particular national culture, while also influenced by other national and organizational cultures associated with their employer, allowing multiculturalism (Gould \& Grein, 2009). GCCM however is thought to be underdeveloped with regard to the complex, dynamic interplay between cultural identities based on national differences and various aspects of globalization (Leung, Bhagat, Buchan, Erez, \& Gibson, 2010).

In more recent studies, Leung and Morris (2015) move beyond values and expand cultural elements to include schemas and norms in a model that dynamically explains how intensities of each element change as the situation changes. Stahl and Tung (2015) also call for a new theoretical framework of culture in IB/IM that pays more attention to context and process, for which both the positive and negative aspects aspect of cultural differences are accounted. Analyzing culture-related articles published in Journal of International Business Studies between 1989 and 2012, they found most works emphasize the adverse outcomes associated with cultural differences, which they argued are not a true reflection of the reality when practitioners deal with cultural differences. They asserted the need for a complementary perspective that can deal with both the liability and beneficial aspects of cultural differences (Stahl \& Tung, 2015).

In sum, while previous attempts to provide models that go beyond simple dimensions approach are one step in the right direction, there remains an urgent need for a new conceptualization of culture that can better capture the dynamics of cultural change with a scope beyond the element of cultural values and national boundaries. I believe the time has come for a new theoretical perspective of culture that comprehensively 
integrates the dynamic changes of myriad cultural elements within various socio-cultural contexts.

\section{PROPOSED THEORETICAL FRAMEWORK}

An ancient Greek philosopher, Heraclitus, once said, "the only thing that is constant is change” (Engels. 1939: 27). Indeed, as technology-driven global interdependence becomes a reality of life, none of us is immune to change (Friedman, 2005). While in general it is widely recognized that change occurs in virtually all facets of social life, often in an accelerated manner, I believe it has not been sufficiently considered in the conceptualizations of culture in international business (IB). In fact, since the highly influential work of Hofstede (1980, 1991, 2001), most studies in cross-cultural management (CCM) have rested on the "onion” metaphor in which culture is treated as equivalent to cultural values, which is hard to change, or at best change slowly over time (e.g. , Hofstede, 1980, 1991, 2001; House et al., 2004). In fact, the study of culture in CCM has traditionally focused on identifying differences in cultural values across nations or organizations and examining their implications for IB. The study has primarily utilized the dimensions approach in which the complexity of cultural values is reduced to several descriptive bipolar dimensions or factors based on theoretical exposition and/or formal statistical factor analysis (Minkov, 2013).

The assumption of stable cultural values in the dimensions approach has an early root in the structural functionalist paradigm in sociology which views society as objective, stable, cohesive and well-integrated. It places a value system at the heart of culture (Westwood \& Everett, 1987). This approach suggests culture change is hard to 
occur, or at most gradual and predictable, while persistence and regularities are viewed as the normal state and focus of analysis (Parsons \& Shils, 1951). Although the structuralfunctionalist paradigm has enlightened our understanding on social structure and its mechanisms, the paradigm's contribution to the understanding of cultural change is minimal (Lauer, 1982).

By contrast, the symbolic interaction perspective in sociology perceives culture as highly dynamic and fluid. It rests on three premises: first, things are known through meanings and human action depends on meanings; second, meanings are given to things based on human social interactions; and third, meanings can change through social interactions (Fine, 1993). The symbolic interaction perspective views culture as the product of the everyday social interactions of individuals, and thus is capable of explaining how aspects of society can change as they are created and recreated by social interactions (Blumer, 1969; Herman \& Reynolds, 1994). Culture is thus conceptualized as a continuous process of individuals consensually deriving shared meanings from both objects in the environment and the action of others. Hence, every object and action has no inherent meaning, but a symbolic meaning; making or producing culture is therefore seen basically as a symbolic phenomenon. Moreover, people interact with each other by interpreting and re-defining each others' actions, and because patterns of this social interaction are constantly changing over time and over space, meanings are also changing intertemporally as well as interspatially. Consequently, culture as the collective manifestation of human social interaction is also evolving and is never completely static (Blummer, 1969; Cardwell, 1971). 
In this section, I borrow mainly insights from the symbolic interactionism paradigm along with ideas from anthropology and economics and integrate them into various strong features of the existing conceptualizations of culture to develop the Dynamic Socio-Cultural Model (DSCM), which is a general theoretical framework that helps explain how culture is created and how it changes over time in groups, organizations, and societies. The proposed DSCM makes the process of cultural creation and cultural change more systematic and explicit, and encompass in its model other elements of culture beyond cultural values. Following sociological tradition, we develop the model by analytically treating culture and the social system in which it resides as two distinctive but interrelated entities (Kroeber \& Parsons, 1958). Furthermore, people and their social systems are interdependent. Culture is thus fluid and subjectively perceived in peoples’ minds, because people are continuously manipulating symbols and creating collective meanings through social interactions. Accordingly, cultural differences are context-specific, and their effects on IB are dynamically context-dependent, as people and organizations from different cultures interact with one another. The diagrammatic representation of my proposed dynamic socio-cultural model (DSCM) is provided in Figure 1.

\section{Social system}

I begin describing my proposed dynamic socio-cultural model (DSCM) by focusing on the social system, which is the center, or core, where all human social interactions occur. Social system is defined as the collection of interacting individuals (Wasserman \& Faust, 1994). Except in an extremely rare case where an individual lives in complete isolation 
(e.g., total institutions such as solitary confinement in prison), every individual typically interacts with other human beings. Interaction or social interaction (hereinafter will be

Figure 1. The Dynamic Socio-Cultural Model (DSCM)

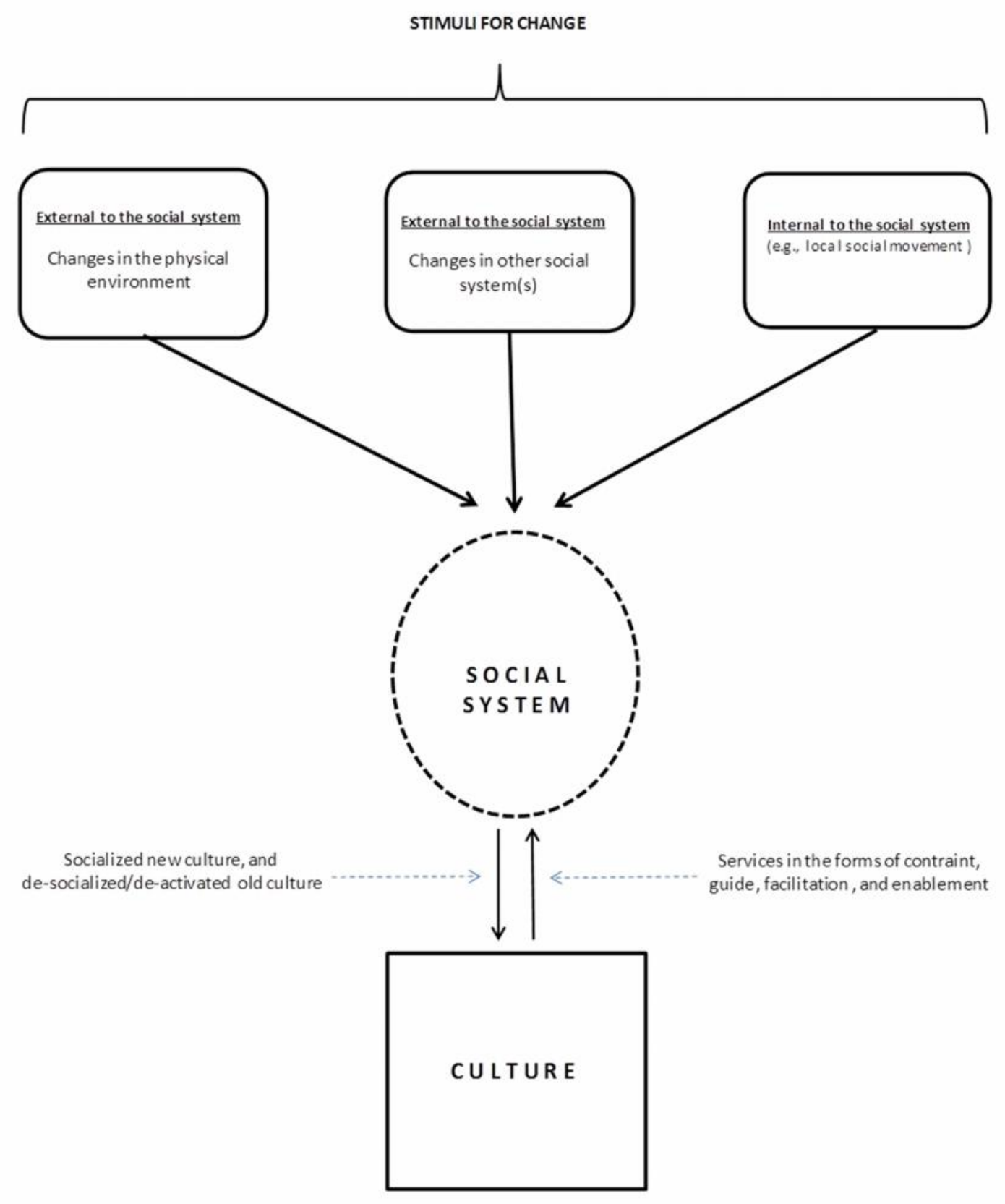


used interchangeably) refers to at least two agents acting upon one another (McCall, 2003). Interactions can take many forms. Social exchange is one of those forms, where interactions are viewed as exchanges in which one person's actions are interdependent and contingent on the actions of another person/s (Blau, 1964). Reciprocity or repayment in kind is the most often used rule in such exchange, albeit not the only one (Cropanzano \& Mitchell, 2005). Other resources that may be exchanged can include love, status, information, money, goods, and/or services (Foa \& Foa, 1980). Economic or market exchange is in fact a special type in the broader social exchange framework. An interaction may simultaneously involve multiple types of exchanges, resources, and exchange rules, as in marriages between two people. In addition to social exchange, other forms of social interaction include cooperation, competition, conflict, and coercion (Thompson \& Hickey, 2004). Different kinds of interaction lead individuals to be connected to one another. These connections or "ties" can be measured as present or absent, strong or weak, positive or negative, bi-directional or unidirectional (Mohr, 2000).

As shown in Figure 2, the dyad and triad are the building blocks of any social system. Regardless of the social system's forms and complexities, at the smallest unit every social system always consists of dyads and triads (Bohannan, 1995). The simplest form of any social system is a dyad, in which there are only two interacting persons involved (e.g., friendship, husband-and-wife, etc.). Furthermore, a triad is a compound structure of individual interactions, composed of three individuals and three dyads. Family is a slightly more complex social system, followed by extended family and kinship (Hofstede, 1994). More complex social systems include, but are not limited to, 
Figure 2. Various social systems and interactions

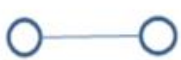

(a)

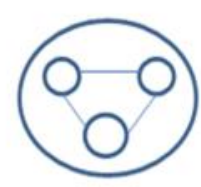

(b)

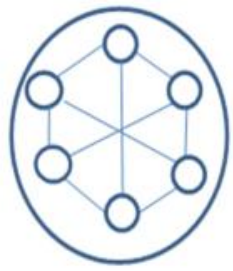

(c)

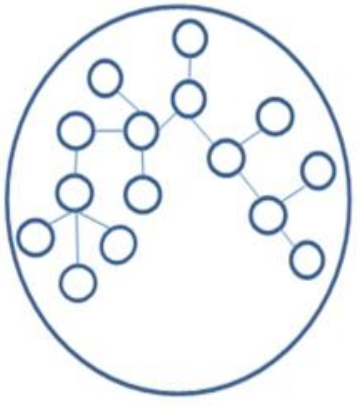

(d)

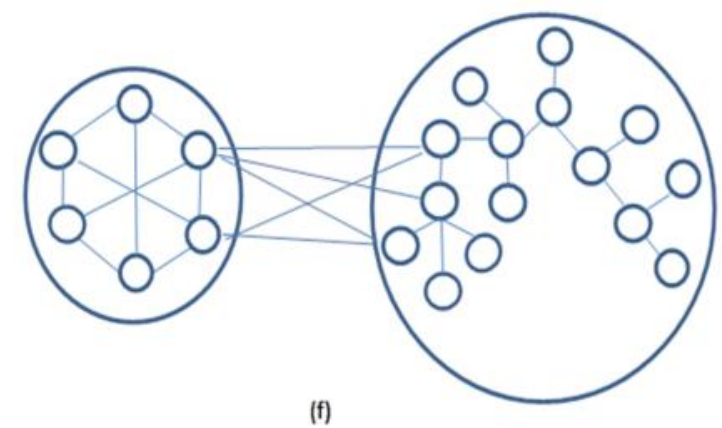

(f)

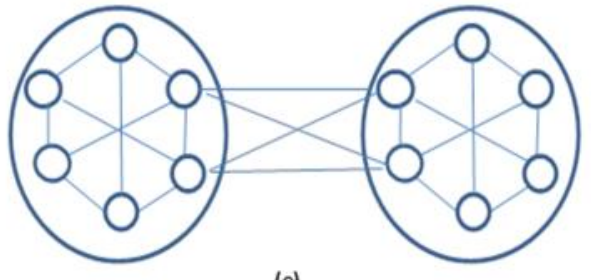

(e)

Examples of various social systems and interactions (a) husband-wife, (b) group, (c) organization, (d) society, (e) inter-organizational/group interaction, (f) cross-level organization-society interaction

organizations, groups or communities based on personal characteristics, lifestyle communities, nation-state, other geography-based societies including the global society of nations (Gould \& Grein, 2009). The nation-state, for example, is still essentially composed of dyadic individual interactions, in which an individual's choice or action depends on what other individual(s) are doing, and vice versa (Bohannan, 1995). An individual has the capacity to participate in multiple social systems. S/he can belong to two or more social systems of similar forms (e.g., a bilingual person belongs to two different language groups), or s/he can also be part of multiple social systems of different 
forms (e.g., a person can simultaneously be a citizen of a country, an employee of a firm, a member of a civic organization, and a member of a family.

Each individual in every social interaction has a set of preferences and engages in purposive behavior (Schelling, 2006). Without personal goals, there is no point for individuals to interact. The interaction can be face-to-face (non-virtual) or mediated (virtual), direct or indirect, transient or recurrent, unacquainted or acquainted, real time (synchronous) or delayed (asynchronous), and/or short-term or long-term (McCall, 2003). To further characterize interaction processes at the individual level, I resort to the idea of Dramaturgy in the symbolic interaction perspective, which approaches social interaction in everyday life as a theatrical performance that features two regions of impression formation that affect how individuals interact with others, namely, the front stage and the back stage (Goffman, 1959).

In the front stage, individuals purposefully act in certain ways to create impressions on the people around them (i.e., the audience), while in the back stage individuals practice for roles to be played in the front stage (Dolch, 2003). The back stage is where individuals symbolically create behavior based on role definition - defined as the expected behavior patterns or the plans of action which are associated with a particular role/position -- before they physically enact or engage in behavior which corresponds to the symbolic model. Role definition is similar to the "script" used by actors for preparing a theatrical performance, and it may be in the form of models, plans of actions, or blueprints (Cardwell, 1971).

Individuals regularly move in and out the front stage and the back stage, as they play multiple parts and each of the parts has an associated role which must be learned and 
acted out of the front stage (Goffman, 1959). Furthermore, role definition (or script) itself is subject to change and modification, as it is constantly shaped by changing human interaction (Cardwell, 1971). Clearly, human beings do not have innate knowledge necessary for playing multiple roles in life, especially with constantly changing role definitions. They must therefore learn the appropriate script for each role they will play. Just as in a theatrical performance, sometimes the actor does not rehearse well enough for the script in the backstage, causing a less successful performance in the front stage. In other cases, the associated role definitions may or may not be closely followed by the actor. In such cases, all role playing will involve a non-scripted part that requires a dynamic, improvisational and creative behavior (Cardwell, 1971). Since individuals are constantly taking on roles rather than having roles impinge on them (Dolch, 2003), the dramaturgy idea argues that social interactions are dependent upon time, place, and audience, suggesting that an individual's identity is not stable and independent, but constantly redefined as the individual interacts with others (Ritzer \& Stepnisky, 2007). Indeed, due to the dynamic and fluid nature of the social interaction, change is inherent in every social system regardless of its size and complexity (Griswold, 1994). In addition, because of humans' basic abilities to move, grow, reproduce, and respond to stimuli, the social system continuously and naturally changes (Bohannan, 1995). Every social system whether it is simple in theory (e.g., husband-and-wife) or complex (e.g., business organizations, global communities, etc.) by its very nature changes, albeit at different speeds or rates of change. In fact, change in a social system is a matter of its very own survival. Viewing society as a social system, Schumpeter (1975) argued that social change is inevitable as society continually undergoes a process of "creative 
destruction," referring to the incessant product and process innovation by which new production units replace outdated ones.

Although the dyadic relationship is the smallest unit of social interaction in any kind and size of social system, social interaction itself is not limited to interpersonal interaction. Interaction may also take place at the group, organizational, or societal level. Moreover, the interactive partner can be at the same level, cross level (downward or upward), or multiple levels (McCall, 2003). Imagine, for example, a U.S. MNE engages in an FDI in India. The MNE's subsidiary has to interact not only with other organizations (e.g., suppliers, business customers, government), but also with the Indian society as a whole (legal institutions). Thus, the effect of a seemingly simple interaction at the individual-level may be more complex in reality, as individuals typically belong to multiple social systems. After describing the social system as the core of the DSCM where social interactions occur, I am now ready to move to culture, which is another central feature of my model.

\section{Culture}

There are literally hundreds of definitions for culture (Kroeber \& Kluckhohn, 1952). At its most expansive definition culture is conceptualized as everything material and nonmaterial humanity produces (Berger, 1969). On the other hand, the most restrictive definition conceptualizes culture as merely exclusive art (Arnold, 1949), in which culture represents the "wisest and the most beautiful expressions of human effort" (Griswold, 1994, 4). While the former definition suffers from the lack of precision typically needed in scientific investigations, the latter definition is so narrow that it de-couples culture 
from society or civilization, rendering scientific inference equally limited. For analytical purpose, drawing from symbolic interaction theory (Blumer, 1969; Ryan, 1969, \& Geertz, 1973), I define culture as the collective manifestation of shared meanings created by socially interacting human beings. As discussed previously, social interactions occur in multiple social systems of various sizes and complexities. A single individual cannot produce culture. Creations such as language and politics make no sense except in terms of the interaction of people. If one were the only human on earth, there would be no need for language or government (Ryan, 1969). An individual also has the choice of permanently leaving any social system in which s/he resides. However, some social systems may be harder or easier from which to exit than others. For example, for most people it is relatively easier to quit their jobs than to migrate from their country of birth to another country. Likewise, a prisoner cannot usually walk out of jail.

As a social construct, culture has elements which are heterogeneous in content and function (Tilly, 1992). Elements of culture include, but are not limited to, knowledge, values, norms, beliefs, custom, law, language, art, concepts of good and evil, tools, technologies, tools and artifacts (Japperson \& Swidler, 1994). Functionally, culture is both a constraint and a resource (Sewell, 1992). It is a constraint in that it provides rules of the game for the interaction through institutions, creating stability in the social system where the culture resides (North, 1991). On the other hand, culture is a form of resource that can be put to strategic use by individuals who possess it (Sewell, 1992; Swidler, 1986). Because a typical human being belongs to multiple social systems of various forms and complexities, s/he can utilize multiple cultural resources that serve as a repertoire, from which s/he can select differing pieces to attain his or her goal (Hannerz, 
1969). Consequently, the size of the cultural resources for a typical individual in modern society is very large, as most people know more culture than they utilize (DiMaggio, 1997; Swidler, 1986). Indeed, as a resource, culture liberates and enables interacting human beings to achieve their individual as well as collective goals. Compared to privately-owned resources (e.g., physical capital, human capital, financial capital, and labor services), cultural resources are unique because they are commonly learned, shared, possessed, and understood (in terms of meanings) by all interacting members of the social system where the culture resides. While private goods or resources are relatively distinguishable, culture is inherently present in any private goods and services, and for that reason, can be seen almost everywhere.

Every social system regardless of the size and complexity has cultural resources. Furthermore, based on usage frequency, we distinguish cultural resources into three major components, namely, active cultural resources, de-activated cultural resources, and "lost" cultural resources (See Figure 3).

Active cultural resources refers to cultural resources that are actively and commonly exploited by the interacting members of the social system. De-activated cultural resources, on the other hand, refers to older cultural resources that are still stored by the social system, but are less likely to be exploited by the social system's interacting members (e.g., older fashion styles, typewriters, skills to drive cars with manual transmission among Americans). Finally, "lost" cultural resources is any cultural resource that has been completely abandoned, or even forgotten by the interacting members of the social system (e.g., dead ancient languages and alphabets, extinct ancient knowledge of medicinal plants). Furthermore, boundaries between cultural components 
are semi-permeable, allowing movements of cultural elements across components over time and/or space. Clearly, social systems influence and are influenced by culture in all its myriad forms. The next section discusses those reciprocal influences from macro-level and micro-level perspectives.

Figure 3. Cultural resources

\section{ULTURE}

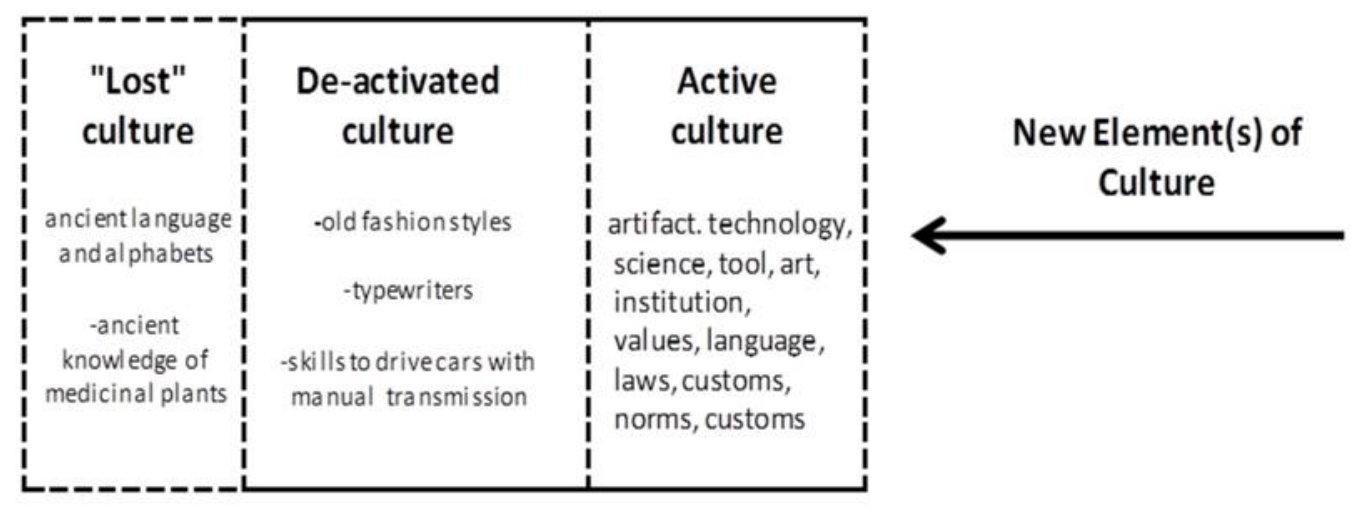

\section{Socio-cultural dynamics: The reciprocal relation between social system and culture}

\section{Macro-level perspective}

As Figure 1 suggests, cultural change is a manifestation of change in the social system where the culture resides. As individuals interact with each other in a social system, collective learning occurs and leads to effects that modify shared knowledge (Luhmann, 1995) and generate new cultural element(s). Cultural change occurs when culture is modified as a result of the arrival of one or more new cultural element(s). Socialization is a formal and informal collective learning process of acquiring one or more elements of new culture by the interacting members of the social system (Griswold, 1994). A 
socialized cultural element becomes part of the active culture component of the social system's cultural resources. Conversely, de-socialization is the process of de-activating one or more element(s) of the older culture, as new culture is being socialized. Deactivated culture is stored passively in the culture's resources.

More specifically, cultural change involves the following four mechanisms: invention, diffusion, accumulation, and adjustment (Martindale, 2013). Invention is defined as a combination of cultural elements which currently exist in any social system's cultural resources, or a modification of a cultural element to form a new one. It includes not only technological invention, but also social inventions (e.g., The World Bank, The World Trade Organization, etc.) and innovations in other cultural elements (e.g., new words, programming languages, etc.). It also covers not only basic or important inventions, but also minor improvements (Ogburn, 1950). Accumulation occurs when more elements are added to a social system's cultural resources than are lost as result of the invention. The more cultural elements the social system has and the larger the accumulation the social system experiences, the easier it is for the social system to produce new inventions through the combination of these elements. Thus, the growth of cultural resources from the accumulation process tends to be exponential, just as in the growth of financial investment with compounded interest rate. Diffusion refers to the spread of inventions to all interacting members of the social system. Adjustment occurs when an invention comes into contact with other cultural elements, as these cultural elements may evolve at different speeds. For example, in social movements, changes in the non-material culture (values, ideas, etc.) tend to lead changes in the material culture 
(e.g., clothing, buildings, etc.). On the other hand, in economic development, changes in material culture tend to lead to changes in the non-material culture (Ogburn, 1950).

Culture and the social system where it resides mirror each other (Griswold, 1994). While the DSCM posits that culture provides stability and integration to the social system (Demerath \& Peterson, 1967), it also suggests that culture facilitates changes in the social system, enabling and guiding innovations that are highly crucial for the survival of the social system (See Figure 1). Hence, culture and its social system coexist and co-evolve. From the social system comes culture and from culture comes the plan and knowledge by which the social system functions, orders, and maintains itself (Ryan, 1969). As a result, socially interacting human beings are both determined by culture and determinants of culture (Meltzer, Petras, \& Reynolds, 1975).

The dialectical action-reaction process between culture's "stabilizing” forces and "enabling” forces results in a socio-cultural equilibrium. Equilibrium here refers to a situation in which some motion or activity or response has died away, in which several things that have been interacting, adjusting to each other and to each other's adjustment, are at last adjusted, in balance and at rest momentarily (Parsons, 1961). It has no normative connotation, and is neither good nor bad. Moreover, consistent with what the ancient Greek philosopher Heraclitus once asserted that all being is "in flux, is constantly changing, constantly coming into being and passing away” (Engels. 1939: 27), the actionreaction process continuously occurs within the social system, leading to a dynamic socio-cultural equilibrium. It is a situation in which the equilibrium is achieved, but only for a short period of time, as a new action-reaction process develops again (Van Den Berghe, 1963). 
Figure 4. Microstructure of a dyadic interaction

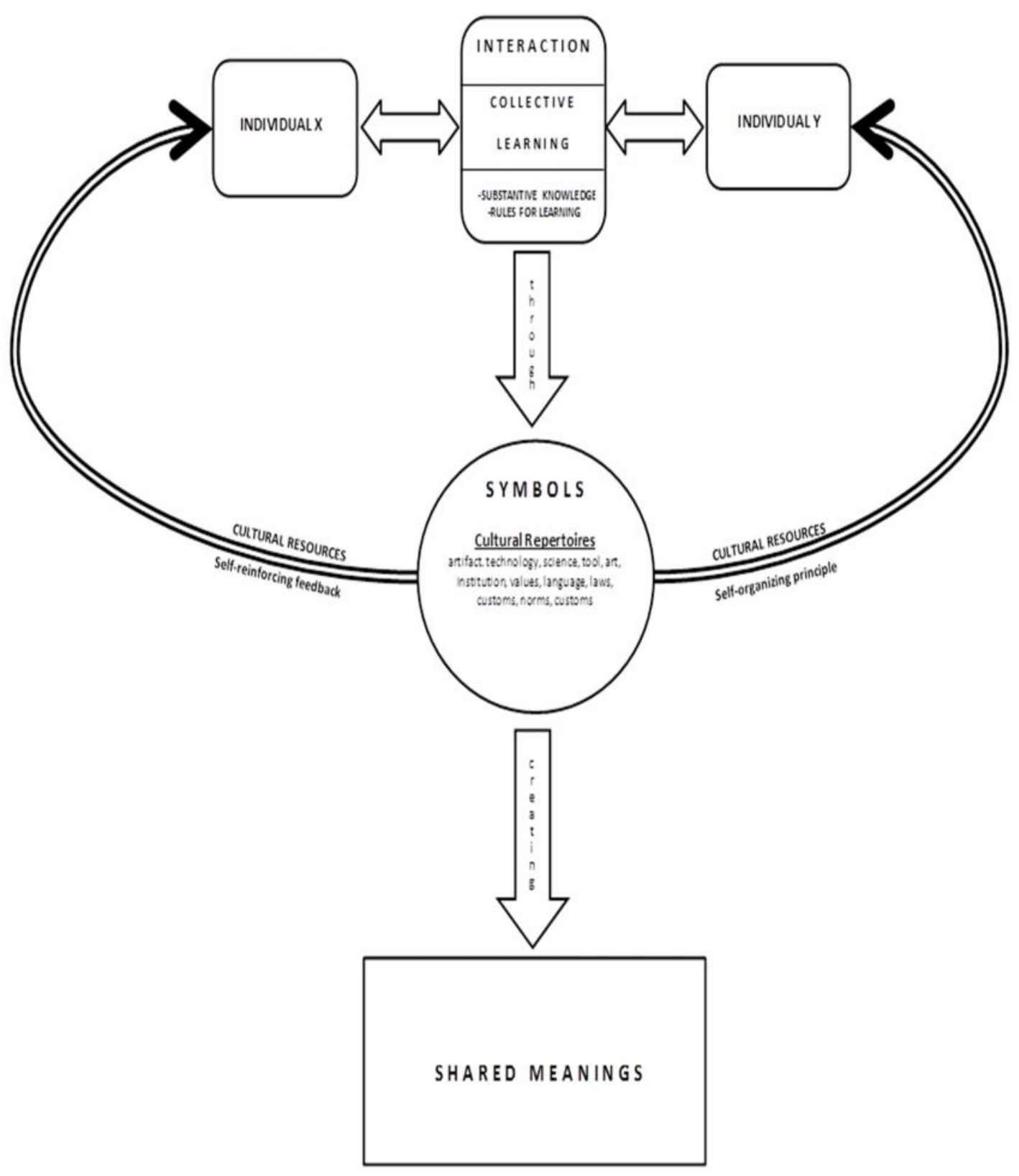

\section{Micro-level perspective}

As described in Figure 4, the creation of culture as a collective learning process occurs in situations where interaction processes yield effects that modify the collectively-shared knowledge, producing novel knowledge in the social system. There are two types of 
collective learning processes that yield two different types of shared knowledge, namely, substantive learning and social rule learning, which produce substantive knowledge and rules for learning, respectively. Substantive learning leads to the accumulation of different types of substantive knowledge (Eder 1999), ranging from simple practical knowledge to advanced scientific knowledge. On the other hand, social rule learning produces tacit knowledge about how to learn, that can be preserved and passed over to future members of the social system, through which interacting individuals collectively learn ways and procedures for generating new knowledge and integrating this new knowledge into their social system’s existing knowledge resource (Eder, 1999).

According to Habermas (1979), the learning process is inevitable in every social system, because humans must learn to live and not learning is impossible. Specifically, Eder (1999) further argues that collective social rule learning is a necessary reaction to uncertainty. In circumstances involving uncertainty, social systems have to reorganize their rules for dealing with uncertainty to survive. Since social systems in modern times largely carry uncertainty inherent in them, interacting individuals within the social systems must then continuously and collectively learn new rules (Beck, 1992; Sabatier \& Jenkin-Smith, 1993). All in all, my proposed theoretical framework suggests social change and cultural change are inevitable features of any surviving social system whether organization, nation, or any type of group.

Both successful substantive learning and social rule learning lead to more cultural resources, which increases the likelihood of the social system's survival as more tools and repertoires are available in the social system. When a new flow of cultural resources arrive in a social system as a result of social interactions, its effect on the social system's 
stocks of active cultural resources is likely to be non-linear and can either be positive or negative, depending on whether or not the new flow of cultural resources and the existing stocks of active cultural resources are complementary. When they are complementary, the total stock of active cultural resources will go up; otherwise it will go down. Nonlinearity itself occurs because of the difference in the rate of new cultural resources inflow and the rate of depletion of the active cultural resources, becoming part of deactivated cultural resources and eventually "lost” cultural resources, which often creates unintended consequences within the social system.

\section{Stimuli for change}

In the right-hand part of the DSCM (Figure 1), the model also features different types of stimuli that are potentially associated with changes within the social system. Stimuli for change are conditions that make social change more likely (Ryan, 1969). A stimulus for change can either be external or internal to a social system. The external conditions include those in the physical environment, and other social systems of various sizes, complexities, and purposes, which come into contact with the social system (Ryan, 1969). The relationship between the stimuli for change and the social change can be nonlinear and probabilistic, as opposed to simply a linearly deterministic cause-and-effect relationship. One of the examples for an external stimulus is the effect of 9-11 in New York City and the subsequent U.S. War on Terror on the behavior of most air travelers even outside of the U.S., as they now have to undergo stricter airport security clearance procedures. Examples of stimuli for change that are internal to the society include social movements (e.g., LGBT legitimacy) and changes in demography, age expectancy, child 
birth rate, etc. By contrast, however, a society with limited outside contacts - hence a lower probability for social change -- is likely to experience little change in its culture.

Furthermore, the rate of change (or speed of change) in the social system is determined not only by the strength of the stimulus for change, but also the culture's reaction to the social change, or the level of cultural inertia - defined as the propensity of culture to avoid cultural change, and also for the propensity of culture to continue changing once it is already in motion (Zarate, Shaw, Marquez, \& Biagas, 2012). Cultural inertia is embedded in the social system, and some cultures are more or less inert than others. In other words, the propensity to change is heterogeneous across cultures. Additionally, Harzing and Hofstede (1996) argued that cultures with high values of power distance, collectivism, and uncertainty avoidance are more resistant to change, compared to those with low values on those dimensions, making the latter more adaptable to changes in the global environment (Erez \& Gati, 2004). As global interdependence becomes a reality, a purely stationary social system is virtually non-existent. In a changing social system elements of culture are not necessarily changing at equal speed, and hence cause a series of maladjustments. The maladjustment of cultural elements along with its associated stresses and strains in the whole system is a distinctive characteristic of a culture in a changing social system (Ogburn, 1936)

In sum, using primarily insights from the symbolic interaction paradigm, I have developed and highlighted the DSCM as a new theoretical perspective that provides insights into how culture is created, changes and evolves over time. 


\section{DISCUSSION AND PROPOSITIONS}

The previous section introduced the DSCM with its dynamic and multi-element features as a conceptual model on culture. In this section, I will discuss the theoretical implications of the DSCM and develop relevant propositions for the role of cultural distance in EMNE's acquisition of firms in developed economies. From the DSCM's view, an organization can essentially be thought of as a social system with other social systems of various types or sizes within or outside it. For example, a purely domestic firm is part of a collection of organizations within a country, and it may have several divisions, branches, departments, and/or teams in it. To be sure, in the case of an EMNE, it can also be part of multiple larger social systems, as it operates in more than one country. Furthermore, a firm continuously interacts with other social systems of various types or sizes including other firms, segments of consumers, governments, etc. In each of

these social systems reside cultural resources with their distinctive cultural elements. Some of the elements in the cultural resources are shared across countries. For example, Mandarin Chinese is a language commonly spoken among people not only in China, but also in Taiwan and Singapore.

The DSCM views a cross-border M\&A as a "marriage" between two firms. It is a cultural event, in which two social systems, each of which brings its own distinctive cultural resources, are interacting with each other. In such an event, crossvergence may occur in one or more elements of the culture (e.g., new technologies resulted from combining resources from the acquiring and acquired firms). Convergence may also concurrently occur (e.g., values, superior managerial practices from the acquiring firm adopted at the acquired firm, etc.). Likewise, divergence may occur, since the acquiring 
and the acquired firms are located in two different countries that may have contrasting sets of national laws and institutions. At the same time, some other elements of culture may simply co-evolve or co-integrate (e.g., hiring practices, local knowledge, etc.), especially if they are different, yet complementary to each other. Clearly no strict or complete convergence, divergence, or crossvergence, occurs in most M\&A cases.

The DSCM suggests a shift from focusing on cultural distance to cultural complementarity. CD itself now becomes subjective, depending on the purpose(s) or context(s) of the interaction, the cultural elements involved in the interaction, the distribution of power among the interacting parties, and the cultural resources collectively shared by the interacting parties. In other words, CD is endogenized. For example, if a firm is to combine its resources with another firm's resources in order to enhance creativity and innovations, finding a partner firm with high CD can actually be useful. In fact in such cases, cultural differences are no longer viewed as a liability, and instead can be thought of as a valued asset (Watson, Kamalesh, \& Michaleson, 1993). The CD may provide opportunities for learning unique ways of doing business from new cultural resources (Larsson \& Finkelstein, 1999; Morosini, Shane, \& Singh, 1998), greater exploration of new resources and capabilities (Reus \& Lamont, 2009), and breaking internal rigidities in the MNEs’ organization (Barkema \&Vermeulen, 1998).

There is virtually no empirical study that has specifically examined the role of cultural distance in the context of EMNE's acquisitions in developed countries, but many studies have been undertaken in a more general context of cross-border acquisitions. The effect of cross-national cultural distance on acquirers' post-acquisition performance in latter context however remains empirically inconclusive (Stahl \& Voigt, 2008), ranging 
from support for a negative effect (e.g., Buono, Bowditch, \& Lewis, 1985; Jemison \& Sitkin, 1986; Datta \& Puia, 1995), positive effect (e.g., Chakrabarti, Gupta-Mukherjee, \& Jayaraman, 2009; Morosini \& Singh, 1994; Morosini, Shane, \& Singh, 1998), to support for a small or no effect at all (e.g., Berkeman, Bell, \& Pennings, 1996; Markides \& Ittner, 1994; Stahl \& Voigt, 2008). In the next sections, I will discuss several aspects and features of the DSCM, namely speed of cultural change, cultural resources, cultural inertia, interaction duration, and expectation formation, to provide a better understanding on the relationship between CD and EMNE's post-acquisition performance in highincome markets. Relevant propositions will be presented accordingly.

\section{Relative speed of cultural change}

The DSCM views society as a social system that must change continuously in order to survive, even in the absence of stimuli for change from outside of the society. Survival makes adaptation inevitable, and it changes the patterns of social interactions, increasing the level of uncertainty within the society. The increased uncertainty triggers a collective learning process among the interacting members of the society (Eder, 1999), in which roles are being redefined and played, and eventually lead to cultural change in the society (Goffman, 1959). When the cultural change occurs, all cultural elements change - some faster than others, leading to adjustments to reach a new dynamic equilibrium.

In an EMNE’s international acquisition, two societal cultures come into contact with one another, namely, the EMNE's home culture and host culture, each of which most likely evolves at a different speed of change, depending on the respective internal conditions and positions in their change trajectories. Cultural distance by definition is the 
distance in cultural values between two countries. While the value element of each culture may be relatively stable, its non-value element(s) (e.g., knowledge, technology, artifacts, etc.) may change at a relatively faster speed, causing maladjustment that ultimately will lead to changes in all cultural elements in both societies. Based on the basic concept in Newtonian physics, the contact between two societies evolving at two different speeds of change brings us to the relative speed of cultural change concept, defined as the speed with which a culture approaches or recedes from another culture, whether both are evolving or only one is evolving.

When the non-value cultural elements in the EMNE's home and host countries evolve at relatively similar speeds, it is arguably easier for the EMNE to adapt to the culture of the host country and offset any possible transaction costs incurred by the differences in cultural values (or CD). For example, although the U.S. and China may initially have high $\mathrm{CD}$ due to differences in cultural values, the speeds of change in the non-value cultural elements (e.g., knowledge, technologies, artifacts, etc.) in the U.S. and China may be relatively more similar. This helps when an acquiring Chinese MNE closes or bridges their initial CD and offsets its negative effect on its post-acquisition performance, allowing a higher probability for the Chinese MNE to operate successfully in the U.S. By contrast, in situations with a high relative speed of change in non-value elements of two cultures, both home and host countries evolve at much different velocities, rendering more complicated difficulties for the EMNE to adapt to the new host country environment, because the cultural differences between the EMNE's home and the host countries are growing larger over time. Thus, the relative speed of cultural change of the home and host countries matters. I thus propose 
Proposition 1: As an EMNE engages in international acquisitions in a developed economy, the relative speed of change in non-value cultural elements of the EMNE's home and host countries negatively moderates the negative relationship between CD and EMNE's post-acquisition performance.

\section{Cultural resources}

As a social system, each country has its own cultural resources. When an EMNE acquires a firm in a foreign advanced economy, the EMNE bring its home country's cultural resources as well as its own firm-specific cultural resources into contact with the cultural resources of both the acquired firm and the host country. This changes social interactions between the EMNE and the acquired firm, or the host country, producing an inherent uncertainty within the EMNE, the acquired firm, and the host country. This uncertainty brings about not only risks, but also opportunities for creating new shared cultures, because these risks incentivize the interacting social systems for further social rule learning. In fact, individuals within the home country, host country, and the MNE (as organization) are forced to learn new rules continuously and collectively in order to adapt and survive (Beck, 1992; Sabatier \& Jenkin-Smith, 1993).

According to the DSCM, larger cultural resources in a social system imply there are more diverse and sizable cultural elements within the social system. The larger the cultural resources, the larger the collective learning capacity of a social system, as more repertoires are available for combinations and inventions, hastening the already exponential growth of the societal or organizational cultural resources. 
Specifically, larger cultural resources within the EMNE, the host country, the acquired firm, or the home country, imply a higher probability for one or more of the cultural elements being complementary across cultures, making it more likely for successful collective learning between the EMNE and the acquired firm, or the host country. For example, if the EMNE's host country has a colonial tie with the home country, EMNE's collective learning to produce new shared culture through role redefinitions and role playing will be less challenging that when there is no previous colonial tie. Similarly, if the EMNE has people in their top management teams who have had work or educational experience in the host country, the "bridging" of the cultural distance will be relatively easier than when it does not, and further collective learning towards new shared culture will also be more time-efficient.

The newly acquired social rules for learning are integrated into existing cultural resources of the EMNE, acquired firm, and host country, for further transmission to future members of the social systems (Eder, 1999). The larger cultural resources also mean more repertoires are available for the process of role redefinitions and role playing among interacting individuals and organizations, which can then offset the negative effect of CD on EMNE's post-acquisition performance. I thus propose

Proposition 2: As an EMNE engages in international acquisitions in a developed economy, the cultural resources (of the EMNE, the acquired firm, the home country, and the host country) positively moderate the negative relationship between CD and EMNE's post-acquisition performance. 


\section{Cultural inertia}

The DSCM suggests social systems with low cultural inertia tend to be mode dynamic.

There is less friction in the social systems that resist changes, or slow changes once they

are in motion (Zarate et al., 2012). Some cultures are more or less inert compared to

others. For example, Harzing and Hofstede (1996) argued that cultures with low values of power distance, collectivism, and uncertainty avoidance tend to have low level of cultural inertia. Societies or organizations with low cultural inertia are more conducive to changes. These changes stimulate learning through increased uncertainties within the society or organization. As these uncertainties generate more risks, to survive and succeed in the changing society or organization, individuals must collectively learn not only new substantive knowledge (e.g., practical knowledge, technology, etc.), but also importantly new social rules for learning to create the new substantive knowledge.

In the EMNE's cross-border acquisition context, an EMNE with a low level of cultural inertia is likely to generate more collective learning in its organization, as it socially comes into contact with the society of its host country. This collective learning involves role redefinitions and role playing as interacting individuals, organizations and societies create a new shared culture. Moreover, a highly adaptable EMNE is also attractive to the host country, because it provides host country with opportunities for innovative combinations. Similarly, a low level of cultural inertia in the EMNE's home country is more conducive for more intensive collective learning that leads to better adaptation to changes across social systems. A highly adaptable host country likewise provides great opportunities for an entering EMNE to produce new shared culture. I thus propose 
Proposition 3: As an EMNE engages in international acquisitions in a developed economy, the cultural inertia (of the EMNE, the acquired firm, and the host country) negatively moderates the negative relationship between CD and EMNE's post-acquisition performance.

\section{Interaction duration}

From the DSCM perspective, an EMNE's acquisition of firm(s) in an advanced host country is nothing less than a cultural event where the time duration of the EMNE's interaction with the acquired target and the host country may attenuate the initial negative effect of cultural distance (CD) on EMNE's acquisition performance. Over time, as the EMNE continues to interact intensively with the acquired firm and the host country, through collective learning processes new culture arises and is shared by the MNE and the host country. This new shared culture enhances the collective learning capacity of the EMNE and accelerates the growth of its cultural resources.

Moreover, over time as new shared cultural resources grow exponentially and become more dynamic, the cultural inertia of the EMNE, the acquired firm, the host country, is likely to decrease. Similarly, over time as both EMNE's culture and host culture co-evolve through the collective learning process and new shared culture, the speeds of change in non-value cultural elements within the two social systems (i.e., the EMNE and the acquired target) are expected to be relatively more similar to one another. Hence, as the time duration of the EMNE's interaction with the acquired target and the host country increases, EMNE's expanded cultural resources, decreased cultural inertia, and lower relative speed of cultural change, reduce the effective CD (i.e., the difference 
in cultural values) actually experienced by the EMNE and should lead to a better postacquisition performance for the acquiring EMNE. In other words, while CD may initially pose an impediment to the EMNE's post-acquisition performance, in the long run its negative effect is likely to lessen. I thus propose

Proposition 4: As an EMNE engages in international acquisitions in a developed economy, the time duration of the EMNE's interaction with the acquired firm and the host country positively moderates the negative relationship between $C D$ and EMNE's post-acquisition performance.

\section{Expectation and time cost}

If the DSCM perceives CD not as negative, as previously thought, why then do some EMNE's acquisitions in developed countries fail and cultural distance are often cited as their causes? To answer this problem, I provide a helpful analogy from a non-Englishspeaking foreign student who wants to go to the U.S. to obtain a college degree. Imagine months or even years before the student leaves, s/he would likely collect as much information as possible about the host country and her destination school, perhaps by browsing the internet or visiting the educational section of the nearby U.S. embassy. Based on this information, she would form expectations on what she might encounter in the U.S., including cultural differences that she is likely to experience in the host country. She would also probably create expectations of various roles she has to play and rehearse for the respective role definitions (or scripts). Her pre-departure English training helps her tremendously in preparing these expected new roles in the U.S. 
Nonetheless, after she arrives in the U.S., she may find out that, despite all her preparations, realities are a lot different than she has expected. For instance, her English may not be good enough to succeed in a demanding American classroom environment. More experience- and interaction-based English training is necessary even after she arrives in the U.S., and this kind of learning needs time, because it cannot be acquired by simply taking more formal classes. Perhaps, because of this she may need to spend more than four years to graduate from college, so that she could carry a lighter academic load in her first few semesters and spend more time adapting to the new social and language environment. However, extra time for real-world learning is not free and may be costly. If she or her parents can afford the extra costs associated with this extra learning time, she will survive and successfully graduate from the U.S. college, perhaps in five or six years. However, if these extra costs are not affordable and her budget has been rigidly fixed for a 4-year study, she may be forced to drop out from college, making the whole college plan collapse.

In the context of EMNE's international acquisitions, I argue that prior to acquiring a target firm in the host country EMNE's top executives also form expectations of the cultural differences they are likely to encounter in the host country after the acquisition transaction is completed. Moreover, the expected cultural differences are not merely static expectations. The top executives also form dynamic expectations based on the cultural change trajectory of the host country. The formation of expectation can be made heuristically as well as rationally. In the latter case the top executives formally consider the home-host $\mathrm{CD}$, the relative speeds of cultural change in non-value elements, cultural resources, and cultural inertia, of the EMNE, the target firm, and the host 
country, and factor them into their expectation formation along with expected role definitions associated each stage of the cultural change trajectory. An acquisition decision is made when the extra transaction cost from the expected cultural differences is less than the expected additional benefits from the planned takeover of.

When the acquisition is implemented, the actual cultural differences may be more than the expected cultural differences due to EMNE's top executives' bounded rationality (Simon, 1979) and/or selective perception (Dearborn \& Simon, 1958). From the DSCM views, such expectation-realization gap creates a post-acquisition uncertainty for the EMNE and brings about an incentive for further collective learning. However, such collective learning is not free because of time costs. If the additional time costs of the collective learning are less than the expected benefit from owning the acquired firm, the acquisition is likely to survive. However, when the additional collective learning costs exceed the benefits from owning the acquired firm, the acquisition will likely be divested. I thus propose

Proposition 5: As an EMNE makes a takeover decision in an international acquisition in a developed economy, the EMNE's top executives form expectations on the future trajectory of the cultural change in the prospective host country and the associated roles and role definitions along the change trajectory. The EMNE's top executives will then factor them into their acquisition plan. Upon the acquisition is implemented, if the actual experience deviates from the pre-takeover expectations, the acquisition will still survive if the extra costs of further social learning in the host country do not exceed the additional benefits; otherwise, the acquisition will be dissolved. 


\section{CONCLUSION}

Nobel laureate Douglass North, the father of institutional economics, once asked, "what is it about [culture] that give[s] [it] such a pervasive influence upon the long-run character of economies?” (1991: 111). Indeed, culture is ubiquitous, yet it is so complex to explain that most economists refrain from studying it systematically. In fact, the new institutional economics decides to focus exclusively on institutions, and treat culture merely as an "informal" constraint. This paper explains how emerging multinational enterprises (EMNE) can handle the cultural distance (CD) they encounter in their operations in developed economies. It does so by broadening the conceptualization of culture to include all elements of culture beyond merely cultural values and demonstrating that managing $\mathrm{CD}$ may not be as insurmountable as often suggested in traditional IB literature. Rather than treating culture as a substratum of institution (e.g., Peng, Wang, \& Jiang, 2008), I have developed the DSCM as a dynamic conceptualization of culture that better reflects the ever changing environment of today's realities and its influence on all aspects of IB. Relating culture to the social system where it resides, I have allowed a rich intertemporal and interspatial interplay between the two. I have also extended the theoretical scope of the DSCM beyond cultural values to include other cultural elements in the model. Using insights from dramaturgy in the symbolic interaction theory, I have further enriched the characterization of the collective learning process among interacting individuals as they are adapting to changes. Moreover, I have discussed several theoretical implications of the DSCM and specifically derived five propositions related to IB research on the effect of $\mathrm{CD}$ on the performance of emerging 
multinationals' international acquisitions in developed economies, for illustrative purposes. Last but not least, the new theoretical perspective of culture I present in this paper has significant practical and research implications for IB and business in general, as outlined below.

\section{Practical implications}

The DSCM suggests in considering options for entering a foreign market, managers must focus on cultural complementarity rather than cultural distance. While CD views cultural differences as "threats," cultural complementarity sees cultural differences as “opportunities” (Stahl \& Tung, 2015). For instance, when an Indonesian MNE is entering the U.S. market, establishing its own sales subsidiary in the U.S. may be intimidating, given the high $\mathrm{CD}$ between the two countries. However, if there are enough IndonesianAmerican diaspora or Indonesian managers who are graduates of U.S. colleges in the hiring pool, the $\mathrm{CD}$ can be bridged, and synergies between cultural resources can be created. Over time this bridge can become shorter, as new shared cultural elements are created and added to the cultural resources of the Indonesian MNE. Thus, from the DSCM perspective an CD becomes less relevant for managers, and should be replaced by managers' focus on analyzing cultural complementarity, which is a subjective measure that largely depends on the context(s) of the interaction, and the dynamic characteristics of the involved cultures.

In my view, reducing culture to a few numerical dimensions of cultural values, or $\mathrm{CD}$ between pairs of countries to a unique numerical index-typed measure, is not particularly useful for practitioners. Instead, a systematic checklist-type assessment of 
culture or cultural differences may perhaps not only be richer, but also more useful for managers, especially given the dynamic nature of culture. In this respect, the cultural due diligence approach often exercised in prospective M\&As or extended partnership decisions to assess “cultural fit” between two organizations seems more useful for practitioners (Carleton \& Lineberry, 2004). Of course, the challenging task is how to generalize the scope of the cultural due diligence approach beyond comparing two organizational cultures in an M\&A or partnership context, to include comprehensive considerations of multiple contexts other than M\&As, with the ultimate goal of assessing potential cultural complementarity between an organization and its surrounding social systems (e.g. countries/nations, other firms, group of consumers).

The DSCM also justifies cross-cultural management training in the academic as well as professional environments, particularly those that involve experience-based activities such as overseas exchange programs, internship abroad programs, immersionbased foreign language courses, corporate management development programs with global rotational assignments, etc. Unlike traditional short-courses in cultural awareness that primarily focus on cultural differences, these trainings emphasize cultural complementarity and help people practice and hone their skills in the actual contexts in which they will be using them (Molinsky, 2015). In the FDI context, people with such training may be able to bridge the initial CD. They also help the MNE form better expectations for the potential cultural differences and cultural change trajectory. Ultimately, their experiential knowledge adds to existing cultural resources of the MNE, which facilitates a smoother adaptation and adjustment. 


\section{Future research}

I believe at this stage obsession with reducing the complexities of culture to a unique single or several indexed-numbers(s) measuring cultural values as in the dimensions approach is detrimental to the theoretical development of culture in IB. Such approaches may have been helpful for the operationalization of culture in early empirical IB research, but it distracts us now from the priority needed to develop a consistent theoretical framework for systematically analyzing such a rich phenomenon as culture, in order to produce consolidated knowledge (Jepperson \& Swidler, 1994). Empirical studies involving culture in IB have largely tried to estimate the extent to which cultural values shape actions. While there is no doubt that culture matters, when, how much, how long, and in what direction it matters still remains empirically inconclusive.

The DSCM provides a new analytical framework that will allow richer empirical analyses of how various kinds of cultural elements (including values) are used by actors to shape their actions in socially interactive contexts. Echoing Jepperson and Swidler (1994), I am in favor of specifying different elements of culture, measuring them directly, and considering any quasi-hierarchic linkages that might be obtained between them. Specifically, there is a need for empirical research to focus on how social change may lead to adjustments in one or more cultural elements. For example, we know very little about how changes in institutions may lead to changes in cultural values. Similarly, empirical research is also needed to examine how changes in one cultural element within a social system may change other cultural element(s) in other social systems. For instance, we are still not clear on how a broadening access to management knowledge in the West may lead to a change in managerial practices in emerging markets. 
Methodologically, I believe we need to push beyond the use of the traditional ordinary least-squares (OLS) regression method on cross-sectional data for examining the effects of culture on IB operations, where dependent and independent variables are $a$ priori determined. Our DSCM suggests culture or CD can also be a dependent variable. Accordingly, our empirical research strategy must adjust its focus toward a more dynamic and multi-element conceptualization of culture. At the initial stage, in the absence of extensive time-series databases for cultural elements, a qualitative approach involving focus groups and interviews, field observation and archival studies, can be launched with an ultimate goal of triangulation. The qualitative approach may also enrich our understanding of how cultural elements conflate with each other, creating distinctively unique cultural resources.

In the long-run a quantitative approach based on flexible multivariate techniques can be employed on empirical specifications where all of the social system's cultural elements are treated endogenously. For this matter, applying time-series or panel multivariate estimation techniques may help capture the dynamics of the cultural elements and uncover not only the causation question, but also the "how" and the "how long” questions, bringing in the time dimension of culture that has been often neglected in empirical research (Kelly \&McGrath, 1988).

Despite the sophisticated statistical techniques available to us presently, I realize that time-series or multi-wave longitudinal data are not as widely available as we would like them to be. However, at the country level, such advanced techniques can readily be applied to time-series datasets such as the World Values Survey and various multi-wave longitudinal datasets with institutional measures that are available from multilateral 
agencies and non-governmental organization sources. At the organizational level, the use of firm-level data focusing on cultural elements should be reasonably feasible.

Additionally, a great number of longitudinal household-level data from various countries may be available. We can also investigate the dynamic interplays among cultural

elements by taking advantage of intra-national data of culturally diverse countries, firms, etc., where time-series or longitudinal data are available (e.g., the U.S., Europe, or firms in these regions). Of course, in the long-run more formal projects are necessary to systematically collect and build a multi-wave longitudinal database on a global basis for various elements of culture and social systems.

\section{Limitations}

There are several limitations in this study of which I am fully aware. Theoretically, a full treatment in the microstructure of the social interactions at the dyadic level is necessary. Modeling the complexities and intricacies of social interactions at the dyadic level would substantially enrich our analysis and enhance the predictive power of our model. Anecdotal evidence suggests that an individual's action can have a profound impact that leads to substantive culture change. One could only contemplate how the American culture would have evolved if, for example, Martin Luther King Jr. had not been assassinated. A more detailed analysis of how cultural resources are formed and changed would also be useful in our endeavor for greater predictive power. Insights from complexity theory (Nicolis \& Prigogine, 1989; Waldorp, 1993) as well as social network approaches (Pachuki \& Breiger, 2010), should prove useful in explaining the bottom-up emergent process and consistent with the basic tenets of our DSCM. 
I have also not given political resources and distribution of power in social interactions the treatment they deserve. Similarly, a better understanding on how scarce privately-owned resources (i.e., physical capital, financial capital and human capital) are combined with socially shared cultural resources would provide a tremendous

enhancement to our analysis of the effects of culture or cultural differences on IB. From a practical perspective, I stopped short of creating an easy-to-use analytical tool that reflects our new theoretical perspective of culture, which is sufficiently practical to help managers as they make decisions involving cultural considerations. Given the scope and space constraints of this paper, all these limitations need to be addressed in future studies.

This paper dynamizes the conceptualization of culture and extends the scope of cross-cultural analysis in IB beyond cultural values with a sharp focus on the collective learning processes occurring among interacting individuals within groups, organizations as well as societies. The proposed new theoretical perspective of culture can substantially improve our understanding of culture and how it influences IB. The DSCM allows the examination of the interplay between firms and their cultural environments in a much more realistic way, which ultimately will help IB practitioners devise more effective corporate strategies and operational decisions.

\section{REFERENCES}

Ailon, G. 2008. Mirror, mirror on the wall: Culture's consequences in a value test of its own design. Academy of Management Review, 33(4): 885-904.

Ambos, B., \& Håkanson, L. 2014. The concept of distance in international management research. Journal of International Management, 20(1: 1-7. 
Arnold, M. 1949. Culture and anarchy: An essay in political and social criticism. London : John Murray.

Beck, U. 1992. Modern society as a risk society. In N. Stehr and Richard V. Ericson (Eds.), The culture and power of knowledge: Inquiries into contemporary societies: 199-214. Berlin: de Gruyter.

Berger, P. L. 1969. A rumor of angels; Modern society and the rediscovery of the supernatural. Garden City, NY: Doubleday.

Barkema, H., Bell, J., \& Pennings, J. M. E. 1996. Foreign entry, cultural barriers and learning. Strategic Management Journal, 17(2): 151-166.

Barkema, H. G., \& Vermeulen, F. 1998. International expansion through start-up or acquisition: A learning perspective. Academy of Management Journal, 41(1): 7-26.

Berry, H., Guillén, M. F., \& Zhou, N. 2010. An institutional approach to cross-national distance. Journal of International Business Studies, 41(9): 1460-1480.

Blau, P. M. 1964. Exchange and power in social life. Transaction Publishers.

Blumer, H. 1969. Symbolic interactionism: Perspective and method. Englewood Cliffs, NJ: Prentice Hall.

Bohannan, P. 1995. How culture works. New York: The Free Press.

Buono, A. F., Bowditch, J. L., \& Lewis III, J. W. 1985. When cultures collide: The anatomy of a merger. Human relations, 38(5): 477-500.

Caprar, D. V., Devinney, T. M., Kirkman, B. L., \& Caligiuri, P. 2015. Conceptualizing and measuring culture in international business and management: From challenges to potential solutions. Journal of International Business Studies, 46(9):1011-1027.

Cardwell, J. D. 1971. Social psychology: A symbolic interaction perspective. Philadelhpia, PA: F.A. Davis.

Carleton, J. R., \& Lineberry, C. 2004. Achieving post-merger success: A stakeholder's guide to cultural due diligence, assessment, and integration. San Francisco: Pfeiffer.

Chakrabarti, R., Gupta-Mukherjee, S., \& Jayaraman, N. 2009. Mars-Venus marriages: Culture and cross-border M\&A. Journal of International Business Studies, 40(2): 216-236. 
Chen, Y. R., Leung, K., \& Chen, C. C. 2009. Bringing National Culture to the Table: Making a Difference with Cross-cultural Differences and Perspectives. The Academy of Management Annals, 3(1): 217-249.

Cropanzano, R., \& Mitchell, M. S. (005. Social exchange theory: An interdisciplinary review. Journal of Management, 31(6): 874-900.

Cuervo-Cazurra, A., \& Genc, M. 2008. Transforming disadvantages into advantages: developing-country MNEs in the least developed countries. Journal of International Business Studies, 39(6): 957-979.

Datta, D. K., \& Puia, G. 1995. Cross-border acquisitions: An examination of the influence of relatedness and cultural fit on shareholder value creation in US acquiring firms. Management International Review, 35(4): 337-359.

Dearborn, D. C., \& Simon, H. A. 1958. Selective perception: A note on the departmental identifications of executives. Sociometry, 140-144.

Demerath, N. J., \& Peterson, R. A. (Eds.). 1967. System, change, and conflict:A reader on contemporary sociological theory and the debate over functionalism. New York: Free Press.

Dimaggio, P. 1997. Culture and cognition. Annual Review of Sociology, 23: 263-287.

Dolch, N. A. 2003. Role. Handbook of symbolic interactionism, 391-410.

Dunning, J. H. 1988. The theory of international production. The International Trade Journal, 3(1): 21-66.

Earley, P. C. 2006. Leading cultural research in the future: A matter of paradigms and taste. Journal of International Business Studies, 37(6): 922-931.

Eder, K. 1999. Societies Learn and yet the world is hard to change. European Journal of Social Theory, 2(2): 195-215.

Engels, F. 1939. Anti-Duhring, trans. Burns, E. New York: International Publishers.

Erez, M., \& Gati, E. 2004. A Dynamic, multi-level model of culture: From the micro level of the individual to the macro level of a global culture. Applied Psychology, 53(4): 583-598.

Fang, T. 2005. From "onion" to "ocean": Paradox and change in national cultures. International Studies of Management and Organization, 35(4): 71-90. 
Fine, G. A. 1993. The sad demise, mysterious disappearance, and glorious triumph of symbolic interactionism. Annual Review of Sociology, 19(1): 61-87.

Foa, E., \& Foa, U. 1980. Resource theory: Interpersonal behavior as exchange. In K. J. Gergen, M. S. Greenberg, \& R.H. Willis (Eds.), Social exchange: Advances in theory and research: 77-94. New York: Plenum Press.

Friedman, T. 2005. The world is flat: A brief history of the globalized world in the 21st century. London: Allen Lane.

Geertz, Clifford. 1973. The interpretation of cultures. New York: Basic.

Goffman, E. 1959. The presentation of self in everyday life. Garden City, New York: Doubleday.

Gould, S. J., \& Grein, A. F. 2009. Think glocally, act glocally: a culture-centric comment on Leung, Bhagat, Buchan, Erez and Gibson (2005). Journal of International Business Studies, 40(2): 237-254.

Govindarajan, V., \& Ramamurti, R. 2011. Reverse innovation, emerging markets, and global strategy. Global Strategy Journal, 1(3-4): 191-205.

Griswold, W. 1994. Cultures and societies in a changing world. Thousand Oaks, CA : Pine Forge Press.

Guillén, M. F., \& García-Canal, E. 2009. The American model of the multinational firm and the "new" multinationals from emerging economies. The Academy of Management Perspectives, 23(2): 23-35.

Habermas, J. 1979. Communication and the evolution of society. London: Heinemann.

Hannerz, U. 1969. Soulside: Inquiries into ghetto culture and community. New York: Columbia University Press.

Harzing, A. W., \& Hofstede, G. 1996. Planned change in organizations: The influence of national culture. Research in the Sociology of Organizations, 14: 297-340.

Hennart, J. F., \& Larimo, J. 1998. The Impact of culture on the strategy of multinational enterprises: Does national origin affect ownership decisions? Journal of International Business Studies, 29(3): 515-538.

Herman, Nancy J., \& Larry T. Reynolds. 1994. Symbolic interaction: An introduction to social psychology. Lanham, MD: Altamira Press. 
Hofstede, G. 1980. Culture's consequences: International differences in work-related values. London: Sage.

Hofstede, G. 1991. Cultures and organizations: Software of the mind. London: McGrawHill.

Hofstede, G. 1994. The business of international business is culture. International Business Review, 3(1): 1-14.

Hofstede, G. 1995. Multilevel research of human systems: Flowers, bouquets and gardens. Human Systems Management, 14(3): 207-217.

Hofstede, G. 2001. Culture's consequences: Comparing values, behaviors, institutions and organizations across nations. Thousand Oaks, CA: Sage

House, R.J., Hanges, P.J., Javidan, M., Dorfman, P., \& Gupta, V. 2004. Culture, leadership, and organizations: The GLOBE study of 62 societies. Thousand Oaks, CA: Sage Publications.

Hymer, S. 1960. On multinational corporations and foreign direct investment. London: Routledge for the United Nations.

Jemison, D. B., \& Sitkin, S. B. 1986. Corporate acquisitions: A process perspective. Academy of Management Review, 11(1): 145-163.

Jepperson, R. L., \& Swidler, A. 1994. What properties of culture should we measure? Poetics, 22(4): 359-371.

Kelly, J. R., \& McGrath, J. E. 1988. On time and method. Newburry Park, CA: Sage Publications.

Kirkman, B. L., Lowe, K. B., \& Gibson, C. B. 2006. A quarter century of culture's consequences: A review of empirical research incorporating Hofstede's cultural values framework. Journal of International Business Studies, 37(3): 285-320.

Kogut, B., \& Singh, H. 1988. The effect of national culture on the choice of entry mode. Journal of International Business Studies, 19(3): 411-432.

Kroeber, A. L., \& Kluckhohn, C. 1952. Culture: A critical review of concepts and definitions, 47(1). Cambridge, MA: Peabody Museum

Kroeber, A. L., \& Parsons, T. 1958. The concepts of culture and of social system. American Sociological Review, 23(5): 582-583. 
Larsson, R., \& Finkelstein, S. 1999. Integrating strategic, organizational, and human resource perspectives on mergers and acquisitions: A case survey of synergy realization. Organization Science, 10(1): 1-26.

Lauer, R. H. 1982. Perspectives on social change. Boston: Allyn and Bacon.

Leung, K., Bhagat, R.S., Buchan, N.R., Erez, M., \& Gibson, C.B. 2005. Culture and international business: Recent advances and their implications for future research. Journal of International Business Studies, 36(4): 357-378.

Leung, K., Bhagat, R., Buchan, N. R., Erez, M., \& Gibson, C. B. 2010. Beyond national culture and culture-centricism: A reply to Gould and Grein (2009). Journal of International Business Studies, 42(1): 177-181.

Leung, K., Bond, M.H., Reimel de Carrasquel, S., Munoz, C., Hernandez, M., Murakami, F., Yamaguchi, S., Bierbrauer, G., \& Singelis, T.M. 2002. Social axioms: The search for universal dimensions of general beliefs about how the world functions. Journal of Cross-Cultural Psychology, 33(3): 286-302.

Leung, K., \& Morris, M. W. 2015. Values, schemas, and norms in the culture-behavior nexus: A situated dynamics framework. Journal of International Business Studies, 46(9): 1028-1050.

Luhmann, N. 1995. Social systems. Stanford University Press.

Luo, Y. 2002. Contract, cooperation, and performance in international joint ventures. Strategic Management Journal, 23(10): 903-919.

Luo, Y., \& Tung, R. L. 2007. International expansion of emerging market enterprises: A springboard perspective. Journal of International Business Studies, 38(4): 481-498.

Madhok, A., \& Keyhani, M. 2012. Acquisitions as entrepreneurship: asymmetries, opportunities, and the internationalization of multinationals from emerging economies. Global Strategy Journal, 2(1): 26-40.

Markides, C. C., \& Ittner, C. D. 1994. Shareholder benefits from corporate international diversification: Evidence from US international acquisitions. Journal of International Business Studies, 25(2): 343-366.

Martindale, D. 2013. The Nature and Types of Sociological Theory. New York: Routledge.

Mathews, J. A. 2006. Dragon multinationals: New players in 21 st century globalization. Asia Pacific Journal of Management, 23(1): 5-27. 
McCall, G. J. 2003. Interaction. Handbook of symbolic interactionism, 327-348.

McGaughey, S. L., \& Cieri, H. D. 1999. Reassessment of convergence and divergence dynamics: Implications for international HRM. International Journal of Human Resource Management, 10(2): 235-250.

McSweeney, B. 2002. Hofstede's model of national cultural differences and their consequences: A triumph of faith-a failure of analysis. Human relations, 55(1): 89118.

Meltzer, B. N., Petras, J. W., \& Reynolds, L. T. 1975. Symbolic interactionism: Genesis, varieties and criticism. London: Routledge \& Kegan Paul.

Minkov, M. 2013. Cross-cultural analysis. Thousand Oaks, CA: Sage.

Mohr, J. W. 2000. Introduction: Structures, institutions, and cultural analysis. Poetics, 27(2): 57-68.

Molinsky, A. 2015. The mistake most managers make with cross-cultural training. Harvard Business Review, January 15, 2015. Retrieved from https://hbr.org/2015/01/the-mistake-most-managers-make-with-cross-culturaltraining

Morosini, P., Shane, S., \& Singh, H. 1998. National cultural distance and cross-border acquisition performance. Journal of International Business Studies, 29(1): 137-158.

Morosini, P., \& Singh, H. 1994. Post-cross-border acquisitions: Implementing 'national culture-compatible'strategies to improve performance. European Management Journal, 12(4): 390-400.

Nachum, L. 2003. Liability of foreignness in global competition? Financial service affiliates in the city of London. Strategic Management Journal, 24(12): 1187-1208.

Nardon, L., \& Steers, R.M. 2009. The culture theory jungle: Divergence and convergence in models of national culture. In R.S. Bhagat \& R.M. Steers (Eds.), Cambridge handbook of culture, organizations, and work: 3-22. Cambridge, England: Cambridge University Press.

Nicolis, G., \& Prigogine, I. 1989. Exploring complexity. New York: WH Freeman.

North, D. C. 1991. Institutions. Journal of Economic Perspectives, 5(1): 97-112.

Ogburn, W. F. 1936. Stationary and changing societies. American Journal of Sociology, 42(1): 16-31. 
Ogburn, W. F. 1950. Social change with respect to culture and original nature. New York: Viking Press.

Pachucki, M. A., \& Breiger, R. L. 2010. Cultural holes: Beyond relationality in social networks and culture. Annual Review of Sociology, 36, 205-224.

Parsons, T. 1961. Theories of society: Foundations of modern sociological theory. New York: Free Press.

Parsons, T., \& Shils, E. 1951. Toward a general theory of action. New York: Harper \& Row.

Peng, M. W., Wang, D. Y., \& Jiang, Y. 2008. An institution-based view of international business strategy: A focus on emerging economies. Journal of International Business Studies, 39(5): 920-936.

Ralston, D. A., Gustafson, D. J., Cheung, F. M., \& Terpstra, R. H. 1993. Differences in managerial values: A study of US, Hong Kong and PRC managers. Journal of International Business Studies, 24(2): 249-275.

Ramamurti, R. 2012. What is really different about emerging market multinationals? Global Strategy Journal, 2(1): 41-47.

Ramamurti, R., \& Singh, J. V. 2009. Emerging multinationals in emerging markets. Cambridge University Press.

Reus, T. H., \& Lamont, B. T. 2009. The double-edged sword of cultural distance in international acquisitions. Journal of International Business Studies, 40(8): 12981316.

Ritzer, G., \& Stepnisky, J. 2007. Contemporary sociological theory and its classical roots. The Basics.

Rugman, A. M. 2009. Theoretical aspects of MNEs from emerging economies. Emerging multinationals in emerging markets, 42-63.

Ryan, B. F. 1969. Social and cultural change. New York: Ronald Press.

Sabatier, P. A., \& Jenkins-Smith, H. 1993. Policy change and learning: An advocacy coalition framework. Boulder: Westview.

Sauvant, K. P., Maschek, W. A., \& McAllister, G. 2010. Foreign direct investment by emerging market multinational enterprises, the impact of the financial crisis and recession, and challenges ahead. In Foreign direct investments from emerging markets. 3-29. Palgrave Macmillan US. 
Schein, E.H. 1992. Organizational culture and leadership. San Francisco: Jossey-Bass.

Schelling, T. C. 2006. Micromotives and macrobehavior. New York: W.W. Norton \& Company.

Schumpeter, J. 1975. Capitalism, Socialism and Democracy. New York: Harper and Row.

Schwartz, S.H. 1992. Universals in the content and structure of values: Theoretical advances and empirical tests in 20 countries. In M.P. Zanna (Ed.), Advances in experimental social psychology: 1-65. New York: Academic Press.

Sewell, W. H. Jr. 1992. A theory of structure: Duality, agency, and transformation1. American Journal of Sociology, 98(1): 1-29.

Shenkar, O. 2001. Cultural distance revisited: Towards a more rigorous conceptualization and measurement of cultural differences. Journal of International Business Studies, 32(3): 519-535.

Shenkar, O. 2012. Beyond cultural distance: Switching to a friction lens in the study of cultural differences. Journal of International Business Studies, 43(1): 12-17.

Shenkar, O., Luo, Y., \& Yeheskel, O. 2008. From “distance” to “friction”: Substituting metaphors and redirecting intercultural research. Academy of Management Review, 33(4): 905-923.

Simon, H. A. 1979. Rational decision making in business organizations. The American Economic Review, 69(4): 493-513.

Sivakumar, K., \& Nakata, C. 2001. The Stampede toward Hofstedes framework: Avoiding the sample design pit in cross-cultural research. Journal of International Business Studies, 32(3): 555-574.

Stahl, G. K., \& Tung, R. L. 2015. Towards a more balanced treatment of culture in international business studies: The need for positive cross-cultural scholarship. Journal of International Business Studies, 46(4): 391-414.

Stahl, G. K., \& Voigt, A. 2008. Do cultural differences matter in mergers and acquisitions? A tentative model and examination. Organization science, 19(1): 160176.

Swidler, A. 1986. Culture in action: Symbols and strategies. American Sociological Review, 51: 273-286. 
Thompson, W. E., \& Hickey, J. V. 2004. Society in focus: An introduction to sociology. Pearson

Tilly C. 1992. How to detect, describe, and explain repertoires of contention. Working Paper

No. 150. Center for Studies of Social Change. New Schol for Social Research.

Trompenaars, F. 1994. Riding the waves of culture: Understanding diversity in global business. New York: Irwin.

Tung, R. L. 2008. The cross-cultural research imperative: the need to balance crossnational and intra-national diversity. Journal of International Business Studies, 39(1): 41-46.

Tung, R. L., \& Verbeke, A. 2010. Beyond Hofstede and GLOBE: Improving the quality of cross-cultural research. Journal of International Business Studies, 41(8): 12591274.

Van den Berghe, P. L. 1963. Dialectic and functionalism: Toward a theoretical synthesis. American Sociological Review, 28(5): 695-705.

Waldrop, M. M. 1993. Complexity: The emerging science at the edge of order and chaos. Simon and Schuster.

Wasserman, S., \& Faust, K. 1994. Social network analysis: Methods and applications. Cambridge, England: Cambridge University Press.

Watson, W. E., Kumar, K., \& Michaelsen, L. K. 1993. Cultural diversity's impact on interaction process and performance: Comparing homogeneous and diverse task groups. Academy of Management Journal, 36(3): 590-602.

Westwood, R. G., \& Everett, J. E. 1987. Culture's consequences: A methodology for comparative management studies in Southeast Asia? Asia Pacific Journal of Management, 4(3): 187-202.

Wind, Y., Douglas, S. P., \& Perlmutter, H. V. 1973. Guidelines for developing international marketing strategies. The Journal of Marketing, 37(2): 14-23.

Zaheer, S. 1995. Overcoming the liability of foreignness. Academy of Management Journal, 38(2): 341-363.

Zaheer, S., Schomaker, M. S., \& Nachum, L. 2012. Distance without direction: Restoring credibility to a much-loved construct. Journal of International Business Studies, 43(1): 18-27. 
Zárate, M. A., Shaw, M., Marquez, J. A., \& Biagas, D. 2012. Cultural inertia: The effects of cultural change on intergroup relations and the self-concept. Journal of Experimental Social Psychology, 48(3): 634-645. 


\section{Essay 2. The Effects of Home Country Economic Characteristics and Target Industry on Control Mode Choice and Performance: An Acquirer's Perspective}

\section{INTRODUCTION}

Decades of rapid growth fueled by economic reforms have led to a substantial increase in net exports as well as inward FDI in emerging economies. Longer international experience and higher foreign currency reserves generated by their export revenues have encouraged emerging multinational enterprises (EMNE) to invest abroad including in developed economies. Ramamurti (2012) argues that EMNE invest in developed markets to obtain technologies and brands primarily for exploitation in their home markets. Simultaneously, they also explore, and learn about the host markets (Luo \& Tung, 2007; Madhok \& Keyhani, 2012; Mathews, 2002). Many EMNEs transfer technologies and brands from industries that have matured in high-income markets, but are still booming in their home market or other emerging markets. For many EMNE, acquisition is the preferred choice of entry mode when establishing their operations in developed countries (Williamson \& Zeng, 2009). Many of these acquisitions in high-income markets are noncontrolling minority acquisitions in which the EMNE acquirers own equal or less than 50 percent of their targets' equity shares after the transactions, as opposed to controlling majority acquisitions in which they own more than 50 percent of targets' equity shares after the transactions. Anderson and Gatignon (1986) classify these two choices of control as low-control mode and high-control mode, respectively. The choice of equity ownership level affects not only acquirer's control of the target, but also acquirer's resource commitment, risk, and returns (Chari \& Chang, 2009). While a high-control 
mode may be desirable in terms of reaping potential economic returns, it also comes with a higher risk, because the acquirer must assume full responsibility for all decision making in its foreign market operation (Anderson \& Gatinon, 1986). Between 1990 and 2016, EMNEs made 28,073 acquisition deals in developed countries ${ }^{4}$, about 19 percent of which were low-control mode acquisitions. ${ }^{5}$

From a strategic management research perspective, the choice of control mode made by EMNEs in their acquisitions of firms in developed economies is interesting because it may not be a random decision. Instead, the choice of control mode may be strategic in the EMNEs' attempts to create sustainable competitive advantage (Hamilton \& Nickerson, 2003; Shaver, 1998) and, similar to other strategic decisions, it may have performance implication. Despite few notable exceptions (Chari \& Chang, 2007; Ouimet, 2013), acquisitions control modes remain largely unexplored in the strategy literature, especially in the context of emerging multinationals' acquisitions in developed economies. Other related studies have recently focused on partial acquisitions, although not necessarily on non-controlling minority acquisitions (e.g., Chari \& Chang, 2009; Chen \& Hennart. 2004; Contractor, Lahiri, Elango, \& Kundu, 2014; Elango, Lahiri, \& Kundu, 2013; Gaffney, Karst, \& Clampit, 2016; Lahiri, Elango, \& Kundu, 2014; Piscitello, Rabellotti, \& Scalera, 2014; Yang, 2015).

In this essay, I specifically ask the following research questions: (1) Do EMNE's acquisitions in developed economies create value for the EMNE acquirers? (2) What drives certain EMNE acquirers to choose low -control acquisition over high-control

\footnotetext{
${ }^{4}$ These are countries classified by UNCTAD as developed economies.

${ }^{5}$ Data were retrieved from Thomson One database on June 14, 2017.
} 
acquisition when they take over targets in developed countries? (3) Do EMNE acquirers gain when their selection of low-control acquisition or high-control acquisition fits what has been prescribed by the answer to the second research question? In this essay, I combine strategic management and international business (IB) perspectives by responding to the EMNE acquirer's control mode choice and EMNE acquirer performance questions in a single framework of analysis. By doing so, I account for a potential self-selection or strategic nature of the control mode choice making, which would then help me in answering the third research question on what would happen to EMNE acquirer performances had they inadvertently made suboptimal choice of control mode.

To address these three research questions, I primarily draw theoretical insights from the dynamic socio-cultural change model proposed in my Essay 1 and enrich them with parallel ideas from the organizational learning literature, particularly the concept of ambidexterity, defined as a dynamic capability possessed by a firm to manage exploitation and exploration learning processes simultaneously (Raisch, Birkinshaw, Probst, \& Tushman, 2009). Exploitation and exploration refer to the adaptive processes of exploiting old certainties and exploring new possibilities, respectively, both of which are needed by every organization to survive (March, 1991). I argue that acquisitions of firms in developed economies provide EMNEs with a unique interspatial configuration of simultaneous exploration and exploitation, which has a strategic value that may lead to enhanced synergistic benefits and therefore value creation for the EMNE.

Moreover, I argue that certain home country profiles of the EMNE acquirer is likely to increase the likelihood for the EMNE to choose low-control mode in its 
acquisitions of firms in high-income markets. I characterize emerging economies into four types of industrializing economies based on their export and labor market characteristics. I show that unlike many other emerging economies, the rapidly growing emerging economies (or "the rapid industrializer"), such as China, has to uniquely face dual challenges from reliance on manufacturing-based exports and the rapidly shrinking labor force, which comes from aging population and previous distortionary population policy that have rapidly increased real wages relative to labor productivity and threatened the sustainability of the country's trade-driven economic growth. This in turn provides the utmost drive for EMNEs from these economies to engage in exploration-dominant acquisitions in advanced economies to upgrade their resources and capabilities in the speediest way possible. I argue that the low-control mode acquisition in many cases might better accommodate this drive than the high-control mode acquisition, as it provides the EMNEs with a relatively faster and more effective route in terms of deal completion time as well as post-acquisition collective learning.

I also argue that low-control acquisition is associated with learning benefits most relevant to the exploration learning process, which implies a greater incentive for an EMNE to choose low-control mode when it acquires a target in one of the high technology industries in advanced economies. While both exploitation and exploration learning occur when an EMNE acquires a target in a developed economy, in general the exploration learning is relatively more dominant than the exploitation learning when an EMNE takes over a target in an advanced economy, because the EMNE acquires the target primarily to access its strategic assets to build on the EMNE's limited firm-specific advantages. I further argue that the exploratory nature of EMNE's learning is even more 
dominant when the target is in a high technology industry where research and development (R\&D) is far more intensive than in non-high technology industry.

Finally, I argue there is a self-selection process involved in the control mode choice that EMNE acquirers make. Thus, EMNEs choose control mode by strategically considering their firm and home country characteristics as they attempt to optimize learning that leads to sustainable competitive advantages and, ultimately, better postacquisition performance. In addition, assuming a perfectly competitive market for corporate control, if an EMNE acquirer inadvertently made a sub-optimal control mode choice contrary to what our previous theoretical arguments prescribe, then such choice would lead to sub-optimal post-acquisition performance for the EMNE acquirer.

This essay begins in the next section by reviewing extant literature. I then present theoretical expositions to provide a basis for developing testable hypotheses. Next, I highlight the methodology employed in the study including the data which are used to test the formulated hypotheses. I subsequently discuss the empirical results. In the final section, I summarize and explore the implications of the study for managers and future research.

The study in this essay contributes to a growing stream of research in emerging multinational enterprises (EMNEs), highlighting the collective learning benefits of control mode choice in EMNE's acquisitions of firms in developed economies from the dynamic socio-cultural and the organizational learning perspectives. To the best of my knowledge, it is the first empirical study that simultaneously examines drivers of acquirer's control mode choice and the effect of the choice on acquirer's performance while also accounts for self-selection/endogeneity in the choice-making process. From a 
practical perspective, it has the potential of being insightful for executives of emerging market firms aspiring to venture into high-income markets.

\section{LITERATURE REVIEW}

\section{Control mode choice in acquisitions}

Very few studies have examined the determinants of low-control versus high-control mode choice in acquisitions. These studies, however, were not conducted in the "SouthNorth” acquisition context, and they did not empirically examine the performance implication of the chosen mode. Using a sample from cross-border acquisitions made by U.S. firms during the years 1996-2002, Chari and Chang (2007) explored factors that that lead acquiring firms to non-controlling minority acquisitions and found that firms strategically use non-controlling minority acquisitions to attenuate high country-, industry- and firm-level risks associated with cross-border acquisitions. Ouimet (2012) also investigated determinants of minority interest acquisitions, based on a sample of domestic acquisitions of publicly-listed U.S. firms between 1994 and 2006. Based on a corporate finance perspective, her study found that minority interest acquisitions have a greater likelihood to be pursued by the acquirer if 1) preserving managerial incentives is crucial for the acquirer, 2) the target has liquidity constraint, 3) there is uncertainty surrounding acquirer's valuation of the target, 4) combining the internal capital markets of the acquirer and target is expensive, or 5) target earning consolidation lowers acquirer’s earnings per share (EPS).

Other related studies have not dealt explicitly with the strategic choice of minority acquisition versus majority acquisition, but rather focused on the trade-off between 
partial acquisition and full acquisition. None of these studies, however, empirically investigated the effect of the choice made on firm performance. Chen and Hennart (2004) developed a hostage theory of joint ventures and empirically explained why Japanese multinational enterprises (MNE) opted for partial over full acquisitions with a sample from Japanese manufacturing acquisitions in the United States between 1981 and 1989. They found the Japanese acquirers had a greater probability to choose a partial acquisition of their U.S. target when the acquisition involved high transaction costs such as negotiation and contracting costs. Using multiple theoretical lenses, Chari and Chang (2009) examined a sample of international acquisitions by U.S. firms in the years 19962002 and showed the determinants of the share sought in cross-border acquisitions, which include the costs of local firm asset valuation, challenges from integrating subsidiary local managers in culturally distant host countries, the cost of separating the desired assets from the rest of the target assets, and the resource commitment cost under uncertainty.

Several recent studies on the determinants of partial versus full acquisitions have focused on the effects of cultural, institutional and other types of distance between the acquirer's nation and the target's nation. Elango, Lahiri, and Kundu (2013) found acquirer's acquisition experience and institutional distance are positively related to the probability of full acquisitions over partial acquisitions in cross-border acquisitions of high-technology targets in BRIC countries by firms from 36 countries from 2001 to 2008 . Lahiri, Elango and Kundu (2014) conducted a similar empirical analysis based on the international acquisitions of Indian service firms from 1998 to 2008 and showed that soft services and institutional distance between acquirer and target nations are positively 
related to the probability of full acquisitions if the acquirers originated in emerging markets; and are negatively related if the acquirers originated in developed economies. Contractor, Lahiri, Elango, and Kundu (2014) expanded ownership choices to three different modes, namely full, majority, and minority ownership. Using a sample from acquisitions of Indian and Chinese firms by acquirers from 33 nations between 1998 and 2008, they found a greater probability for minority acquisition over full or majority acquisition is positively associated with uncertainty avoidance (UA) distance and industry relatedness, and negatively associated with institutional distance. Gaffney, Karst, and Klampit (2016) compared international acquisitions undertaken by EMNEs from BRIC countries and MNEs from the U.K in the years 2000-2010. They found that acquirer's equity participation has a positive linear relationship with knowledge distance, and a curvilinear relationship with economic distance. Furthermore, these relationships are stronger when the acquirer is an EMNE relative to when the acquirer is a traditional MNE.

Yang (2015) investigated the determinants of acquirer's equity participation and their performance implication. To measure performance, the study relied on the event study methodology (Brown \& Warner, 1985) to generate the stock market reaction on acquirers' stock prices upon acquisition announcements. A cross-sectional examination was then performed to uncover the relationship between equity participation and acquirer's performance, but without statistically correcting potential endogeneity bias from acquirers' self-selection process of determining levels of equity participation in the target ownership. Based on cross-border acquisitions made by firms from nine major emerging economies in the years of 2000-2012, the study found institutional distance, 
industry unrelatedness, and acquirer’s board concentration positively influence acquirer's level of equity participation in target ownership. Moreover, high equity participation elicits positive stock market reaction for acquirers.

\section{EMNEs' acquisitions in the developed countries}

Using the event study methodology, a large number of prior empirical studies found EMNE acquirers on average enjoy positive returns when they engage in cross-border acquisitions (e.g., Bhagat, Malhotra, \& Zhu, 2011; Boateng, Qian, \& Tianle, 2008; Kohli \& Mann, 2012; Gubbi, Aulakh, Sarkar, \& Chittoor, 2010; Ning, Kuo, Strange, \& Wang, 2014). Additional studies have further investigated the sources of value creation for EMNE acquirers in their international acquisition in both developed economies as well as other emerging markets. Factors known to have effects on EMNE acquirer's value creation include firm-level factors such as acquirer's pre-acquisition performance (Wu \& Xie, 2010), acquirer’s size (Aybar \& Ficici, 2009; Kohli \& Mann, 2012), acquirer’s preacquisition international experience (Delios \& Beamish, 2001; Thomas, Eden, Hitt, \& Miller, 2007), government ownership in the acquiring firm (Chen \& Young, 2010; Wu \& Xie, 2010), acquirer's absorptive capacity (Deng, 2010), acquirer’s governance structure

(Ning et al., 2014), public or private target (Fuller, Netter, \& Stegenoller, 2002; Aybar \& Ficici, 2009), industry-level factors such as acquirer’s industry (Aybar \& Ficici, 2009), industry relatedness (Aybar \& Ficici, 2009; Bhagat et al., 2011), country-level factors such as host country's economic and institutional level (Gubbi et al., 2010), geographic distance (Aybar \& Ficici, 2009), and cultural distance (Aybar \& Ficici, 2009). 
Despite these previous studies, there is virtually no study that has focused on the determinants of acquirer's control mode choice in the "South-North" acquisition context (i.e., EMNE's acquisition in developed economies), or the effect of the chosen control mode on EMNE acquirer's post-acquisition performance. In this study, I simultaneously examine drivers of EMNE acquirer's control mode choice and the effect of the chosen mode on EMNE acquirer's post-acquisition performance. In the next section, I develop testable hypotheses based on theoretical insights from the dynamic socio-cultural model (DSCM) I developed in Essay 1, combined with complementary insights from the organizational learning literature.

\section{THEORETICAL DEVELOPMENT AND HYPOTHESES}

In Essay 1 I conceptually introduced the dynamic socio-cultural model (DSCM) with its dynamic and multi-element features as a generalized perspective on cultural change and creation. The DSCM views an organization as a form of social system with other forms of social systems within and outside it. Social system is defined as a collection of interacting human beings. An EMNE, for example, is a social system with several smaller social systems within it including divisions, branches, departments, and/or teams. An EMNE is also a part of multiple larger social systems, including its own home country and other countries where it has operations. Thus, the EMNE continuously interacts with not only the physical environment, but also other social systems of various types or sizes (e.g., other firms, segments of consumers, governments, etc.). In each of these social systems reside cultural resources, defined broadly as to include distinctive cultural 
elements such as knowledge, values, norms, beliefs, custom, law, language, art, concepts of good and evil, tools, technologies, and artifacts (Japperson \& Swidler, 1994).

When an EMNE acquires a target firm in a developed country, the DSCM views such a "marriage" between two firms as a cultural event, in which two social systems, each of which brings its own distinctive cultural resources, are interacting with each other. From the DSCM perspective, any social system must change continuously in order to survive, even without stimuli for change from outside of the social system. Continuous learning is part of the inevitable change in every social system, because humans as an inherent part of the social system must learn to live, and hence not learning is impossible (Habermas, 1979). Specifically, in circumstances involving uncertainty, social systems have to reorganize their rules for dealing with uncertainty to survive (Eder, 1999). Moreover, since most social systems in modern times inherently carry uncertainty in them, interacting individuals within the social systems must then continuously and collectively learn new rules (Beck, 1992; Sabatier \& Jenkin-Smith, 1993).

Successful international acquisitions require the so-called post-integration “double layer acculturation process” (Berkema, Bell, \& Pennings, 1996), as both acquirer and target must overcome not only organizational-level cultural differences, but also national cultural differences. Acculturation is defined as change in two cultures induced by diffusion of cultural elements in between the two in both directions (Berry, 1980). In international acquisitions, both the acquirer's home country and the target's host country possess distinctive cultural resources. Similarly, both the acquirer and the target as separate social systems also possess their unique firm-specific cultural resources. When an EMNE takes over a target in a developed country, the contacts between EMNE and 
the host society, and between the EMNE and acquired target organization, change the social interactions in each of these contacts and bring about uncertainties to them. These uncertainties yield not only risks, but also opportunities for creating new shared cultures between the EMNE and the host country, and between the EMNE and its acquired target, since these risks incentivize the interacting social systems for further collective learning. Thus, the international acquisitions trigger collective learning processes that generate new shared culture and modify cultural resources at organizational and country levels.

From a societal-level learning perspective, the collective learning processes modify existing shared knowledge of the interacting socities, producing novel knowledge in the societies. Eder (1999) argued that there are two types of collective learning process that yield two different types of shared knowledge, namely, substantive learning and social rule learning. Substantive learning leads to the accumulation of different types of substantive knowledge, ranging from simple practical knowledge to advanced scientific knowledge. On the other hand, social rule learning is about collectively learning to create situations in which experience can be preserved and passed over to future members of the society, which is clearly tacit knowledge. It is about collectively learning how to learn, through which interacting individuals collectively learn ways and procedures for generating new knowledge and integrating this new knowledge into the society's existing knowledge resource (Eder, 1999).

From an organizational-level learning perspective, the concepts of substantive learning and social rule learning in societal-level learning are parallel to the concepts of exploitation and exploration (March, 1991). As the evolutionary views of organizational forms and technologies suggest, exploitation is essentially the process of selection among 
existing forms, routines, or practices, while exploration is the process of generating new variations of alternative practices, both of which are necessary for the organization's survival (Ashby, 1960; Hannan \& Freeman, 1987). Thus, all organizational activities involve some learning. Even in merely replicating past actions, experience is accumulated and it generates an incremental amount of learning, as demonstrated by the idea behind the "learning curve" (Yelle, 1979). Moreover, learning always involves the twin processes of exploration and exploitation. Exploitation is fundamentally a learning process that refines and extends organization's existing competencies, technologies and ways of thinking with relatively proximate, predictable and positive economic returns (e.g., refinement, selection, and/or implementation of existing techniques, choice, production methods, efficiency, etc.). Exploration, on the other hand, is a learning process that involves experimentation with new alternatives characterized by relatively uncertain, distant and (often) negative economic returns (e.g., searching for novel ideas, markets, relations, etc.) (March, 1991). To survive and succeed organizations rely on organizational ambidexterity, which is a dynamic capability to simultaneously and synchronously pursue both exploitation and exploration, with the actual composition between the two possibly different across cases and over time (Benner \& Tushman, 2003).

Unlike traditional multinational enterprises (MNEs) from developed countries that venture to emerging markets to exploit their distinctive competitive advantages in technologies, brands and managerial know-how (Hymer, 1960), most EMNEs enter highincome markets without unique initial resources that can be immediately exploited (Matthews, 2006) to offset their liabilities of foreignness operating in culturally distant 
countries (Zaheer, 1995). While MNE’s direct investment in emerging markets are typically motivated by their drive for market expansion, natural resource outsourcing, and/or cheaper production costs, EMNE's acquisitions of firms in advanced economies are primarily driven by their search for strategic assets that would give them new competitive advantages (Guillen \& Garcia-Canal, 2009) to complement their existing resources and capabilities (Dunning, 1991). Those acquisitions enable EMNE to immediately strengthen their competitive position in their existing home markets against their local or foreign competitors in those markets through exploitation of complementary and superior technologies, brands, and managerial skills readily available in the acquired firms. Those acquisitions also simultaneously provide the EMNE with the option to explore the target's high-income home markets by leveraging the experience of the acquired firms for exploitation in the long run after the EMNE acquirer gains more experience in the high-income markets (Meyer, 2015).

From an organizational learning perspective, this “dual path” of concurrently entering into a developed market and expanding existing operations in the developing markets back home and regionally (Guillen \& Garcia-Canal, 2009) can be viewed as the EMNE's strategic maneuver to achieve organizational ambidexterity. This path of expansion facilitates both exploitative and explorative learning processes simultaneously (Puranam \& Srikanth, 2007) and provides the EMNE with unique dynamic capability for creating and sustaining organizational ambidexterity (Raisch et al., 2009). Indeed, through their acquisitions of targets in advanced economies, the EMNEs are able to satisfy both their need for short-term exploitation in their home markets and their need for long term exploration to enhance their competitive advantage in advanced host 
markets, as EMNEs gain more operational experience in them (Luo 2002; Meyer, Estrin, Bhaumik, \& Peng, 2009; Teece, 2014).

Furthermore, since all organizational activities always involve learning, and all learning is simultaneously composed of certain amount of exploitation and exploration processes (Gupta, Smith, \& Shalley, 2006), EMNE’s “South-North” investment in advanced economies is more likely to be exploration-dominant, while its "South-South" investment at home or other developing markets is more likely to be exploitationdominant. Thus, in this dual "South-North" and "South-South" investment context, choosing low-control mode versus high-control mode in its acquisition of targets in advanced economies may be a strategic decision for an EMNE as it may influence EMNE's balancing of exploitation and exploration learning processes in its whole global operation. Indeed, the choice for low-control versus high-control acquisition is likely to

affect the EMNE acquirer's process of creating optimal organizational ambidexterity and hence influence the EMNE acquirer's organizational performance.

\section{Low-control versus high-control acquisitions}

For an acquiring EMNE, acquisition control mode is associated with certain costs and benefits. When the expected net benefits from a high-control acquisition exceed the expected net benefits from a low-control acquisition, the EMNE acquirer will choose a high-control acquisition. Conversely, the EMNE acquirer will choose a low-control acquisition when the expected net benefits of doing so surpass the expected net benefits from a high-control acquisition. It comes as no surprise that a high-control acquisition is primarily associated with control benefits. A controlling majority interest in an acquired 
target enables the EMNE to fully integrate the target into the EMNE's larger parent organization (Puranam, Singh, \& Chauduri, 2009), allowing the combining of common procedures, common goals and common governance between the acquirer and target, which creates value by generating efficiency in the overhead costs (Hapeslagh \& Jemison, 1991). A fully integrated structure can also provide a better coordination between the target and the parent company (Kale \& Puranam, 2004) and facilitate more effective transfer of technologies and capabilities from the acquired target, which are often tacit and socially embedded (Ranft \& Lord, 2002). Conversely, the low-control acquisition traditionally has been associated with several disadvantages for the acquirer, which include limited or no voting power and less benefit from growth in the acquired target firm.

There are, however, several benefits associated with low-control acquisitions. First, from a financial theory perspective, the low-control mode is far less exposed to business risks, and when the target is private, the acquirer often has the option to purchase equity from major interests before it is offered to other parties. Second, from a real-option theory perspective, a low-control acquisition can provide a valuable "stepping stone” before the EMNE fully engages operationally in the advanced host market, generating a higher real option value. Entering unfamiliar high-income markets with relatively more sophisticated customers poses uncertainties for the EMNE, in which having a non-controlling minority interest in the target has lower opportunity costs than having a controlling majority interest, because the level of equity ownership in the target is positively related to the EMNE acquirer's opportunity costs in terms of foregone real option value. Thus, a minority interest in the target provides the EMNE acquirer with the 
future right (but without the obligation) to increase its level of equity ownership in the target after it is able to offset its unfamiliarity with the target organization the host country (Folta \& Miller, 2002). Furthermore, from a transaction cost economics perspective, while a low-control acquisition may incur higher governance costs due to post-acquisition preservation of a structurally separate target organization, the process of deal completion in low-control acquisitions may be relatively faster than in high-control acquisitions, providing speedy access to the target's technologies, capabilities and home market (Jacobsen \& Meyer, 2008; Williamson, 1975). Moreover, from an institutional theory perspective, having a separate and autonomous subsidiary operation may generate higher legitimacy for the EMNE, as they start operating in developed countries (Crystal, 2003).

In addition to the aforementioned advantages, there are specific learning-related benefits associated with a low-control acquisition. A low-control acquisition leads to operational, structural and administrative autonomy of the target firm. Thus, the collective learning process to achieve post-acquisition synergies is now to be implemented through partnership-like relationship (Zheng, Wei, Zhang, \& Yang, 2016) by aligning selective potential major areas rather than all aspects of businesses (Cogman $\&$ Tan, 2010). From this standpoint, the acquirer and the target are treated more equally in low-control acquisitions than in full takeover cases where the acquirers usually have the upper hand. This in turn is likely to induce more cooperative attitudes from the target firms in the post-acquisition collective learning process (Madhok \& Keyhani, 2012), easing the process of knowledge transfer and new shared knowledge creation. Additionally, the target firm has more incentive to cooperate with the acquirer in low- 
control acquisitions because of lower agency costs (Grossman \& Hart, 1986). For example, in low-control acquisitions, the original target shareholders still partially retain their rights of the target's future gains, preserving their motivation to cooperate with the acquirer in the collective learning process to make the new relationship a success (Kale \& Puranam, 2004). Moreover, the top management team of a target firm is more likely to stay and keep its autonomy after a low-control acquisition, providing them with more incentive to be actively engaged in a collective learning process with the acquirer's top management team (Zheng et al., 2016). Similarly, target firms’ employees are likely to have higher post-deal motivation in low-control acquisitions than in high-control acquisitions, since they will have better post-acquisition job security and stability (Kale \& Puranam, 2004). Furthermore, a low-control acquisition implies less disruption from the limited and less complex integration, and thus is likely to limit target employees' dissatisfaction and maintain their motivation to engage in a collective learning process in post-deal organizational arrangement with the acquirer's organization (Zheng et al., 2016). Furthermore, from a societal learning perspective, the autonomy of the target firm provided in low-control acquisitions may minimize the negative effect of cultural differences between the acquirer's home country and the host country (Very, Lubatkin, Calory, \& Veiga, 1997), while still help the acquirer to maximize learning benefits from such cultural differences through access to a new source of value creation (Stahl, Bjorkman, \& Vaara, 2004) such as the host country's novel and diverse cultural resources, which can be combined with the acquirer's resources and capabilities to create new competitive advantages (Stahl \& Voigt, 2005). 
In the next section, using the DCSM and organizational learning perspective, I examine the post-acquisition performance of the EMNE acquirers. I further look into the effect of low-control versus high-control acquisitions on the EMNE acquirer's performance. I then consider several related determinants that influence an EMNE to choose a low-control acquisition or a high-control acquisition. I specifically theorize on the effects of the acquirer's country of origin and target industry. Finally, I investigate the performance implication for the EMNE acquirer when it does not choose the optimal control mode, as prescribed by the hypothesized theories.

\section{Post-acquisition EMNE acquirer's performance}

In EMNE's acquisitions of firms in developed economies, the acquirer's shareholders are likely to enjoy a positive return after the acquisition. From a DSCM perspective, collective learning between acquirers and their acquired target firms generates new shared cultural resources and expands the number of repertoires and routines available to the acquirers. In acquisitions with a high degree of complementarity between the acquirer's resources and the target firm's resources, the acquirers are expected to generate synergistic benefits. Value creation in acquisitions is positively correlated with future synergistic benefits (Ning, Kuo, Strange, \& Wang, 2014). Gubbi et al. argued that, regardless of target country destination, EMNE’s international acquisitions are expected to generate synergistic benefits for the acquirers because they allow them to transfer critical resources and capabilities, overcome "latecomer" disadvantages, internationalize faster, and recombine their distinctive local advantages with resources and capabilities of the acquired targets (2010). 
In the “South-North” EMNE’s acquisition context, there are additional advantages that may lead to even more synergistic benefits and hence enhanced value creation for the acquirers. From an organizational learning perspective, EMNE's acquisitions of firms in developed economies provide the EMNE with a unique organizational ambidexterity that allows them to concurrently enter high-income markets and expand their operation in home markets as well as other emerging markets (Guillen \& Garcia-Canal, 2009). This dynamic capability has a strategic value, because it allows the EMNE to contemporaneously meet their need for short-term exploitation in their home and other emerging markets and long term exploration to enhance their competitive advantage in the advanced host market (Luo 2002; Meyer, Estrin, Bhaumik, \& Peng, 2009; Teece, 2014). Based on other theoretical lenses, some empirical studies have also confirmed that EMNE enjoy, on average, positive returns in their acquisitions of firms in developed economies (e.g., Bhagat, Malhotra \& Zhu, 2011 Gubbi et al., 2010). I thus posit Hypothesis 1: In EMNE's acquisitions of firms in developed economies, all else being equal, the mean of post-acquisition EMNE acquirer's return is positive.

\section{Drivers of control choice in acquisitions}

\section{Acquirer's home country economic characteristics}

The EMNE acquirer's country of origin may affect the EMNE's choice of control mode in its acquisition of firms in developed markets. The idea builds on the "country of origin effect” research that suggests there are profile similarities among multinational firms from a particular country that are unequivocal to those of multinational firms from another country due to unique home countries' characteristics, which influence firm-level 
decision making and ultimately performance (Lahiri, Elango, \& Kundu, 2014; Porter, 1990; Sethi \& Elango, 2000). This essay deals with acquirers that originate from emerging economies. The emerging economies are developing countries characterized by relatively rapid Gross National Income (GNI) growth, large domestic markets, promarket domestic reforms, integration with the global economy through rapid increase in international trade and foreign direct investment, expanding middle classes, improved living standards, political stability, and increased cooperation with multilateral institutions (Kvint, 2009; Wright, Filatochev, Hoskisson, \& Peng, 2005). Based on the World Bank classification, all of the emerging economies are part of the middle-income group of countries whose per capita Gross National Income (GNI) in 2016 was between \$1,006 and \$12,236 (World Bank, 2017).

The middle-income group represents the largest number and most diverse group of countries, mostly located in Asia and Latin America. Countries in this group are experiencing or struggling to avoid the so-called "middle-income growth trap" (Economist, 2012; Time, 2013). It is a phenomenon where a middle-income country is caught in a situation characterized by a sharp deceleration in growth and in the pace of productivity increases, having difficulty in making an additional leap to become highincome economies. During a typical initial phase of economic development, firms from low-income countries usually can compete in international markets by producing laborintensive, low-cost products using technologies imported from abroad. These firms can achieve large productivity gains initially through a reallocation of labor from lowproductivity agricultural sectors to high-productivity manufacturing sectors. However, once the low-income countries reach a middle-income status, the pool of labor surplus in 
the rural areas shrinks and real wages begin to rise, eroding the export competitiveness of the countries' firms. When the trap is in full effect, productivity growth and technology catch-up are exhausted, making the economy stuck in the middle-income-and-low-growth status, as foreign investors leave and relocate to other developing countries with lower wages (Agenor, Canuto, \& Jelenic, 2012).

Nevertheless, treating emerging economies as a homogenous entity is a fallacy. Accordingly, further dissection of the emerging economies is necessary to better understand country-level characteristics that influences the behavior of EMNEs from each of these countries. Figure 5 shows that Brazil, South Africa, Russia and Indonesia have had large shares of metal and other mineral exports in their total exports, being the world's major producers of mineral and other basic commodities, while China and India have had relatively much lower share of mineral exports in their total exports.

Figure 5. Mineral export's share in total export revenues, 1996-2015

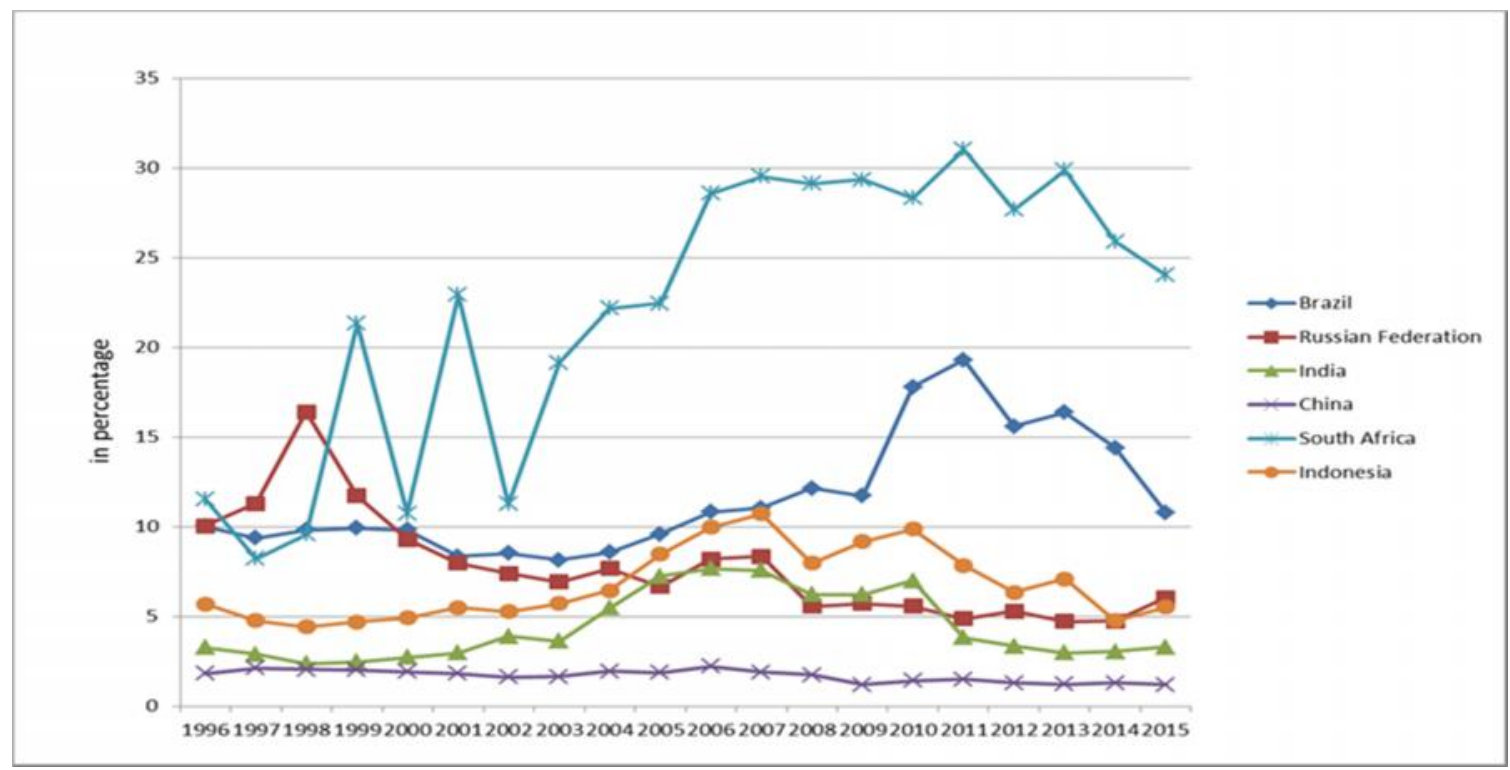

Source: constructed by the author with data from World Bank’s World Development Indicators 
By contrast, Figure 6 confirms that China and India’s export have been manufacturing-based, compared to the other emerging economies. In particular, about 88 percent of Chinese exports between 1996 and 2015 were manufacturing exports, compared to around 20 percent for Russia during the same period.

Figure 6. Manufacturing export's share in total export revenues, 1996-2015

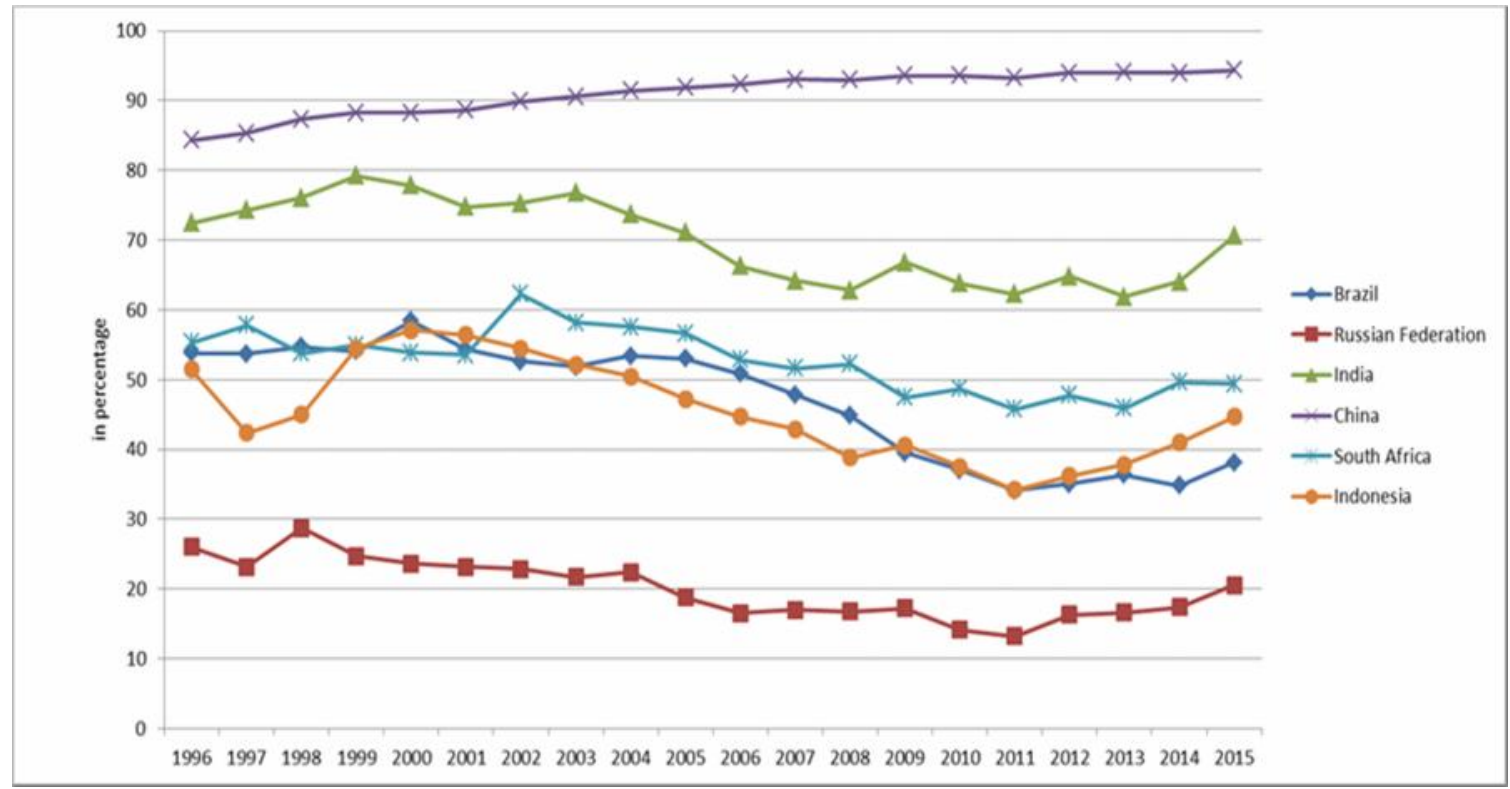

Source: constructed by the author with data from World Bank's World Development Indicators

Figure 7 suggests that China has always had the highest labor participation rate since 1990, but the trend has been declining sharply over time. Between 1990 and 2016, the labor force participation has steadily decreased by more than $0.4 \%$ per year, indicating an aging population and a low birth rate in China. Indeed, as demonstrated in Figure 8, between 1990 and 2016 China had the lowest population growth among the emerging economies with the exception of Russia which at several points during the same time even showed a negative population growth. 
Figure 7. Labor force participation rate, 1990-2016

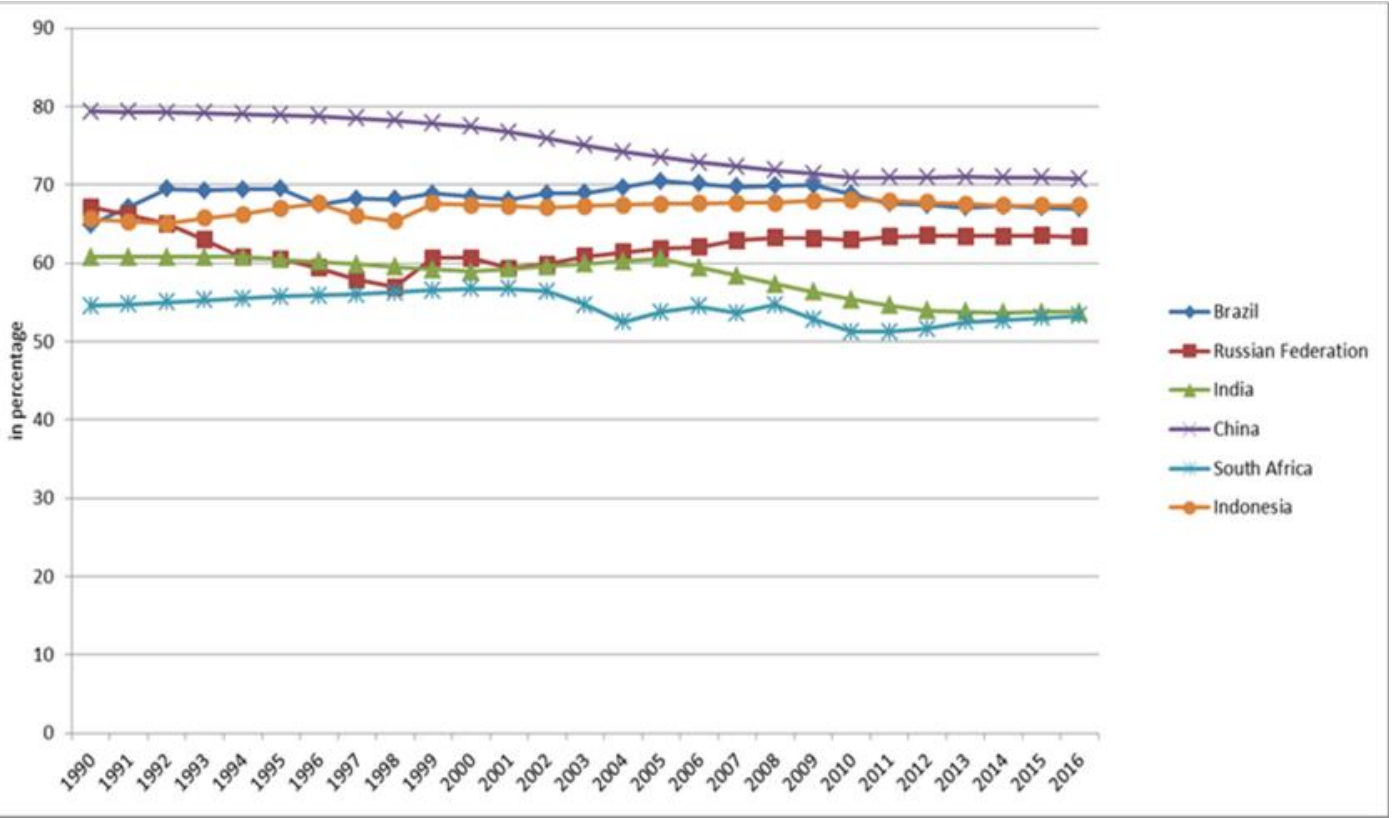

Source: constructed by the author with data from World Bank's World Development Indicators

Figure 8. Population growth, 1990-2016

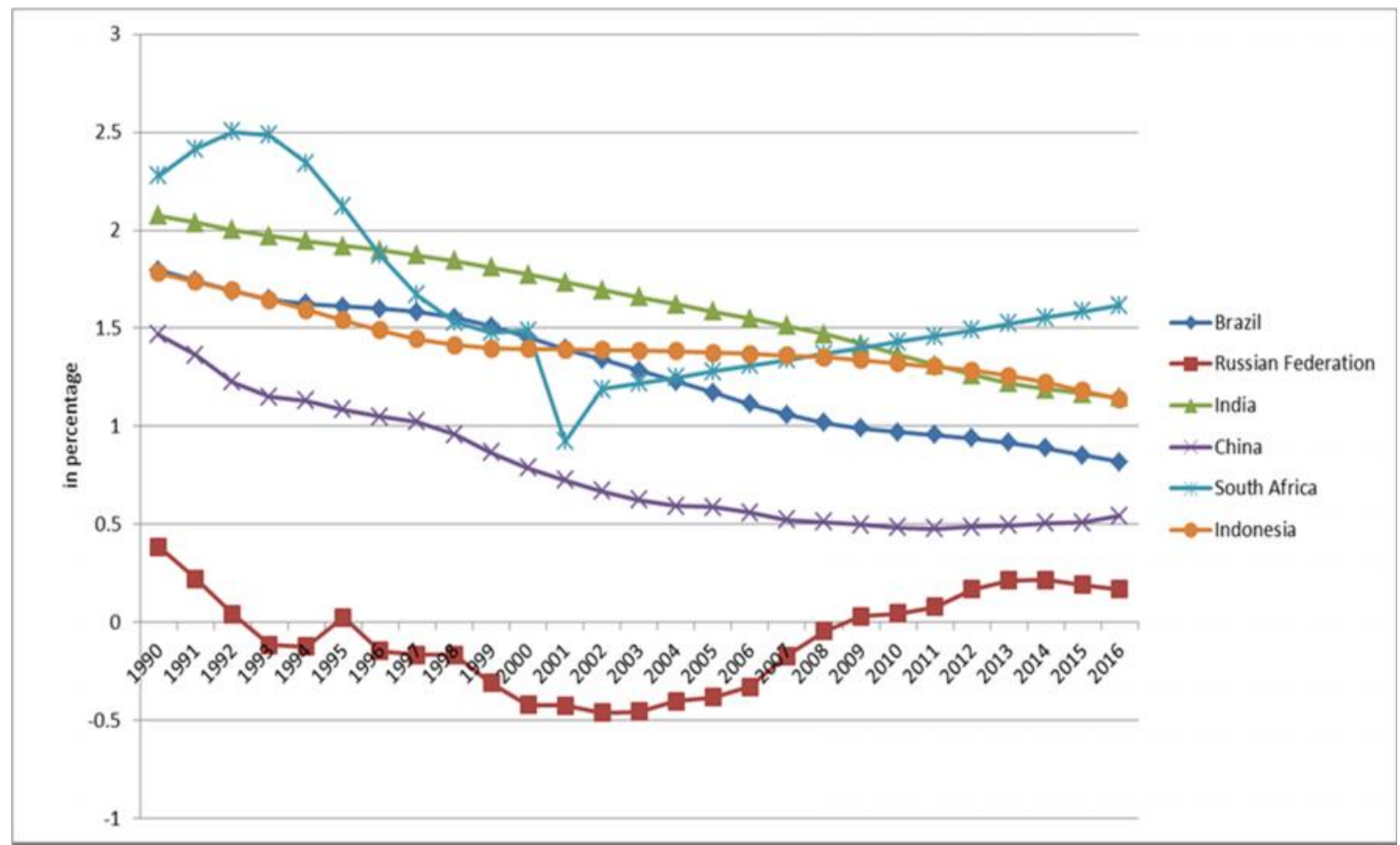

Source: constructed by the author with data from World Bank’s World Development Indicators 
Clearly emerging economies are heterogeneous in terms of economic

characteristics. A summary characterization of these emerging economies is necessary to appreciate the effect of country of origin on the EMNE acquirer's choice of control

mode. In Figure 9, I classify the emerging economies into four different types of industrializing nations based on two dimensions, namely the natural resources' share in country’s export value and the country’s labor force growth trend.

Figure 9. Typology of emerging economies

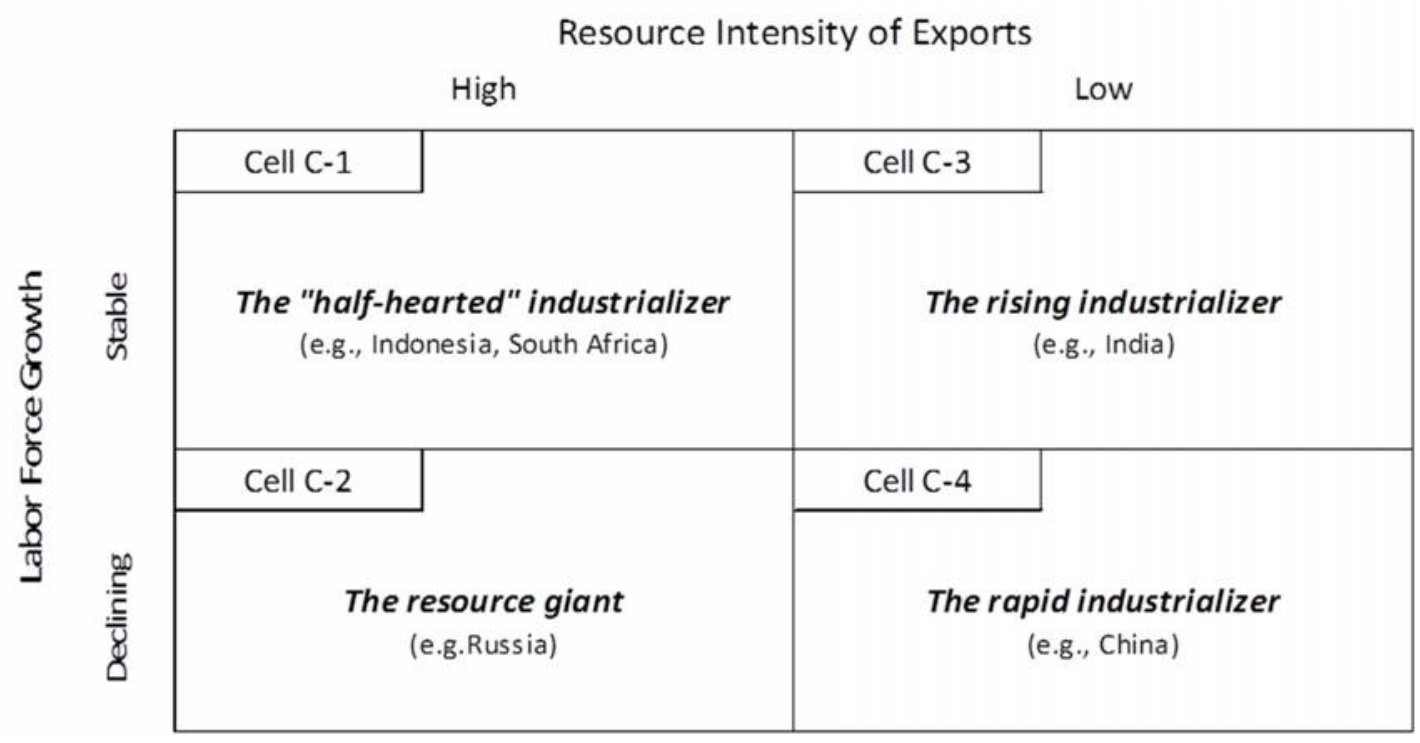

Cell C-1 represents "the half-hearted industrializers”, which are emerging economies that have high share of natural resources in their exports (World Trade Organization, 2013) and a stable labor force growth (e.g., Indonesia). As in other rapidly growing middle-income countries, the real wages in these economies are rapidly rising faster than labor productivity growth, as decades of economic expansion are exhausting the surplus of labor who have migrated from the rural areas to the urban areas. As income 
and living standards rise, product markets in these economies are characterized by growing demand not only for generic products, but also more sophisticated products. Resource-based exports also provide healthy level of foreign reserves, somewhat softening the drive for further development of the manufacturing industries, especially since rapid economic growth in resource-poor countries such as China and India have escalated basic commodity prices and created booms in the resource markets. Indonesia, for example, has relied on its exports of coal and natural gas meeting sharply rising demands from other expanding middle-income countries such as China, and for some time its manufacturing sector has in fact been downsizing (Grabowski, 2017).

Cell C-2 represents “the resource giant.” The countries in this group were actually among the earliest countries to industrialize their economies in the early 1980s, primarily through manufacturing substitution, but over time they have relied more on natural resource exports, as demand from rapidly industrializing China drive up prices of basic energy and natural resource commodities, making oil and basic mineral exports more dominant than manufacturing goods as a source of foreign exchange reserves. Brazil and Russia are in this group. Brazil is a large exporter of iron, ore and oil, while Russia supplies oil, metal ores, and coal to the world (World Trade Organization, 2013). Living standards (as measured by per capita GDP) in Brazil and Russia were roughly similar at around $\$ 11,000$ in 2016 , which is relatively much higher than those in many other middle-income economies. The difference between countries in this group and in the previous group is the former are facing serious pressures from demographic changes, as their population is aging and their labor force is getting smaller (World Bank, 2017). 
Next, cell C-3 represents “the rising industrializer” such as India. Emerging economies in this group have a low share of natural resources in their exports and a stable labor force. They have relied on manufacturing exports to grow their economies (World Trade Organization, 2013). In 2016, India’s per capita GDP stood at \$1,861 (World Bank, 2017). With its large population and relatively natural limited resource base, India is likely to boost its labor-intensive manufacturing sector to maintain its growth momentum and raise its future living standards. Fortunately, India has a relatively stable labor force, leaving plenty of room for further growth in the manufacturing sector while keeping labor costs in control.

Finally, cell C-4 represents “the rapid industrializer” emerging economies. China is the only emerging economy that uniquely belongs to this group. It is a large importer of natural resources with shrinking labor force. China and India are the world's two most populous countries, but unlike India which has a stable labor force growth, China's labor force is downsizing. The one-child labor policy that was instituted in the past seems to have had a negative long-run impact on the country's demographic structure, as it is attempting to maintain the momentum of the past two decades of very rapid economic growth. China's foreign reserves stood at more than 17 months value of imports in 2016. It is the highest among all middle-income countries and it demonstrates how rapid and sizable is China's manufacturing exports to the rest of the world, given the negligible share of natural resources in their exports. Nonetheless, China's living standards remain relatively low at $\$ 6,894$ per capita GDP in 2016 , especially if compared to Russia or other middle-income countries in Latin America such as Brazil or Mexico (World Bank, 2017). 
The history of nations show comparative advantages of many growing economies evolve. Countries export different types of goods at different stages of development, starting from low-income countries producing a narrow range of labor-intensive and unsophisticated goods (Imbs \& Wacziarg 2003; Cadot, Carrère, \& Strauss-Kahn, 2011) and moving up the product ladder to capital-intensive and highly sophisticated goods as their incomes rise (Schott, 2003, 2004). As economies grow, real wages typically rise, both in absolute terms and relative to real costs of capital and land. As each of the rapidly growing middle income economies in all the above four cells experiences changes in its comparative advantage, firms in China have the highest motivation to upgrade their technological base. The shrinking Chinese labor force puts upward pressure on the already rapidly rising unit labor costs, defined as the ratio between real wages and labor productivity. Chinese manufacturers are losing their cost advantages faster than firms in most other middle-income countries. By contrast, being a net exporter of resources and facing relatively stable real wages, firms in Indonesia focus on producing and exporting resource-related products, and has the least motivation to upgrade their manufacturing facilities to labor-saving technologies. Similarly, the declining labor force in Brazil and Russia puts pressure on their firms to shift up their technology bases, but not as much as what Chinese firms experience, since Brazilian and Russian exports are relatively resource-intensive in terms of value. Furthermore, while India does not suffer from a dwindling labor force, the limited natural resources in its export share make India rely on manufacturing trade, putting pressures on Indian firms to upgrade their technologies and manufacturing facilities, but generally not as much as the Chinese firms. 
China is an example where unit labor costs are rising fast due to rapid and continuous trade-driven economic growth in the last two decades. Figure 10 and Figure 11 show manufacturing wage in Brazil has increased considerably between 2002 and 2012. Moreover, compared to manufacturing wages in other Asian emerging economies (i.e., India and the Philippines), Chinese manufacturing wages were also substantially higher. Although the Chinese manufacturing wage was still much lower than the Brazilian manufacturing wage in 2012, it had increased at a faster rate, more than quadrupled, from 2002 to 2012.

Figure 10. Hourly manufacturing compensation costs (in US\$)

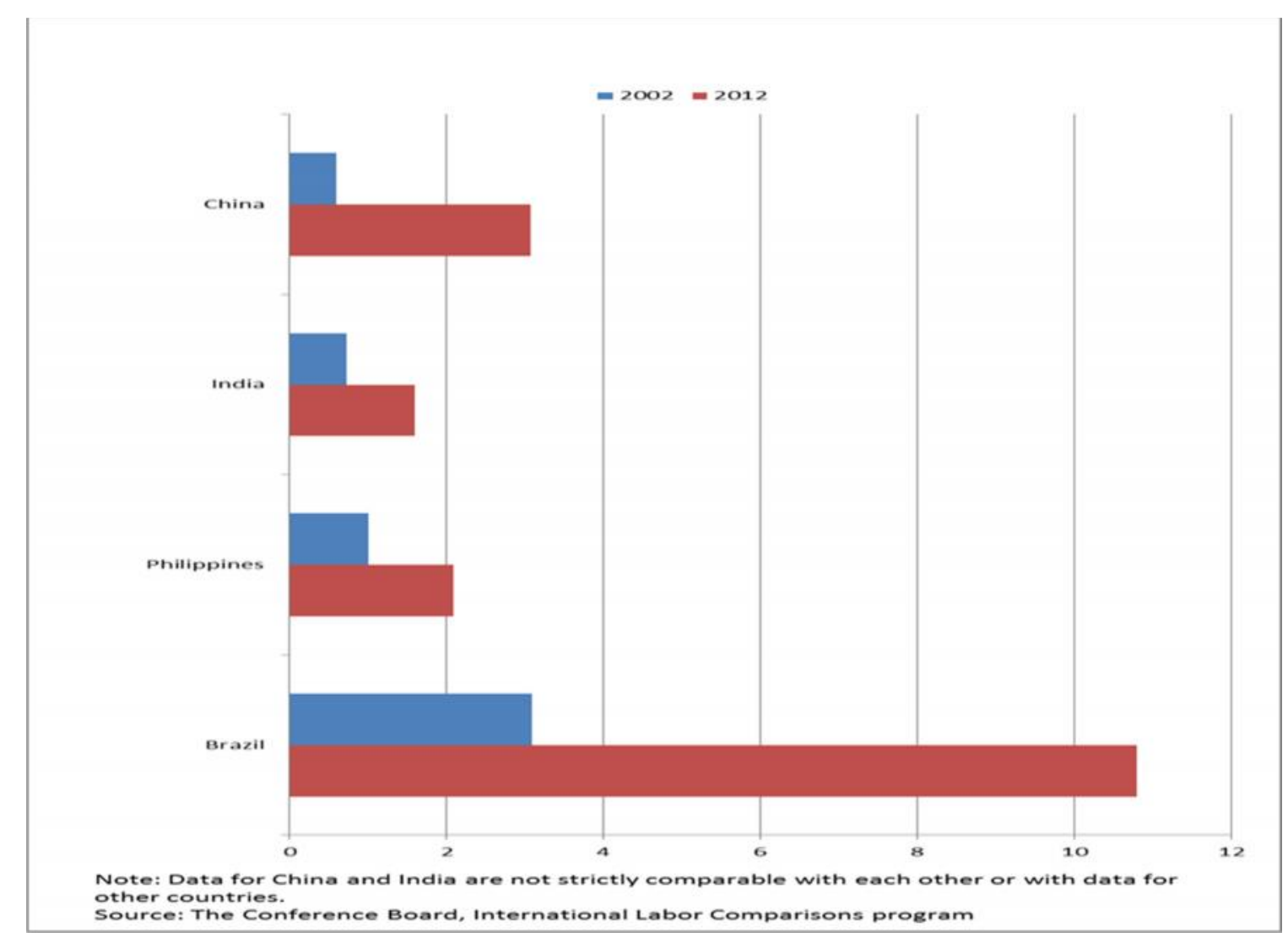


Figure 11. Change in hourly manufacturing compensation costs (in percent)

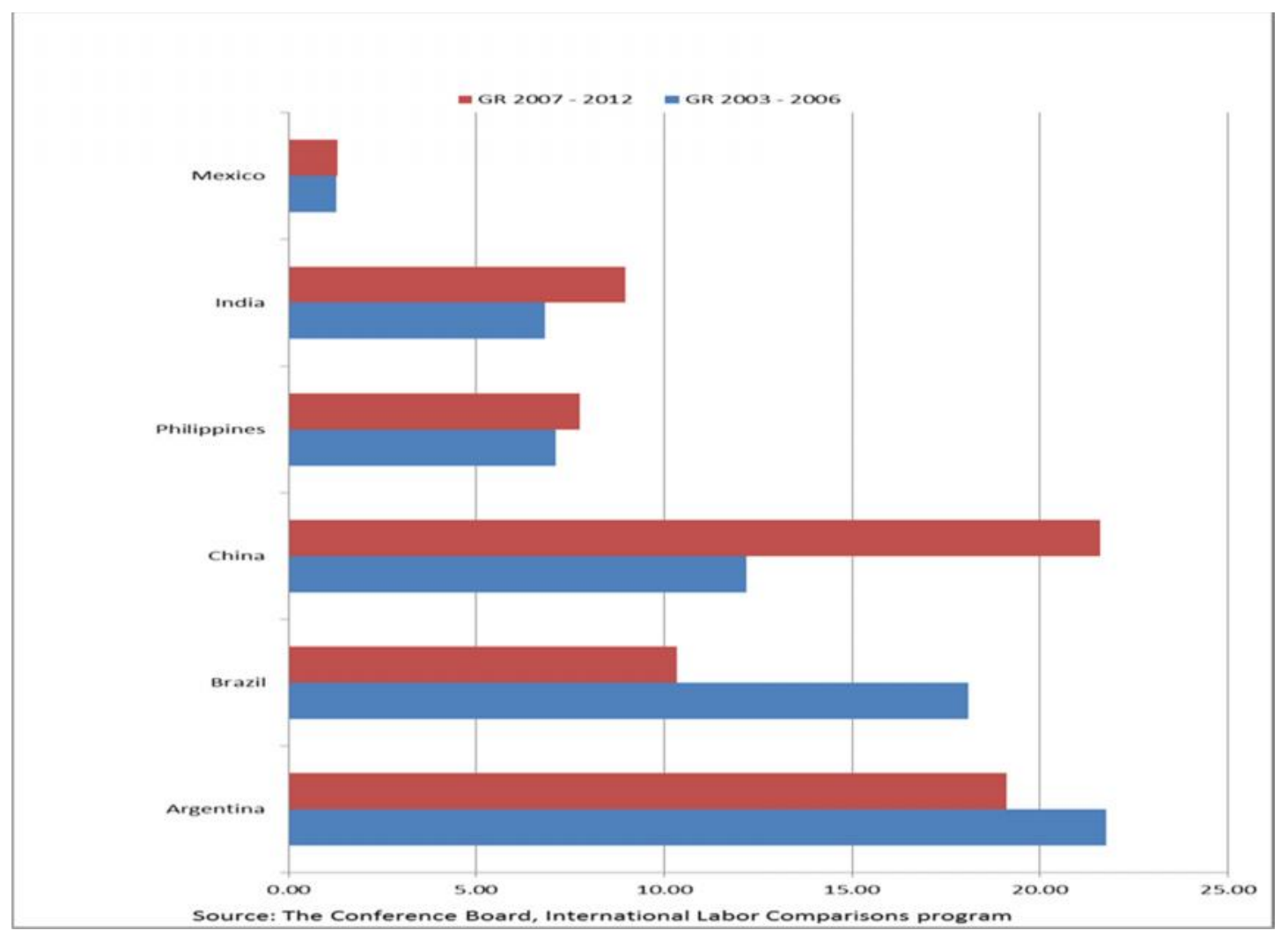

Indeed, unit labor cost in the labor-intensive Chinese manufacturing sector is getting relatively more expensive compared to other Chinese sectors as well as similar labor-intensive manufacturing sectors in other neighboring countries (Deutsche Bank, 2013). Unlike the other emerging economies, China has to face dual challenges from limited resource-based exports and the rapidly shrinking labor force. Aware of the potential danger of the "middle-income growth trap" to the economy, the Chinese government has actively encouraged their EMNEs to upgrade their resources and capabilities (Peng, 2012). In fact, leveraging the unusually high level of foreign reserves that have accumulated from years of trade surpluses with the developed countries, the Chinese government has been more eager to lend "cheap money" to their EMNEs, 
particularly the state-owned ones, in their outward foreign direct investment, including in the developed countries (Rugman, 2009).

The changes of comparative advantages brought by rapid economic growth across the emerging markets and the detailed characterization of the economies provide a rationale to infer that EMNE from emerging economies such as China are likely to have the utmost motivation for exploration-intensive acquisitions in advanced economies, in which, as argued earlier, a minority interest acquisition provides a more effective control mode for the EMNE acquirer relative to a majority acquisition. I thus posit

Hypothesis 2: An EMNE acquirer from a "rapid industrializer" emerging economy is more likely to choose a low-control mode than acquirers from other emerging economies in acquisitions of targets in developed economies.

\section{Target industry}

When an EMNE enters a high-income market and acquires a target in a high tech industry, the learning-related benefits from a low-control acquisition are likely to be greater than the control-related benefits from a high-control acquisition, rendering a greater likelihood for the EMNE acquirer to select low-control over high-control in their target ownership. While both exploitation and exploration learning processes occur when an EMNE acquires a target in advanced economies, exploration is likely to be relatively more dominant than exploitation compared to when an EMNE acquires a target in their home countries or other emerging markets. In other words, the EMNE focuses more on exploring resources and capabilities of the target's organization than exploiting those of their own (Baum, Li, \& Usher, 2000). This is especially so because EMNE acquirers 
have relatively limited firm-specific advantages in resources and capabilities compared to their targets in the advanced economies (Baum et al., 2000), and they are primarily driven to enter the high-income markets for a search of tacit and socially embedded knowledge such as innovative technologies, specialized human resources, and other proprietary know-how (Chen \& Hennart, 2004), which cannot simply be acquired in the open market (Dierickx \& Cool, 1989).

The exploration-dominant nature of learning in EMNE's acquisitions of firms in developed economies becomes more pertinent when the target operates in one of the high technology industries, defined as industries characterized by a relatively high percentage of sales expended on research and development (R\&D) and a high ratio of technical workers to the total workforce (Malecki, 1985). High technology firms operate in a rapidly changing environment and thus must adapt continuously and quickly in order to succeed (Mohrman \& Von Glinow, 1990). Clearly, when the target is an R\&D-intensive organization, EMNE's exploration is even more intensive than exploitation. High technology industries (e.g., electric car, software, semiconductors) have short product development cycles with technologies becoming obsolete very rapidly compared to traditional capital-intensive manufacturing industries that evolve much slower (Gupta et al., 2006). For high tech firms, frequent and speedy new technology development is imperative and is an integral part of survival (Bacon, Beckman, Mowery, \& Wilson, 1994). Thus, while EMNE's acquisition of firms in developed economies in general is exploration-dominant, it is more so when it involves high tech targets.

Moreover, technology development within high tech target firms often involves path dependent and complex process with tacit knowledge not easy to codify, which 
suggests the EMNE acquirer must rely more on their targets' cooperation in the transfer of knowledge (Graebner, Eisenhardt, \& Roundy, 2010). The relatively higher exploration intensity in EMNE's acquisitions of high technology firms in developed economies suggests the low-control mode is the more effective control mode to pursue relative to the high-control mode. An empirical work by Piscitello and Scalera (2014) demonstrated that EMNEs prefer less control and retaining the local partnership when they acquire European high-tech targets. I thus posit

Hypothesis 3: An EMNE acquirer is more likely to choose low-control mode than high-control mode in acquisitions of targets in developed economies when the target is in a high-tech industry compared to when the target is in a non-high-tech industry.

\section{EMNE acquirer's self-selection and contingency return}

While on average a certain control mode may be the optimal choice in terms of economic returns for EMNE acquirers, an individual EMNE acquirer may have its own optimal choice of control mode that is different than the average EMNE, depending on its firmlevel attributes, home country characteristics and other unobserved heterogeneities. Assuming the market for corporate control in developed economies has a sufficient number of target firms available for acquisitions under low-control and high-control modes, an individual EMNE may choose a control mode dissimilar to what is selected by most EMNEs. In other words, I argue that, given the completeness of the market for corporate control, an individual EMNE receives a higher economic return when it self- 
selects a control mode consistent with what the theory would predict under hypotheses 2 and 3, with other observed as well as unobserved influential factors being constant.

To illustrate, based on Hypotheses 2 and 3, an EMNE acquirer from China that acquires a high-tech target in the United States has a greater probability to choose a lowcontrol mode over high-control mode, all else being equal, and enjoy a better return than had they chosen a high-control mode. Conversely, a non-Chinese EMNE acquirer that acquires a non-high-tech target in the United Kingdom is more likely to choose a highcontrol mode over low-control mode, all else being equal, and enjoy better performance than had they chosen a low-control mode. Obviously each of the above illustrations assumes a complete market for corporate control in the high-income economies, in which any EMNE acquirer can freely choose from enough number of potential targets regardless of the control mode it wants to select. Thus, I posit Hypothesis 4a: In EMNE's acquisitions of targets in developed economies, those EMNE acquirers who choose the low-control mode do not do so randomly, but by (strategic) self-selection, based on observed as well as unobserved characteristics unique to each EMNE.

Hypothesis 4b: In EMNE's acquisitions of targets in developed economies, those EMNE acquirers who choose the high-control mode do not do so randomly, but by (strategic) self-selection, based on observed as well as unobserved characteristics unique to each EMNE. 
Hypothesis 4c: In EMNE's acquisitions of targets in developed economies, selfselecting a low-control mode over a high-control mode, based on observed as well as unobserved characteristics unique to each EMNE, increases postacquisition EMNE acquirer's return; i.e., an EMNE which acquires a low-control mode under conditions that are favorable to the purchase of a low-control mode perform better than if they had acquired a high-control mode.

Hypothesis 4d: In EMNE's acquisitions of targets in developed economies, selfselecting a high-control mode over a low-control mode, based on observed as well as unobserved characteristics unique to each EMNE, increases postacquisition EMNE acquirer's return; i.e., an EMNE which acquires a highcontrol mode under conditions that are favorable to the purchase of a highcontrol mode perform better than if they had acquired a low-control mode.

\section{METHODS AND DATA}

\section{Analytical model}

I combined two major methods to test the hypotheses in this study. I started with the event study method (McWilliams \& Siegel, 1997) to test Hypothesis 1. I then performed the endogenous switching regression method to test the remaining hypotheses. 


\section{Event study}

An event study was carried out to measure the effect of acquisition announcements on the shareholder value of the EMNE acquirers. The event study method assumes that the stock market is efficient and all stock prices incorporate all relevant and publicly available information in an instantaneous manner (Bromiley, Govekar, \& Marcus, 1988); the acquisition announcement is an unanticipated event; and the acquisition announcement is an isolated event with no other events with potential confounding effects (McWilliams \& Siegel, 1997).

\section{Endogenous switching regression}

From a strategic management perspective, firms frequently make strategic choices to create sustainable competitive advantage and ultimately generate superior organizational performance. Thus, firms make decisions not randomly, but based on expectations of how their choices influence their future performance. In fact, a decision is strategic only if it is endogenous to its expected performance outcome (Hamilton \& Nickerson, 2003). Such endogeneity must be accounted for in any statistical method used to empirically examine the performance implication of firms' strategic choices. If firms self-select strategies, failure to statistically correct for endogeneity may yield both biased and inefficient coefficient estimates (Masten, 1993), which ultimately can lead to model misspecification and incorrect conclusions on the theoretical propositions (Shaver, 1998). In the context of my study, as an EMNE acquires a target in a high-income market, it strategically chooses its control mode by considering its firm-level, industry-level and/or 
country-level characteristics and the effect of the chosen control mode on the firm's expected performance.

A popular method to account for endogeneity biases in a self-selection or strategic phenomenon has been to use the Heckman two-step estimation procedure (Heckman, 1979), an approach widely used in empirical labor economics (Kennedy, 2008). It is an estimation procedure that combines two models, namely the selection model and the performance outcome model (Shaver, 1998). In the first step, a probit regression generates coefficient estimates for the selection model, and in the second step, an ordinary least-squares regression factors in an endogeneity bias control variable obtained from the first step, in order to produce unbiased coefficient estimates for the performance outcome model (Certo, Busenbark, Woo, \& Semadeni, 2016).

Alternatively, the Heckman Maximum Likelihood (ML) estimation procedure, a variation of the two-step estimator, utilizes the maximum likelihood method to simultaneously estimate the two models from the first and second stages of the Heckman two-step estimation procedure (Kennedy, 2008). From an econometric perspective, the Heckman ML estimation procedure is superior to the Heckman two-step estimation procedure, because it provides a more efficient estimator, especially when the error terms are not normally distributed, sample size is small, the mount censoring is small, the correlation between the errors of the performance and selection models is small, and/or the degree of collinearity between the explanatory variables in the performance outcome and selection models is high (Hartman, 1991; Stolzenberg \& Relles, 1990; Zuehlke \& Zeman, 1991; Nawata, 1993). 
While the use of Heckman's two-step estimation procedure to correct for a potential self-selection or endogeneity in a strategic decision has become increasingly common in strategic management (e.g., Arikan \& Capron, 2010; Capron \& Shen, 2007; Chen, 2015, Masten, 1993; Shaver, 1998), the procedure itself was initially proposed to handle sample selection bias issue (rather than self-selection), in which a selection mechanism determines whether or not an observation enters the sample, creating bias in the estimation results (Wooldridge, 2015). Following Kennedy’s (2008) recommendation for a more appropriate estimation procedure involving cases with a self-selection mechanism that places observation into two sub-samples that can both be observed, I apply the endogenous switching regression estimation procedure in this study. This estimation procedure is superior to the Heckman’s two-step and Heckman ML procedures, because it is based on the full-information maximum likelihood (FIML) estimation that simultaneously fit the selection and performance models to generate a consistent estimator with relatively more efficient standard errors (Lokshin \& Sajaia, 2004). In the context of my study, the procedure features two regimes of EMNE acquirer's performance outcome model and a selection model for the control mode choice made by the EMNE acquirer. Based on Maddala (1983), the selection model is as follows:

$$
\begin{aligned}
& I_{i}=1 \text { if } \delta_{1} H i \text { h tech target }{ }_{i}+\delta_{2} \text { "Rapid industrializer" }^{\text {acquire }}{ }_{i}+\gamma \text { Control }_{i}+\mu_{i}>0 \\
& I_{i}=0 \quad \text { if } \delta_{1} H i \text { htech target }{ }_{i}+\delta_{2} \text { "Rapid industrializer" } \text { acquirer }_{i}+\gamma \text { Control }_{i}+\mu_{i} \leq 0
\end{aligned}
$$

where $I_{i}=1$ is low-control mode, $I_{i}=0$ is high-control mode, $\delta_{i}$ are parameters for independent variables, $\gamma$ is vector of parameters for control variables, and $\mu_{i}$ is error term 
assumed to be normally distributed with mean zero. The two regimes of performance outcome model are as follow:

Regime 1:

EMNE performanc ${ }_{1, i}=\beta_{1}$ Performance predictors $(\text { control })_{i}+\varepsilon_{1, i}$ if $I_{i}=1$ Regime 2:

EMNE performance $e_{2, i}=\beta_{2}$ Performance predictors $(\text { control })_{i}+\varepsilon_{2, i}$ if $I_{i}=0$ where $\beta_{1}$ and $\beta_{2}$ are parameters for performance predictors/control variables in regime 1 and regime 2 of the performance outcome model, respectively, and $\varepsilon_{1, i}$ and $\varepsilon_{2, i}$ are error terms assumed to be normally distributed with mean zero (Maddala, 1983).

\section{Rho variables: Correction for endogeneity bias}

The $r h o$ variables (i.e., $\rho_{1}$ and $\rho_{2}$ ) are ancillary parameters created as part of performing the above endogenous switching regression procedure. The coefficient estimate for $\rho_{1}$ represents the correlation in the error term between the selection model and the regime 1 performance outcome model; and the coefficient estimate for $\rho_{2}$ represents the correlation in the error term between the selection model and the regime 2 performance outcome model. Incorporating the rho variables in the performance outcome models corrects for the potential endogeneity bias from the self-selection process. A statistically significant rho coefficient suggests firms strategically choose their control mode based on their unique attributes, as opposed to just rely on a random choice, indicating the presence of a self-selection bias (Lokshin \& Sajaia, 2004). 


\section{Sample and data collection}

I collected a sample of 1314 completed cross-border acquisitions of private and public target firms from non-financial, non-infrastructure and non-property sectors in 22 OECD advanced countries ${ }^{6}$ made by publicly-listed EMNE from BRICS economies from January 1, 2000 to December 31, 2015. The sample excluded cases where the EMNE acquirers already held partial ownerships in the targets. By EMNE from BRICS economies, I mean firms whose ultimate parents were headquartered in Brazil, Russia, India, China (including Hong Kong) and South Africa, although the direct acquiring companies themselves might be some shell companies registered in other countries or tax haven jurisdictions. The BRICS countries were selected because acquisitions made by EMNEs from these countries constitute the largest share of emerging market acquisitions in developed countries. I considered Hong Kong as part of China, as the Hong Kong economy had been closely integrated with the Chinese economy even long before its handover to China in 1997. I confined my analysis to acquirers from the five countries because this study focuses on the acquirers' event-induced stock market reaction, and therefore potential differences in market efficiency characteristics across countries must reasonably be controlled for. Adding more countries in the sample could create an unnecessary complexity, since in multi-country settings event-induced stock market reaction of acquiring firms from different countries might not be comparable due to significant differences in the institutional environments of stock exchanges across

\footnotetext{
${ }^{6}$ The 22 OECD developed economies of North America, Western Europe, and Japan, are Canada, the United States, Austria, Belgium, Denmark, Finland, France, Germany, Greece, Iceland, Ireland, Italy, Luxembourg, Netherlands, Norway, Portugal, Spain, Sweden, Switzerland, the United Kingdom, Japan, and Australia.
} 
countries (Park, 2004). Moreover, 2000 was selected as the starting year of the sample observation period because many emerging countries began to liberalize and reform their economies during the early 1990s (Bhagat, et al., 2011), which arguably provided them with the incentive to engage in outward FDI a decade later.

Data on international acquisition deals were obtained from Thomson One M\&A database, which includes basic information on deal, acquirer and target financial and institutional characteristics. The event study method requires EMNE acquirers' stock price data around the acquisition announcement dates. I obtained the stock price data from Datastream database together with financial information on the EMNE acquirers. I also utilized a few additional databases to collect data for country-level control variables, including World Bank’s World Development Indicators and Hofstede Center’s cultural dimension indices.

I excluded from the initial sample observations that contained EMNE acquirers with material news releases (unrelated to the acquisition activity) around the announcement time to better isolate the effect of the acquisition on EMNE acquirers' stock prices. The announcement date of the deal was used as the event's cut-off date, which is an important element of any event study. This date is the date that a bid announcement first appears in electronic databases. To avoid comparability problem s, I also restricted observations with acquirers whose stocks are exclusively listed in exchanges outside their home countries such as NASDAQ and/or NYSE.

After further data cleaning by dropping observations with missing or incomplete financial and stock price data, inaccurate entries, and entry duplications, the final sample size is 1157 observations. In this sample, 40.1 percent (472) acquirers were Indian 
EMNEs, 33 percent (382) were Chinese EMNEs, 16.5 percent (191) were South African EMNEs, 5.4 percent (62 were Brazilian EMNEs, and 31.8 percent (50) were Russian EMNEs. Around 17.4 percent (201) of the deals were low-control acquisitions. Twentyone target countries were in the final sample, 37.8 percent (437) of which were in the U.S., 13.7 percent (158) in the U.K., 12.8 percent (148) in Australia, 8.7 percent (101) in Germany, 6.2 percent (72) in Canada, 3.11 percent (36) in Italy, 3 percent (35) in France, 2.9 percent (34) in Japan, and 11.8 percent (136) in Austria, Belgium, Denmark, Finland, Greece, Ireland, Luxembourg, Netherlands, Norway, Portugal, Spain, Sweden and Switzerland, collectively. About 85.5 percent (989) of the targets were private firms, while 14.5 percent (168) were publicly listed firms. High-tech targets and non-high-techtargets constituted 37.2 percent (430) and 62.8 percent (727) of all deals, respectively.

\section{Measures}

\section{Dependent variable of the performance outcome model}

The EMNE acquirer's performance is represented by the acquirer's abnormal returns (AR) surrounding the public announcement of the acquisition, which is measured by utilizing the event study methodology (Brown \& Warner, 1985). The event study assumes that the market is efficient and, on balance, can accurately discern the value of the announced transaction. This approach has emerged as a popular method for measuring the effects of various economically relevant factors on the market valuation of corporations (Caves, 1989; Desai, Kroll, \& Wright, 2005; Lubatkin \& Shrieves, 1986; Wright, Ferris, Hiller, \& Kroll, 1995). 
To construct AR for each acquirer, I specifically calculated for each acquiring firm $j$ the abnormal return for various lengths of event window during a five-day period surrounding the date of the announcement, using the following market return model (Brown \& Warner, 1985) formula:

$$
A R_{j, t}=R_{j, t}-\left(\alpha_{j}+\beta_{j} R_{m, t}\right),
$$

where $A R_{j, t}$ is the abnormal return, $R_{j, t}$ is the acquirer's daily stock return, $R_{m, t}$ is the daily stock market return (for the market in which the acquiring firm is listed), and $\alpha_{j}$ and $\beta_{j}$ are market model parameters. A short event window can capture the significant effect of an event more effectively, because a longer the event window implies a higher risk for having confounding effects (McWilliam \& Siegel, 1997). In fact, it has been demonstrated that transmission of information in the capital market can be so quick that a stock price can fully adjust within 15 minutes of the release of firm-specific information (Dann, Mayers, \& Raab, 1977). The market return model parameters, $\alpha_{j}$ and $\beta_{j}$, were estimated based on a 200-day estimation window before the announcement date, which is in line with what is suggested by McWilliams and Siegel (1997). Daily stock market return and acquirer's return data for estimating market parameters and calculating the acquirer's abnormal returns were all obtained from Datastream database.

For an event window with a length of more than 1 day, cumulative abnormal returns (CAR) need to be computed in place of the abnormal returns (AR). Daily abnormal returns need to be summed up to measure the CAR of the acquirers for various lengths of event window during the five-day period surrounding the acquisition announcement to account for potential leakage or slow transmission of information 
(McWilliams \& Siegel, 1997). For example, for a 3-day $(-1,+1)$ event window, the acquirer's CAR was calculated by using the following formula:

$$
C A R_{j}=\sum_{t=-1}^{+1} A R_{j, t}
$$

In the regression for the cross-section examination of the effect of control mode choice on post-acquisition acquirer's performance, I applied a 1-day $(-1,+1)$ event window to allow for potential slow transmission or early leakage of information. Since this study focuses on EMNE acquirers that were listed in their respective home market stock exchanges, it is arguably reasonable to expect a quick transmission of information between the announcement of the acquisition at the EMNE headquarters and the stock market reaction (Mitchell \& Netter, 1989). For a robustness check, however, I also examined additional results under various lengths of event window within a five-day period surrounding the acquisition announcement. The use of a five-day period is consistent with practices recommended by other researchers (e.g., Fuller, Netter, and Stegemoller, 2002; Masulis, Wang, and Xie, 2009).

\section{Dependent variable of the control mode selection model}

Control mode is a dichotomous variable that takes the value of 1 if an EMNE acquirer chose a low-control mode (i.e., post-acquisition ownership of equal or less than $50 \%$ of the target total shares), or the value of 0 if the acquiring EMNE chose a high-control mode (i.e., post-acquisition ownership of greater than $50 \%$ of the target total shares). 


\section{Information on acquirer's target equity ownership after the transaction was obtained from}

\section{Thomson One M\&A database.}

\section{Table 1. Variable definitions and data sources}

\begin{tabular}{|c|c|c|}
\hline Variable & Definition & Source \\
\hline \multicolumn{3}{|l|}{ Dependent variables } \\
\hline $\begin{array}{l}\text { Acquirer's cumulative abnormal } \\
\text { return (CAR) }\end{array}$ & $\begin{array}{l}\text { Acquirer's cumulative daily abnormal log return over a }(-1,+1), 3 \text {-day } \\
\text { event window, calculated using the event study method based on the } \\
\text { market return model (Brown \& Werner, 1985) with parameter } \\
\text { estimates obtained based on an OLS regression with a 200-day } \\
\text { estimation window. }\end{array}$ & $\begin{array}{l}\text { Thomson One, } \\
\text { Datastream }\end{array}$ \\
\hline Control mode (low versus high) & $\begin{array}{l}\text { An acquisition was classified as low-control mode acquisition when the } \\
\text { acquirer owns } \leq 50 \% \text { of the target after the acquisition and was } \\
\text { coded as } 1 \text {; otherwise } 0 \text {. }\end{array}$ & Thomson One \\
\hline \multicolumn{3}{|l|}{$\underline{\text { Independent variables }}$} \\
\hline $\begin{array}{l}\text { Country of origin - rapid } \\
\text { industrializer }\end{array}$ & $\begin{array}{l}\text { If the acquirer's ultimate parent company was headquartered in China } \\
\text { or Hong Kong, it was coded } 1 \text {; otherwise } 0 \text {. }\end{array}$ & Thomson One \\
\hline High-technology industry target & $\begin{array}{l}\text { If target was in high technology industry (based on Thomson Reuters' } \\
\text { 3-digit classification), it was coded 1; otherwise } 0 .\end{array}$ & Thomson One \\
\hline \multicolumn{3}{|l|}{$\underline{\text { Control variables }}$} \\
\hline Acquirer's prior performance & $\begin{array}{l}\text { Acquirer's return on asset at the year prior to the acquisition } \\
\text { announcement year (in \%) }\end{array}$ & Datastream \\
\hline Acquirer’s profitability & $\begin{array}{l}\text { Acquirer's net profit margin in the year prior to the acquisition } \\
\text { announcement year (in \%) }\end{array}$ & Datastream \\
\hline Acquirer's firm size & $\begin{array}{l}\text { Acquirer's total asset in the year prior to the acquisition announcement } \\
\text { year (in million US\$), transformed to natural logarithms }\end{array}$ & Datastream \\
\hline Acquirer's leverage & $\begin{array}{l}\text { Average of acquirer's net debt-to-capital ratio for the 3-year period prior } \\
\text { to the acquisition announcement year in } \%\end{array}$ & Datastream \\
\hline Acquirer's state-owned status & $\begin{array}{l}\text { If acquirer or acquirer ultimate parent was fully or partially owned by } \\
\text { home country's government, it was coded } 1 \text {; otherwise } 0\end{array}$ & Thomson One \\
\hline Target's public status & If target was a publicly listed company, it was coded 1 ; otherwise 0 & Thomson One \\
\hline Method of payment & $\begin{array}{l}\text { If an acquisition was a } 100 \% \text {-cash transaction, it was coded } 1 \text {; } \\
\text { otherwise } 0 .\end{array}$ & Thomson One \\
\hline Geographic distance & $\begin{array}{l}\text { Country-level Mahalanobis geographic distance index, derived from } \\
\text { great circle distance between two countries according to the } \\
\text { coordinates of the geographic center of the countries }\end{array}$ & Berry, Guillen and Zhou (2010) \\
\hline Industry relatedness & $\begin{array}{l}\text { If target or target ultimate parent's operated in the same industry as the } \\
\text { acquirer or acquirer ultimate parent (based on Thomson Reuters' } 85 \\
\text { mid-level industry classifications), it was coded 1; otherwise } 0 \text {. }\end{array}$ & Thomson One \\
\hline Cultural distance & $\begin{array}{l}\text { Country-level cultural distance index, derived from cultural value scores } \\
\text { of Hofstede (1980)'s four original cultural dimensions and computed } \\
\text { with the formula in Kogut and Singh (1988) }\end{array}$ & The Hofstede Centre \\
\hline Acquirer industry dummies & $\begin{array}{l}\text { Categorical variables for acquirer industries. Industry categories are } \\
\text { based on Thomson Reuters' industry group classification } \\
\text { (manufacturing, finance, energy \& natural resources, service). Base } \\
\text { acquirer industry: manufacturing. }\end{array}$ & Thomson One \\
\hline Target industry dummies & $\begin{array}{l}\text { Categorical variables for target industries. Industry categories are based } \\
\text { on Thomson Reuters' industry group classification (manufacturing, } \\
\text { energy \& natural resources, service). Base target industry: } \\
\text { manufacturing. }\end{array}$ & Thomson One \\
\hline Target region dummies & $\begin{array}{l}\text { Categorical variables for each different target region in North America, } \\
\text { Europe, Asia and Australia. Base target region: North America }\end{array}$ & Thomson One \\
\hline Year dummy & $\begin{array}{l}\text { If the acquisition was announced in } 2008,2009,2010,2011,2012 \text {, } \\
2013,2014 \text {, or } 2015 \text {, it was coded } 1 \text {; otherwise } 0 \text {. }\end{array}$ & Thomson One \\
\hline
\end{tabular}




\section{Independent variables of the control mode selection model}

"Rapid industrializer" acquirer is a binary variable, which was coded 1 if the EMNE acquirer's ultimate parent company was headquartered in China or Hong Kong.

Information about geographic locations of acquirers' ultimate parent companies was available in Thomson One M\&A database.

High-technology industry target is a binary variable, which was coded 1 if a target firm was classified by Thomson One M\&A database as operating in a high-technology industry. The Thomson One high-technology industry classification is based on 3-digit SIC codes for the high-technology industries.

\section{Control variables}

Based on extant literature on cross-border acquisitions, several control variables were included, since they are likely to have effects on the acquirer's control mode selection and/or the performance outcome model. First, there were six firm-level control variables. Acquirer's prior performance refers to the value of return on assets at the year before the acquisition announcement year. Acquirer's profitability represents acquiring firms' preacquisition profit margin at the year prior to the acquisition announcement year.

Acquirer's leverage was measured as the net debt to equity ratio of acquiring firms at the year prior to the year the acquisition was announced (Yang, 2015) Acquirer's firm size refers to acquirer's total asset (in million U.S. dollars) in the year prior to the acquisition announcement year, transformed to natural logarithm (Ning et al., 2014). Acquirer's state-owned status was coded as 1 if the acquirer was classified as government owned or controlled in Thomson One database (Yang, 2015). Target's public status was coded as 1 
if the target was a publicly listed company prior to the acquisition (Aybar \& Ficici, 2009).

I also included a deal-specific control variable, Method of payment, a dichotomous variable, which was coded 1 if an acquisition deal was a 100\%-cash transaction, and other types of payment were coded as 0 (Elango et al., 2013). In addition, I included three industry-level control variables. Industry relatedness was coded 1, if the acquirer and the target or the target's ultimate parent company operated in the same industry. The industry classification is based on Thomson Reuters' 85 mid-level industry categories and was available in Thomson One M\&A database. Acquirer industry dummies are dummy variables to account for the effect of acquirer's industries, while Target industry dummies are dummy variables to capture the effect of target firms' industries. Thomson Reuters’ industry group classification was used to define whether firms operated in manufacturing, finance, energy and natural resources, or service industry.

Finally, three more control variables were included. Geographic distance is a continuous variable, measured with the Mahalanobis distance formula (1936). It represents the great circle distance between two countries according to the coordinates of geographic centers of the two countries. The country-level scores were obtained from Berry et al. (2010). Cultural distance is a continuous variable that represents the countrylevel cultural distance index. The index was derived from the cultural value scores of Hofstede’s four original dimensions of culture, namely power distance, uncertainty avoidance, individualism, and masculinity (1980), and was computed with Kogut and Singh’s formula (1988). Year dummy captures the effect of the global Great Recession 
that started with the housing bubble burst in the United States and severely affected the performance of firms in most parts of the world. It was coded 1 if the acquisition was announced between 2008 and 2015 (inclusive), and was coded 0 for any other year. A complete description of all variables included in the model is provided in Table 1 with sources from which the data for the variables were obtained.

\section{RESULTS AND DISCUSSION}

Based on 1157 Chinese and Indian EMNE’s acquisitions of publicly listed firms in 18 OECD countries, I performed an event study for various lengths of event window within the five-day period surrounding the day acquisitions were announced. Table 2 reports the (cumulative) average abnormal returns (CAAR) for the target firms during the 1-day 2day, 3-day, 4-day and 5-day event windows. For all event windows, the mean CAAR range from 0.52 percent to 0.96 percent and are all statistically significant under various parametric and non-parametric tests. The results support Hypothesis 1 and confirm that on average EMNE's acquisitions of firms in developed economies yield positive

Table 2. EMNE acquirers' CAR around the acquisition announcement days

\begin{tabular}{|c|c|c|}
\hline Observed choice (real situation) & Counterfactual choice ("What if” analysis) & Mean difference \\
\hline $\begin{array}{l}\text { EMNE acquirers with observed low-control } \\
\text { choice mode when choosing low-control } \\
\text { mode }\end{array}$ & $\begin{array}{l}\text { EMNE acquirers with observed low-control mode } \\
\text { choice had they chosen high-control mode instead } \\
\text { of low-control mode }\end{array}$ & \\
\hline$+0.03 \%$ & $-6.19 \%$ & $+6.23 \% * * *$ \\
\hline $\begin{array}{l}\text { EMNE acquirers with observed high-control } \\
\text { choice mode when choosing high-control } \\
\text { mode }\end{array}$ & $\begin{array}{l}\text { EMNE acquirers with observed high-control mode } \\
\text { choice had they chosen low-control mode instead } \\
\text { of high-control mode }\end{array}$ & \\
\hline$+1.20 \%$ & $-8.56 \%$ & $+9.76 \% * * *$ \\
\hline
\end{tabular}

Note: $* * *$ denotes statistical significance at $1 \%$ level. 
(cumulative) abnormal returns for the acquirers. The acquisitions of targets in advanced economies are viewed by the market as a value creating strategy for the EMNE acquirers.

To test the remaining hypotheses, I ran an endogenous switching regression, as discussed in the method section. Pair-wise correlation test was performed on the variables used in this study to detect the presence of any multicollinearity problems, since highly correlated independent variables can lead to biased or no estimation results. Table 3 presents the pair-wise correlation coefficients along with summary descriptive statistics for every included variable. Almost all of the correlation coefficients are between 0.002 and 0.37 , well below the 0.7 maximum standard typically used in empirical management literature, suggesting there is no multicollinearity problem that may detrimentally affect the regression estimation results. Variance inflation factors (VIFs) were also computed, which gave a mean value of 1.48 , confirming there is no multicollinearity problem that may detrimentally affect the subsequent estimation procedure.

Estimation results from the endogenous switching regression are provided in Models 5-7 in Table 4. For a comparison purpose, I also ran the Heckman Maximum Likelihood (ML) regression whose results are given in Models 1-4 in Table 4. Robust standard errors are given in the parentheses. The use of robust standard error (White, 1980) is in line with consistent with MacKinlay’s suggestion (1997).

All models in Table 4 have significant Wald statistics, indicating their explanatory statistical powers in explaining the variation in both the control mode choice and the EMNE acquirers' post-acquisition performance, as measured by the acquirer's CAR. In Model 5, the coefficient of country of origin - rapid industrializer is positive and significant $\left(\delta_{1}=+0.360, p<0.01\right)$, thus supporting Hypothesis 2 . Results from Heckman 
Table 3. Descriptive statistics and correlations $(N=1157)$

\begin{tabular}{|c|c|c|c|c|c|c|c|c|c|c|c|c|c|c|}
\hline & 1 & 2 & 3 & 4 & 5 & 6 & 7 & 8 & 9 & 10 & 11 & 12 & 13 & 14 \\
\hline 1. Acquirer's CAR & 1 & & & & & & & & & & & & & \\
\hline 2. Control mode $(1=$ low-mode control $)$ & $-0.07^{\star x}$ & 1 & & & & & & & & & & & & \\
\hline 3. Country of origin-rapid industrializer & -0.01 & $0.16^{\mathrm{xx*}}$ & 1 & & & & & & & & & & & \\
\hline 4. High-techn ology in dustry target & 0.02 & $-0.07^{\star * *}$ & $-0.08^{* \times *}$ & 1 & & & & & & & & & & \\
\hline 5. Acquirer's prior performance & $-0.07^{\star \star}$ & -0.04 & -0.002 & $0.06^{\mathrm{xx}}$ & 1 & & & & & & & & & \\
\hline 6. Acquirer's profitability & -0.05 & 0.0002 & 0.01 & 0.04 & $0.73^{* \times \star}$ & 1 & & & & & & & & \\
\hline 7. Acquirer's firm size & $-0.15^{\star \approx \pi x}$ & $0.14^{\mathrm{x} \times x}$ & 0.007 & $-0.23^{\mathrm{x} \times x}$ & $-0.09^{\mathrm{x \times \pi}}$ & 0.01 & 1 & & & & & & & \\
\hline 8. Acquirer's leverage & $-0.08^{\mathrm{*x}}$ & $-0.02^{\approx * *}$ & $-0.11^{\times \times *}$ & $-0.16^{\star \times \pi}$ & -0.04 & -0.03 & $0.05^{*}$ & 1 & & & & & & \\
\hline 9. Acquirer's state-owned status & -0.04 & $0.06^{\times *}$ & $-0.18^{\times \times \approx}$ & $-0.08^{\approx \times \pi}$ & 0.001 & 0.004 & $0.23^{\times \times x}$ & -0.01 & 1 & & & & & \\
\hline 10. Target's public status & -0.01 & $0.42^{* * *}$ & $0.10^{* \times *}$ & $-0.11^{\mathrm{x \times x}}$ & $-0.03^{* x}$ & -0.03 & $0.12^{\star \star \star \star}$ & -0.02 & -0.01 & 1 & & & & \\
\hline 11. Method of payment & 0.03 & 0.02 & $0.15^{\times \times \times}$ & 0.02 & -0.02 & -0.04 & 0.01 & $-0.06^{\mathrm{xx}}$ & $-0.05^{*}$ & $0.21^{\times \mathrm{xx}}$ & 1 & & & \\
\hline 12. Geographic distance & 0.02 & $-0.13^{\mathrm{x \times x}}$ & $-0.22^{\times \times \times}$ & $0.22^{* \times x}$ & 0.03 & 0.02 & $-0.12^{\times \times x}$ & $-0.08^{\times \times \times}$ & $-0.05^{\times \times *}$ & -0.04 & 0.02 & 1 & & \\
\hline 13. Industry relatedness & $0.06^{\star \star x}$ & -0.01 & $-0.09^{\times \times \times}$ & 0.01 & -0.01 & -0.003 & $-0.05^{\star}$ & -0.03 & 0.04 & $0.09^{* \times \approx}$ & 0.03 & 0.02 & 1 & \\
\hline 14. Cultural distance & $-0.03^{\mathrm{x} \times}$ & $0.09^{\mathrm{x*x}}$ & $0.71^{\times \times \times}$ & $-0.09^{x \times x}$ & 0.01 & 0.02 & $0.10^{\times \times \star}$ & $-0.06^{\times \times x}$ & $0.06^{\mathrm{xxx}}$ & $0.07^{\times \times x}$ & $0.11^{\times \times x}$ & $-0.37^{* \times *}$ & $-0.07^{\times \pm x}$ & 1 \\
\hline Mean & 0.01 & 0.17 & 0.33 & 0.37 & 11.30 & 11.73 & 13.72 & 30.78 & 0.02 & 0.15 & 0.30 & 9648.2 & 0.42 & 2.42 \\
\hline S.D. & 0.06 & 0.38 & 0.47 & 0.48 & 61.56 & 260.0 & 2.11 & 33.52 & 0.13 & 0.35 & 0.46 & 2894.8 & 0.49 & 1.30 \\
\hline Min & -0.24 & 0 & 0 & 0 & -142.5 & -4631 & 3.66 & -521.2 & 0 & 0 & 0 & 2978.7 & 0 & 0.22 \\
\hline Max & 0.39 & 1 & 1 & 1 & 2065.1 & 6212 & 20.05 & 702.9 & 1 & 1 & 1 & 16860 & 1 & 5.93 \\
\hline
\end{tabular}

Note: ***, ${ }^{* *}$, and *den ote statistical significance at $1 \%, 5 \%$ and $10 \%$ levels, respectively. 
Table 4. Estimates of acquirer's control mode selection and performance models

\begin{tabular}{|c|c|c|c|c|c|c|c|}
\hline \multirow[b]{3}{*}{ Dependent variable } & \multicolumn{4}{|c|}{ Heckman (ML) } & \multicolumn{3}{|c|}{ Endogenous Switching Regression (FIML) } \\
\hline & $\begin{array}{c}\quad(1) \\
\text { Selection } \\
\text { Equation }\end{array}$ & $\begin{array}{c}\text { (2) } \\
\text { Performance } \\
\text { Equation } \\
\text { (Non-control) }\end{array}$ & $\begin{array}{c}\text { (3) } \\
\text { Selection } \\
\text { Equation }\end{array}$ & $\begin{array}{c}\text { (4) } \\
\text { Performance } \\
\text { Equation } \\
\text { (Control) }\end{array}$ & $\begin{array}{c}\text { (5) } \\
\text { Selection } \\
\text { Equation }\end{array}$ & $\begin{array}{c}\text { (6) } \\
\text { Performance } \\
\text { Equation } \\
\text { (Non-control) }\end{array}$ & $\begin{array}{c}\text { (7) } \\
\text { Performance Equatior } \\
\text { (Control) }\end{array}$ \\
\hline & $\begin{array}{l}\text { Low-control } \\
\text { Mode } \\
{[=1]}\end{array}$ & $\begin{array}{l}\text { Acquirer's } \\
\text { Abnormal } \\
\text { Return }\end{array}$ & $\begin{array}{l}\text { High-control } \\
\text { Mode } \\
{[=1]}\end{array}$ & $\begin{array}{l}\text { Acquirer's } \\
\text { Abnormal } \\
\text { Return }\end{array}$ & $\begin{array}{l}\text { Low control } \\
\text { Mode } \\
{[=1]}\end{array}$ & $\begin{array}{c}\text { Acquirer's } \\
\text { Abnormal } \\
\text { Return }\end{array}$ & $\begin{array}{c}\text { Acquirer's } \\
\text { Abnormal } \\
\text { Return }\end{array}$ \\
\hline \multicolumn{8}{|l|}{ Independent variables } \\
\hline $\begin{array}{l}\text { Country of origin - } \\
\text { rapid industrializer }\end{array}$ & $\begin{array}{l}0.544^{* * * *} \\
(0.149)\end{array}$ & & $\begin{array}{l}-0.334 * * \\
(0.150)\end{array}$ & & $\begin{array}{l}0.360^{\text {**** }} \\
(0.138)\end{array}$ & & \\
\hline $\begin{array}{l}\text { High-technology } \\
\text { industry target }\end{array}$ & $\begin{array}{l}0.360^{* * * *} \\
(0.115)\end{array}$ & & $\begin{array}{l}-0.344 * * * \\
(0.106)\end{array}$ & & $\begin{array}{l}0.353^{* * *} \\
(0.102)\end{array}$ & & \\
\hline \multicolumn{8}{|l|}{ Control variables } \\
\hline $\begin{array}{l}\text { Acquirer's } \\
\text { prior performance }\end{array}$ & $\begin{array}{l}-0.011^{* *} \\
(0.005)\end{array}$ & $\begin{array}{l}-0.001 * * \\
(0.0004)\end{array}$ & $\begin{array}{l}0.0012^{* * * *} \\
(0.004)\end{array}$ & $\begin{array}{l}-0.00004 \\
(0.00003)\end{array}$ & $\begin{array}{l}-0.012 * * * \\
(0.005)\end{array}$ & $\begin{array}{l}-0.001 * * * \\
(0.0003)\end{array}$ & $\begin{array}{l}-0.00004 \\
(0.00004)\end{array}$ \\
\hline Acquirer’s profitability & $\begin{array}{c}0.0003 \\
(0.0002)\end{array}$ & $\begin{array}{l}-0.00004 * * * \\
(0.00001)\end{array}$ & $\begin{array}{l}-0.0005 \\
(0.0003)\end{array}$ & $\begin{array}{l}-0.00001 \\
(0.00001)\end{array}$ & $\begin{array}{l}-0.001^{*} \\
(0.0003)\end{array}$ & $\begin{array}{l}-0.00004^{*} \\
(0.00002)\end{array}$ & $\begin{array}{l}-0.000008 \\
(0.00001)\end{array}$ \\
\hline Acquirer's leverage & $\begin{array}{l}-0.001 \\
(0.001)\end{array}$ & $\begin{array}{c}0.0004 \\
(0.0002)\end{array}$ & $\begin{array}{r}0.001 \\
(0.01)\end{array}$ & $\begin{array}{l}-0.0001^{*} \\
(0.00007)\end{array}$ & $\begin{array}{l}-0.006 \\
(0.001)\end{array}$ & $\begin{array}{c}0.0004^{*} \\
(0.0002)\end{array}$ & $\begin{array}{l}-0.0001 * * \\
(0.0001)\end{array}$ \\
\hline Acquirer’s firm size & $\begin{array}{l}0.076^{* * * *} \\
(0.025)\end{array}$ & $\begin{array}{l}-0.002 \\
(0.003)\end{array}$ & $\begin{array}{l}-0.092^{* * *} \\
(0.025)\end{array}$ & $\begin{array}{l}-0.005^{* * * *} \\
(0.001)\end{array}$ & $\begin{array}{l}-0.089^{* * * *} \\
(0.027)\end{array}$ & $\begin{array}{l}-0.001 \\
(0.003)\end{array}$ & $\begin{array}{l}-0.005 * * * \\
(0.001)\end{array}$ \\
\hline Target’s public status & $\begin{array}{l}1.279^{* * *} \\
(0.127)\end{array}$ & $\begin{array}{l}-0.036^{*} \\
(0.021)\end{array}$ & $\begin{array}{l}-1.276^{* * * *} \\
(0.128)\end{array}$ & $\begin{array}{l}-0.022 * * \\
(0.009)\end{array}$ & $\begin{array}{l}1.272^{* * * *} \\
(0.132)\end{array}$ & $\begin{array}{l}0.040 * * \\
(0.016)\end{array}$ & $\begin{array}{l}-0.022^{* * * *} \\
(0.007)\end{array}$ \\
\hline Method of payment & $\begin{array}{l}-0.317^{\text {**** }} \\
(0.116)\end{array}$ & $\begin{array}{l}-0.019^{*} \\
(0.012)\end{array}$ & $\begin{array}{l}0.285^{* *} \\
(0.112)\end{array}$ & $\begin{array}{l}0.009 * * \\
(0.004)\end{array}$ & $\begin{array}{l}-0.290^{* * *} \\
(0.111)\end{array}$ & $\begin{array}{l}-0.020^{* *} \\
(0.009)\end{array}$ & $\begin{array}{l}0.009^{* *} \\
(0.004)\end{array}$ \\
\hline $\begin{array}{l}\text { Acquirer's state- } \\
\text { owned status }\end{array}$ & $\begin{array}{l}0.328 \\
(0.328)\end{array}$ & & $\begin{array}{l}-0.195 \\
(0.284)\end{array}$ & & $\begin{array}{l}0.241 \\
(0.256)\end{array}$ & & \\
\hline Geographic distance & $\begin{array}{l}-0.00004 \\
(0.00003)\end{array}$ & & $\begin{array}{c}0.00004^{*} \\
(0.00003)\end{array}$ & & $\begin{array}{l}-0.00003 \\
(0.00003)\end{array}$ & & \\
\hline Industry relatedness & $\begin{array}{l}-0.215^{*} \\
(0.129)\end{array}$ & & $\begin{array}{l}0.225^{* *} \\
(0.097)\end{array}$ & & $\begin{array}{l}-0.182^{*} \\
(0.098)\end{array}$ & & \\
\hline Cultural distance & $\begin{array}{l}-0.916 \\
(0.060)\end{array}$ & & $\begin{array}{c}0.095^{*} \\
(0.050)\end{array}$ & & $\begin{array}{l}-0.083^{*} \\
(0.049)\end{array}$ & & \\
\hline Constant & $\begin{array}{l}-1.891^{* * * *} \\
(0.582)\end{array}$ & $\begin{array}{l}-0.036 \\
(0.061)\end{array}$ & $\begin{array}{l}2.130^{* * * *} \\
(0.542)\end{array}$ & $\begin{array}{l}0.073 * * * \\
(0.015)\end{array}$ & $\begin{array}{l}-2.242 * * * \\
(0.560)\end{array}$ & $\begin{array}{l}-0.060 \\
(0.053)\end{array}$ & $\begin{array}{l}0.072 * * * \\
(0.013)\end{array}$ \\
\hline Sigma & & $\begin{array}{l}0.059^{* * * *} \\
(0.010)\end{array}$ & & $\begin{array}{l}0.059^{* * * *} \\
(0.003)\end{array}$ & & $\begin{array}{l}0.061 * * * \\
(0.007)\end{array}$ & $\begin{array}{l}0.059 * * * \\
(0.003)\end{array}$ \\
\hline Rho & & $\begin{array}{c}0.622 * \\
(0.263)\end{array}$ & & $\begin{array}{l}0.781^{* * * *} \\
(0.060)\end{array}$ & & $\begin{array}{l}0.677 * * * * \\
(0.168)\end{array}$ & $\begin{array}{l}-0.778^{* * * *} \\
(0.045)\end{array}$ \\
\hline Acquirer industry effects & Yes & Yes & Yes & Yes & & Yes & \\
\hline Target industry effects & Yes & Yes & Yes & Yes & & Yes & \\
\hline Target region effects & Yes & Yes & Yes & Yes & & Yes & \\
\hline Year effects & Yes & Yes & Yes & Yes & & Yes & \\
\hline Log pseudo-likelihood & -84.7 & & 1041.7 & & & & \\
\hline Log likelihood & & & & & & 1354.16 & \\
\hline Wald statistic & $31.87^{* *}$ & & $122.7 * * *$ & & & $40.10^{* * *}$ & \\
\hline$N$ & 1157 & 201 & 1157 & 956 & & 1157 & \\
\hline \multicolumn{8}{|l|}{ Test for indep. eqns. } \\
\hline $\begin{array}{l}\text { Wald statistic } \\
\text { LR statistic }\end{array}$ & $2.88^{*}$ & & $46.3^{* * *}$ & & & $26.84 * * *$ & \\
\hline
\end{tabular}


(ML) regression in Model 1 and Model 3 provide further confirmation. These results imply that EMNEs from a rapidly industrializing countries such as China are more likely to choose a low-control mode in their acquisitions of firms in developed economies, relative to EMNE from other emerging economies. Model 5 also shows that the acquiring high-technology target has a statistically significant positive effect on low-control mode choice $\left(\delta_{2}=+0.353, p<0.01\right)$, supporting Hypothesis 3 . This result is also consistent with the Heckman (ML) regression results in Model 1 and 3, suggesting that when the target is from one of the high-technology industries in the advanced economies, the EMNE acquirer is more likely to choose a low-control mode.

The rho variables in Models 2, 4, 6 and 7 represent the correlations in error terms of the selection and performance outcome models. A statistically significant rho coefficient indicates the presence of self-selection. The coefficient of $r h o$ in Model 6 is positive and significant $\left(\rho_{1}=0.677, p<0.01\right)$, which is consistent with the rho coefficient in Model 2 under the alternative Heckman ML regression $\left(\rho_{1}=0.622, p<0.1\right)$. By contrast, the coefficient of $r h o$ in Model 7 is negative and statistically significant $\left(\rho_{2}=\right.$ $0.778, p=0.01$ ), which is further confirmed by the rho coefficient in Model 4 under the Heckman ML regression $\left(\rho_{2}=0.781, p=0.01\right)$, suggesting there is also a self-selection for those EMNE acquirers who chose high-control acquisitions. Thus, both Hypothesis 4a and Hypothesis $4 \mathrm{~b}$ are supported. Formal tests for the presence of self-selection show significant Wald statistics of 2.88 and 46.3 (for Model 2 and Model 4, respectively) and a significant Likelihood Ratio statistic of 26.84 (for Model 6 and 7), further confirming the above results. The EMNE acquirers indeed strategically chose their acquisition control modes based on their characteristics rather than just relying purely on a random decision. 
Furthermore, the positive signs of the rho coefficients in Model 2 and Model 6 suggest the EMNE acquirers that chose low-control acquisitions would have been worse off had they chosen a high-control mode instead of the low -control mode. Similarly, the negative sign of the rho coefficient in Model 7 (and the negative sign of the rho coefficient in Model 4) also suggest the EMNE acquirers that chose high-control acquisitions would have been worse off had they chosen a low-control mode instead of the high -control mode. To further investigate these results, I used the estimated switching regression model to generate predicted returns (i.e., conditional expectations), so that I could compare observed and counterfactual EMNE acquirer's returns (Maddala, 1983).

Table 5 presents the analytical results of expected EMNE acquirer's returns under low-control mode and high-control mode choices along with their respective counterfactual returns. While the predicted mean return of high-control acquisitions is generally superior to that of low-control acquisitions (1.20 percent versus 0.03 percent), this does not necessary imply firms that consider choosing a low-control mode should opt for a high-control mode instead. In fact, the EMNE acquirers that chose a low-control mode would have been worse-off had they chosen a high control mode ( 0.03 percent versus -6.19 percent, or 6.23 percent less returns). Similarly, the EMNE acquirers that chose a high-control mode would have been worse off had they chosen a low-control mode (1.20 percent versus -8.56 percent, or 9.76 percent less returns). Thus, Hypothesis 4c and Hypothesis 4d are supported. EMNE that have observed and unobserved characteristics advantageous for a low-control (high-control) mode acquisition are more likely to strategically select themselves into the low-control (high-control) mode 
acquisition, leading to a better post-acquisition performance than if they had chosen a high-control (low-control) mode acquisition.

Table 5. Acquirer's predicted returns: observed versus counterfactual control mode

\begin{tabular}{ccc}
\hline \hline Observed choice (real situation) & Counterfactual choice ("What if” analysis) & Mean difference \\
\hline \hline $\begin{array}{c}\text { EMNE acquirers with observed low-control } \\
\text { choice mode when choosing low-control } \\
\text { mode }\end{array}$ & $\begin{array}{c}\text { EMNE acquirers with observed low-control mode } \\
\text { choice had they chosen high-control mode instead } \\
\text { of low-control mode }\end{array}$ & $-6.19 \%$ \\
$\begin{array}{c}\text { EMNE acquirers with observed high-control } \\
\text { choice mode when choosing high-control } \\
\text { mode }\end{array}$ & $\begin{array}{c}\text { EMNE acquirers with observed high-control mode } \\
\text { choice had they chosen low-control mode instead } \\
\text { of high-control mode }\end{array}$ & $+6.23 \% * * *$ \\
\hline \hline Note: *** denotes statistical significance at 1\% level. & $-8.56 \%$ & $+9.76 \%$ ****
\end{tabular}

I checked for robustness by estimating regression models using various lengths of event windows within the five-day period surrounding the announcement days as the dependent variable of the outcome model. I also tried a less-than-30\% cut-off point (instead of less-than-50\%) for determining the control mode dummy, which is the dependent variable of the control mode selection model. It is worth noting that in a similar empirical test on a smaller sample $(N=176)$ of exclusively manufacturing acquisitions by Chinese and Indian firms in OECD countries, Hypothesis 4d was not supported, suggesting those EMNE acquirers that chose high-control acquisition would have been better off had they chosen a low-control mode instead of the high-control mode. It is less clear why the EMNE acquirers with high-control mode choice had not chosen the low-control mode, although that would have generated higher returns for them. One possible reason for this sub-optimal choice is the market for corporate control in some of the target home countries might be incomplete (Arrow \& Debreu, 1954). 
While the EMNE acquirers that chose a high-control mode were well informed about the benefits for them of engaging in low-control acquisitions, the local markets for corporate control in some of the smaller advanced economies might not have sufficient number of target firms willing to partially sell a non-controlling minority interest in their shareholdings. In other words, there is an oversupply of target firms in these countries that preferred letting go control of their firms, or even completely selling their shares to the EMNE acquirers, to retaining controlling majority interests after the acquisitions, forcing EMNE acquirers to settle with a less-than-optimal control mode choice. Overall, the estimation results were not significantly different to my earlier results, and the main findings, particularly with regard to the strategic nature of the control mode decision, were largely unaffected.

\section{CONCLUSION}

This essay extends insights from the dynamic socio-cultural model (DSCM) in my Essay 1 to the context of EMNE's cross-border acquisitions of firms in high-income economies, where collective learning occurs between the EMNE acquirer and the target firm, each of which brings contrastingly different national and organizational cultures. Enriched by the organizational learning perspective, particularly the concepts of exploration and exploitation (March, 1991), I used the insights from the DSCM to better understand the EMNE acquirer's choice of non-controlling minority interest or controlling majority interest in its target ownership in relation to its attempt to optimize effective postacquisition learning and maximize value creation. 
Performing an event study on 1157 acquisitions made by EMNE from BRICS countries in twenty-one major OECD countries, I found that EMNE's acquisitions of firms in developed economies generate, on average, positive post-acquisition performance, as measured by the EMNE acquirers' average abnormal returns upon the acquisition announcements. Employing the endogenous switching regression method, combined with the Heckman Maximum Likelihood method to perform a cross-section examination of the results from the event study, I found that an EMNE from a rapidly industrializing emerging economy such as China is more likely to choose a low-control mode in its acquisition of firms in developed economies than acquirers from other emerging economies. I also found that acquiring a target in one of the high-technology industries in the advanced economies is positively related to a greater probability for an EMNE acquirer to choose a low-control mode over a high-control mode. Moreover, I found that EMNE acquirers that strategically select a low-control mode or a high-control mode in their acquisitions in developed economies did so by considering their observed as well as unobserved firm-level, industry-level and country-level characteristics. I also found EMNE acquirers that chose low-control mode and those that chose high-control both made an optimal decision.

This essay makes several contributions. First, it expands the research in EMNE by demonstrating the collective learning benefits of control mode choice in EMNE's acquisitions of firms in developed economies, based on perspectives of the dynamic socio-cultural model (DSCM) and the organizational learning literature. Second, it contributes to the "country-of-origin effect” literature (e.g., Lahiri et al., 2014; Porter, 1990; Sethi \& Elango, 2000), by further dissecting the emerging economies and 
classifying them into a typology created based on country-level international trade and labor market conditions. Third, it responds to Shaver's call for seriously taking into account potential self-selection biases in performance-related research in strategic management research, especially when strategic choices are involved (1998), by endogenizing the choices in the model estimation through the application of the endogenous switching regression method, which is a technical advantage to the traditional use of the Heckman two-step estimation procedure in management literature for handling a self-selection problem. Fourth, it adds to the relatively rare studies on the determinants of corporate control mode choice within the context of "South-North" international acquisitions and extends some recent related works (e.g., Chari \& Chang, 2009; Contractor et al, 2014; Gaffney et al., 2015; Yang, 2015) by looking into the performance implications of the control mode choice. In addition, from a practical perspective, it provides executives of EMNEs as well as their prospective target firms in advanced economies with the understanding that control mode is an important strategic choice that EMNEs make when acquiring targets, particularly in high-income economies. Insights into how this control mode decision affects acquisition performance should prove important for not only researchers, but also practitioners.

It is useful to highlight some limitations in this essay that need to be addressed in future studies. First, the detailed process of EMNE's simultaneous engagement in interspatial exploration and exploitation is still less clear. There is a need for a qualitative study to better understand ambidexterity in the context of EMNE. Of particular interest is the relationship between EMNE's acquisition motives and EMNE's process of developing this dynamic capability. Second, it would be thought-provoking to 
empirically examine whether the effects of home country characteristics and hightechnology target industry on control mode choice can be generalized beyond the "SouthNorth” acquisition context, but such study needs a wider sample. In addition, it is possible that even under full acquisitions acquirers still opt for a post-acquisition partial integration, giving larger operational and strategic autonomy to their wholly-owned subsidiaries (Kale \& Singh, 2009). There is thus a need to compare EMNE acquirer's performance under post-acquisition partial integration with other forms of "partnership" approaches such as international joint ventures, or even getting partially acquired by an international acquirer from an advanced economy.

Third, I also did not cover sovereign wealth fund (SWF) acquirers in this study, yet in many cases, governments of the emerging economies use this vehicle to acquire assets in developed economies (e.g., Singapore and the Gulf states). Furthermore, from a target's perspective, another intriguing research question is whether being acquired by an EMNE is superior to being acquired by a purely local acquirer or an acquirer from another advanced country. Last but not least, it is worthwhile to empirically examine the performance implication of other strategic choices made by the EMNE acquirers in their acquisitions of firms in developed economies. These strategic choices include publiclylisted versus private targets, state-owned vs. non-state-owned targets, and so forth.

To sum up, this essay has highlighted some aspects of the value creation process in EMNE's acquisitions of firms in developed economies from a dynamic socio-cultural perspective. Specifically, it has demonstrated that by strategically choosing an appropriate control mode, EMNEs can maximize their learning benefits and value creation, as they are interacting with their acquired targets and host countries. It is 
unique in its approach to concurrently examine drivers of acquirer's control mode choice and the performance implication of the choice, while accounting for potential endogeneity in the choice-making process.

\section{REFERENCES}

Agénor, P. R., Canuto, O., \& Jelenic, M. 2012. Avoiding middle-income growth traps. World Bank-Economic Premise, (98), 1-7.

Anderson, E., \& Gatignon, H. 1986. Modes of foreign entry: A transaction cost analysis and propositions. Journal of International Business Studies, 17(3): 1-26.

Arikan, A. M., \& Capron, L. 2010. Do newly public acquirers benefit or suffer from their pre-IPO affiliations with underwriters and VCs? Strategic Management Journal, 31(12): 1257-1289.

Arrow, K. J., \& Debreu, G. 1954. Existence of an equilibrium for a competitive economy. Econometrica, 22(3): 265-290.

Ashby, W. R. 1960. Design for a brain: The origin of adaptive behavior. New York: Wiley

Aybar, B., \& Ficici, A. 2009. Cross-border acquisitions and firm value: An analysis of emerging-market multinationals. Journal of International Business Studies, 40(8): 1317-1338.

Bacon, G., Beckman, S., Mowery, D., \& Wilson, E. 1994. Managing product definition in high-technology industries: A pilot study. California Management Review, 36(3): 32-56.

Barkema, H., Bell, J., \& Pennings, J. M. E. 1996. Foreign entry, cultural barriers and learning. Strategic Management Journal, 17(2): 151-166.

Baum, J. A., Li, S. X., \& Usher, J. M. 2000. Making the next move: How experiential and vicarious learning shape the locations of chains' acquisitions. Administrative Science Quarterly, 45(4): 766-801.

Beck, U. 1992. Modern society as a risk society. In N. Stehr and Richard V. Ericson (Eds.), The culture and power of knowledge: Inquiries into contemporary societies: 199-214. Berlin: de Gruyter. 
Benner, M. J., \& Tushman, M. L. 2003. Exploitation, exploration, and process management: The productivity dilemma revisited. Academy of Management Review, 28(2): 238-256.

Berry, H., Guillén, M. F., \& Zhou, N. 2010. An institutional approach to cross-national distance. Journal of International Business Studies, 41(9): 1460-1480.

Berry, J. W. 1980. Acculturation as varieties of adaptation. In A. Padilla (Ed.), Acculturation: Theory, models and findings: 9-25. Boulder: Westview.

Bhagat, S., Malhotra, S., \& Zhu, P. 2011. Emerging country cross-border acquisitions: Characteristics, acquirer returns and cross-sectional determinants. Emerging Markets Review, 12(3): 250-271.

Boateng, A., Qian, W., \& Tianle, Y. 2008. Cross-border M\&As by Chinese firms: An analysis of strategic motives and performance. Thunderbird International Business Review, 50(4): 259-270.

Bromiley, P., Govekar, M., \& Marcus, A. 1988. On using event-study methodology in strategic management research. Technovation, 8(1-3): 25-42.

Brown, S. J., \& Warner, J. B. 1985. Using daily stock returns: The case of event studies. Journal of Financial Economics, 14(1): 3-31.

Cadot, O., Carrère, C., \& Strauss-Kahn, V. 2011. Export diversification: What's behind the hump? Review of Economics and Statistics, 93(2): 590-605.

Capron, L., \& Shen, J. C. 2007. Acquisitions of private vs. public firms: Private information, target selection, and acquirer returns. Strategic Management Journal, 28(9): 891-911.

Caves, R. E. 1989. Mergers, takeovers, and economic efficiency: foresight vs. hindsight. International Journal of Industrial Organization, 7(1): 151-174.

Certo, S. T., Busenbark, J. R., Woo, H. S., \& Semadeni, M. 2016. Sample selection bias and Heckman models in strategic management research. Strategic Management Journal, 37(13): 2639-2657.

Chari, M. D., \& Chang, K. 2007. Minority acquisitions as a strategy to mitigate international acquisition risks. In meeting of the Academy of Management, BPS Division, Philadelphia, PA.

Chari, M. D., \& Chang, K. 2009. Determinants of the share of equity sought in crossborder acquisitions. Journal of International Business Studies, 40(8): 1277-1297. 
Chen, G. 2015. Initial compensation of new CEOs hired in turnaround situations.

Strategic Management Journal, 36(12): 1895-1917.

Chen, S. F. S., \& Hennart, J. F. 2004. A hostage theory of joint ventures: why do Japanese investors choose partial over full acquisitions to enter the United States? Journal of Business Research, 57(10): 1126-1134.

Chen, Y. Y., \& Young, M. N. 2010. Cross-border mergers and acquisitions by Chinese listed companies: A principal-principal perspective. Asia Pacific Journal of Management, 27(3): 523-539.

Cogman, D., \& Tan, J. 2010. A lighter touch for post-merger integration. McKinsey Quarterly, 34: 8-12.

Contractor, F. J., Lahiri, S., Elango, B., \& Kundu, S. K. 2014. Institutional, cultural and industry related determinants of ownership choices in emerging market FDI acquisitions. International Business Review, 23(5): 931-941.

Crystal, J. 2003. Unwanted Company: Foreign Investments in American Industries, Ithaca: Cornell University Press.

Dann, L. Y., Mayers, D., \& Raab, R. J. 1977. Trading rules, large blocks and the speed of price adjustment. Journal of Financial Economics, 4(1): 3-22.

Delios, A., \& Beamish, P. W. 2001. Survival and profitability: The roles of experience and intangible assets in foreign subsidiary performance. Academy of Management Journal, 44(5): 1028-1038.

Deng, P. 2010. Absorptive capacity and a failed cross-border M\&A. Management Research Review, 33(7): 673-682.

Desai, A., Kroll, M., \& Wright, P. 2005. Outside board monitoring and the economic outcomes of acquisitions: a test of the substitution hypothesis. Journal of Business Research, 58(7): 926-934.

Deutsche Bank. 2013. China's rising labour cost: Opportunity as well as challenge. 7 March.

Dierickx, I., \& Cool, K. 1989. Asset stock accumulation and sustainability of competitive advantage. Management Science, 35(12): 1504-1511.

Dunning, J. H. 1991. The eclectic paradigm of international production. The Nature of the Transnational Firm, 121. 
Economist. 2012. The middle income trap. 27 March. http://www.economist.com/blogs/graphicdetail/2012/03/focus-3. Accessed 1 April 2013.

Eder, K. 1999. Societies Learn and yet the world is hard to change. European Journal of Social Theory, 2(2): 195-215.

Elango, B., Lahiri, S., \& Kundu, S. K. 2013. How does firm experience and institutional distance impact ownership choice in high-technology acquisitions? $R \& D$ Management, 43(5): 501-516.

Folta, T. B., \& Miller, K. D. 2002. Real options in equity partnerships. Strategic Management Journal, 23(1): 77-88.

Fuller, K., Netter, J., \& Stegemoller, M. 2002. What do returns to acquiring firms tell us? Evidence from firms that make many acquisitions. The Journal of Finance, 57(4): 1763-1793.

Gaffney, N., Karst, R., \& Clampit, J. 2016. Emerging market MNE cross-border acquisition equity participation: The role of economic and knowledge distance. International Business Review, 25(1): 267-275.

Grabowski, R. 2017. Premature deindustrialization and inequality. International Journal of Social Economics, 44(2): 154-168.

Gubbi, S. R., Aulakh, P. S., Ray, S., Sarkar, M. B., \& Chittoor, R. 2010. Do international acquisitions by emerging-economy firms create shareholder value? The case of Indian firms. Journal of International Business Studies, 41(3): 397-418.

Guillén, M. F., \& García-Canal, E. 2009. The American model of the multinational firm and the "new" multinationals from emerging economies. The Academy of Management Perspectives, 23(2): 23-35.

Graebner, M. E., Eisenhardt, K. M., \& Roundy, P. T. 2010. Success and failure in technology acquisitions: Lessons for buyers and sellers. The Academy of Management Perspectives, 24(3): 73-92.

Grossman, S. J., \& Hart, O. D. 1986. The costs and benefits of ownership: A theory of vertical and lateral integration. Journal of Political Economy, 94(4): 691-719.

Gupta, A. K., Smith, K. G., \& Shalley, C. E. 2006. The interplay between exploration and exploitation. Academy of Management Journal, 49(4): 693-706.

Habermas, J. 1979. Communication and the evolution of society. London: Heinemann. 
Hamilton, B. H., \& Nickerson, J. A. 2003. Correcting for endogeneity in strategic management research. Strategic Organization, 1(1): 51-78.

Hannan, M. T., \& Freeman, J. 1987. The ecology of organizational founding: American labor unions, 1836-1985. American Journal of Sociology, 92(4): 910-943.

Hartman, R. S. 1991. A Monte Carlo analysis of alternative estimators in models involving selectivity. Journal of Business \& Economic Statistics, 9(1): 41-49.

Haspeslagh, P. C., \& Jemison, D. B. 1991. Managing acquisitions: Creating value through corporate renewal (Vol. 416). New York: Free Press.

Heckman, J. 1979. Sample selection bias as a specification error. Econometrica 47, 153 162.

Hofstede, G. H., \& Hofstede, G. 2001. Culture's consequences: Comparing values, behaviors, institutions and organizations across nations. London: Sage.

Hymer, S. 1960. On multinational corporations and foreign direct investment. London: Routledge for the United Nations.

Imbs, J., \& Wacziarg, R. 2003. Stages of diversification. The American Economic Review, 93(1): 63-86.

Jakobsen, K., \& Meyer, K. E. 2008. Partial acquisition: The overlooked entry mode. Progress in International Business Research, 2: 203-226.

Jepperson, R. L., \& Swidler, A. 1994. What properties of culture should we measure? Poetics, 22(4): 359-371.

Kale, P., \& Puranam, P. 2004. Choosing equity stakes in technology-sourcing relationships: An integrative framework. California Management Review, 46(3): 77-99.

Kale, P., Singh, H., \& Raman, A. P. 2009. Don’t integrate your acquisitions, partner with them. Harvard Business Review, 87(12): 109-115.

Kennedy, P. 2008. A guide to econometrics. Malden, MA: Blackwell Pub.

Kogut, B., \& Singh, H. 1988. The effect of national culture on the choice of entry mode. Journal of International Business Studies, 19(3): 411-432.

Kohli, R., \& Mann, B. J. S. 2012. Analyzing determinants of value creation in domestic and cross border acquisitions in India. International Business Review, 21(6): 9981016. 
Kvint, V. 2009. The global emerging market: Strategic Management and Economics. New York: Routledge.

Lahiri, S., Elango, B., \& Kundu, S. K. 2014. Cross-border acquisition in services: Comparing ownership choice of developed and emerging economy MNEs in India. Journal of World Business, 49(3): 409-420.

Lokshin, M., \& Sajaia, Z. 2004. Maximum likelihood estimation of endogenous switching regression models. Stata Journal, 4, 282-289.

Lubatkin, M., \& Shrieves, R. E. 1986. Towards reconciliation of market performance measures to strategic management research. Academy of Management Review, 11(3): 497-512.

Luo, Y. 2002. Contract, cooperation, and performance in international joint ventures. Strategic Management Journal, 23(10): 903-919.

Luo, Y., \& Tung, R. L. 2007. International expansion of emerging market enterprises: A springboard perspective. Journal of International Business Studies, 38(4): 481498.

MacKinlay, A. C. 1997. Event studies in economics and finance. Journal of Economic Literature, 35(1): 13-39.

Maddala, G. S. 1983. Limited dependent and qualitative models in econometrics. New York: Cambridge University Press.

Madhok, A., \& Keyhani, M. 2012. Acquisitions as entrepreneurship: asymmetries, opportunities, and the internationalization of multinationals from emerging economies. Global Strategy Journal, 2(1): 26-40.

Mahalanobis, P. C. 1975. On the generalized distance in statistics. Multivariate Statistical Methods: Among-Groups Covariation: 124-130.

Malecki, E. J. 1985. Industrial location and corporate organization in high technology industries. Economic Geography, 61(4): 345-369.

March, J. G. 1991. Exploration and exploitation in organizational learning. Organization Science, 2(1): 71-87.

Masten, S. E. 1993. Transaction costs, mistakes, and performance: Assessing the importance of governance. Managerial and Decision Economics, 14(2): 119-129. 
Masulis, R. W., Wang, C., \& Xie, F. 2009. Agency problems at dual-class companies. The Journal of Finance, 64(4): 1697-1727.

Mathews, J. A. 2002. Dragon multinational: A new model for global growth. Oxford University Press on Demand.

Mathews, J. A. 2006. Dragon multinationals: New players in 21st century globalization. Asia Pacific Journal of Management, 23(1): 5-27.

McWilliams, A., \& Siegel, D. 1997. Event studies in management research: Theoretical and empirical issues. Academy of Management Journal, 40(3): 626-657.

Meyer, K. E. 2015. What is “strategic asset seeking FDI”? The Multinational Business Review, 23(1): 57-66.

Meyer, K. E., Estrin, S., Bhaumik, S. K., \& Peng, M. W. 2009. Institutions, resources, and entry strategies in emerging economies. Strategic Management Journal, 30(1): 61-80.

Mitchell, M. L., \& Netter, J. M. 1989. Triggering the 1987 stock market crash: Antitakeover provisions in the proposed house ways and means tax bill? Journal of Financial Economics, 24(1): 37-68.

Mohrman, S. A., and M. A. Von Glinow. 1990. High technology organizations: a synthesis. Managing Complexity in High Technology Organizations: 278-295.

Morosini, P., Shane, S., \& Singh, H. 1998. National cultural distance and cross-border acquisition performance. Journal of International Business Studies, 29(1): 137158.

Nawata, K. 1993. A note on the estimation of models with sample-selection biases. Economics Letters, 42(1): 15-24.

Ning, L., Kuo, J. M., Strange, R., \& Wang, B. 2014. International investors’ reactions to cross-border acquisitions by emerging market multinationals. International Business Review, 23(4): 811-823.

Ouimet, P. P. 2012. What motivates minority acquisitions? The trade-offs between a partial equity stake and complete integration. Review of Financial Studies, 26(4): 1021-1047.

Park, N. K. 2004. A guide to using event study methods in multi-country settings. Strategic Management Journal, 25(7): 655-668. 
Peng, M. W. 2012. The global strategy of emerging multinationals from China. Global Strategy Journal, 2(2): 97-107.

Piscitello, L., Rabellotti, R., \& Scalera, V. G. 2014. Chinese and Indian acquisitions in Europe: The relationship between motivation and entry mode choice. The Routledge Companion to Merger and Acquisition, London: Routledge.

Porter, M. E. 1990. The competitive advantage of nations. Harvard Business Review, 68(2): 73-93.

Puranam, P., \& Srikanth, K. 2007. What they know vs. what they do: How acquirers leverage technology acquisitions. Strategic Management Journal, 28(8): 805-825.

Puranam, P., Singh, H., \& Chaudhuri, S. 2009. Integrating acquired capabilities: When structural integration is (un) necessary. Organization Science, 20(2): 313-328.

Raisch, S., Birkinshaw, J., Probst, G., \& Tushman, M. L. 2009. Organizational ambidexterity: Balancing exploitation and exploration for sustained performance. Organization Science, 20(4): 685-695.

Ramamurti, R. 2012. What is really different about emerging market multinationals? Global Strategy Journal, 2(1): 41-47.

Ranft, A. L., \& Lord, M. D. 2002. Acquiring new technologies and capabilities: A grounded model of acquisition implementation. Organization Science, 13(4): 420441.

Rugman, A. M. 2009. Theoretical aspects of MNEs from emerging economies. In R. Ramamurti (Ed.), Emerging multinationals in emerging markets: 42-63. Cambridge, UK: Cambridge University Press.

Sabatier, P. A., \& Jenkins-Smith, H. 1993. Policy change and learning: An advocacy coalition framework. Boulder: Westview.

Schott, P. K. 2003. One size fits all? Heckscher-Ohlin specialization in global production. The American Economic Review, 93(3): 686-708.

Schott, P. K. 2004. Across-product versus within-product specialization in international trade. The Quarterly Journal of Economics, 119(2): 647-678.

Sethi, S. P., \& Elango, B. 2000. The influence of “country of origin” on multinational corporation global strategy: A conceptual framework. Journal of International Management, 5(4): 285-298. 
Shaver, J. M. 1998. Accounting for endogeneity when assessing strategy performance: does entry mode choice affect FDI survival? Management Science, 44(4): 571585 .

Stahl, G. K., Björkman, I., \& Vaara, E. E. R. O. 2004. National cultural differences and capability transfer in cross-border acquisitions. In Academy of Management Conference, New Orleans.

Stahl, G. K., \& Voigt, A. 2005. Impact of cultural differences on merger and acquisition performance: A critical research review and an integrative model. In Advances in mergers and acquisitions: 51-82. Emerald Group Publishing Limited.

Stolzenberg, R. M., \& Relles, D. A. 1990. Theory testing in a world of constrained research design: The significance of Heckman's censored sampling bias correction for nonexperimental research. Sociological Methods \& Research, 18(4): 395-415.

Teece, D. J. 2014. A dynamic capabilities-based entrepreneurial theory of the multinational enterprise. Journal of International Business Studies, 45(1): 8-37.

Thomas, D. E., Eden, L., Hitt, M. A., \& Miller, S. R. 2007. Experience of emerging market firms: The role of cognitive bias in developed market entry and survival. Management International Review, 47(6): 845-867.

Time. 2013. Can China escape the middle income trap? 12 March. http://business.time.com/2013/03/12/can -china-escape-the-middle-income-trap/. Accessed 1 April 2013.

Very, P., Lubatkin, M., Calori, R., \& Veiga, J. 1997. Relative standing and the performance of recently acquired European firms. Strategic Management Journal, 593-614.

White, H. 1980. Using least squares to approximate unknown regression functions. International Economic Review, 21(1): 149-170.

Williamson, O. E. 1975. Markets and hierarchies: antitrust analysis and implications. New York: The Free Pres.

Williamson, P. J., \& Zeng, M. 2009. Chinese multinationals: Emerging through new global gateways. Emerging multinationals in emerging markets, 81-109.

Wooldridge, J. M. 2015. Introductory econometrics: A modern approach. Nelson Education.

World Bank. 2017. World development indicators. http:// data.worldbank.org/datacatalog/world-development-indicators. Accessed 10 July 2017. 
World Trade Organization. 2013. Statistics database. http://stat.wto.org. Accessed 4 February 2013.

Wright, P., Ferris, S. P., Hiller, J. S., \& Kroll, M. 1995. Competitiveness through management of diversity: Effects on stock price valuation. Academy of Management Journal, 38(1): 272-287.

Wright, M., Filatotchev, I., Hoskisson, R. E., \& Peng, M. W. 2005. Strategy research in emerging economies: Challenging the conventional wisdom. Journal of Management Studies, 42(1): 1-33.

Wu, C., \& Xie, N. 2010. Determinants of cross-border merger \& acquisition performance of Chinese enterprises. Procedia-Social and Behavioral Sciences, 2(5): 68966905.

Yang, M. 2015. Ownership participation of cross-border mergers and acquisitions by emerging market firms: antecedents and performance. Management Decision, 53(1): 221-246.

Yelle, L. E. 1979. The learning curve: Historical review and comprehensive survey. Decision Sciences, 10(2): 302-328.

Zaheer, S. 1995. Overcoming the liability of foreignness. Academy of Management Journal, 38(2): 341-363.

Zheng, N., Wei, Y., Zhang, Y., \& Yang, J. 2016. In search of strategic assets through cross-border merger and acquisitions: Evidence from Chinese multinational enterprises in developed economies. International Business Review, 25(1): 177186.

Zuehlke, T. W., \& Zeman, A. R. 1991. A comparison of two-stage estimators of censored regression models. The Review of Economics and Statistics, 185-188. 


\section{Essay 3. Sources of Value Creation in Emerging Multinational Enterprises' Partial Acquisitions of Firms in High-Income Economies: A Target's Perspective}

\section{INTRODUCTION}

Since Harvard Business Review published Richard Hexter’s “How to sell your company” and William Rockwell, Jr.’s “How to acquire a company” in its September 1968 issue, most researchers in the merger and acquisition (M\&A) literature have primarily built their theories on the buyer's perspective, focusing on which firms make attractive targets given certain buyer motivations and characteristics (Dalziel, 2008). Despite Hexter’s warning about the importance of addressing the imbalance between the buyer's and seller’s perspectives if the M\&A activities are to result in economic sense, very few studies in the strategic management literature have approached acquisitions from the lens of the seller. Graebner and Eisenhardt (2004) is a notable exception. Using a qualitative case study of high technology acquisitions, they developed the seller's side of the M\&A story, in which the relationship between buyer and seller is viewed as more of a “courtship,” rather than "takeovers of the desperate targets,” where both buyer and seller make choices based on strategic considerations.

Between 1990 and 2016 Emerging Multinational Enterprises (EMNEs)’s acquisitions in developed economies reached \$1.9 trillion, involving 28,073 deals. About 26.8 percent of these deals were partial sales where the original shareholders of the target firm sell part of their stakes and retain some controlling majority or non-controlling 
minority shares after the acquisition ${ }^{7}$. EMNE's partial acquisitions of firms in advanced economies have a great deal of resemblance with technology acquisitions in a purely domestic setting. Similar to acquirers in technology acquisitions, the acquiring EMNE typically needs valuable sophisticated technologies, brands and/or managerial know-how from their targets in developed countries for immediate exploitation in the EMNEs' home or regional markets (Stucchi, 2012). Moreover, similar to the target firms in technology acquisitions, the target firms in EMNE's acquisitions in developed economies choose offers from bidder(s) not merely based on bid prices, but also strategic consideration, evaluating how the bidder's resources will affect their post-acquisition configuration of resources. Of course, the target firms always reserve the right to reject the bid offer, stay independent, and continue their businesses as usual (Graebner, Eisenhardt, \& Roundy, 2010).

This essay focuses on the perspective of the target firm to examine the sources of value creation for target shareholders in the partial sales of firms in developed economies. What are the factors that create value in target firms? What valuable characteristics should a firm in a developed economy be looking for in itself as well as its prospective EMNE acquirer? To address these research questions, I extend the idea of collective learning from the dynamic socio-cultural model (DSCM) in Essay 1 and complement it with insights from organizational learning (March, 1991) and M\&A seller’s view (Graebner \& Eisenhardt, 2004) literature. I argue that in EMNE's partial acquisitions of firms in high-income markets, the target firms do not choose their acquirer simply based on who offers the highest bid price, but they strategically consider resources that they

\footnotetext{
${ }^{7}$ Acquisition data were retrieved from Thomson One database on June 14, 2017.
} 
already possess and choose certain acquirers' characteristics to optimize their postacquisition learning and value creation. Specifically, I argue that target's prior presence in acquirer's home market, target's post-acquisition control, target's international experience, and target-acquirer industry relatedness are positively related to postacquisition target performance. Moreover, I argue that acquirer's state-owned status and the cultural distance between acquirer's home and target's home countries are negatively related to post-acquisition target performance. I also argue that the negative effect of cultural distance on post-acquisition target performance is positively moderated by target's international experience and negatively moderated by EMNE acquirer's stateowned status.

I begin the next section with a review of relevant literature and a discussion of the selected research setting, which provides a basis for developing testable hypotheses in the subsequent section. In the following section, I outline the methodology employed in this study, including the data which were used to test the hypotheses. I then present results from statistical analyses in the discussion section. The concluding section provides a summary and some theoretical and practical implications that can be drawn from the study, along with research issues and limitations that still need to be addressed in future research.

I highlight here the fact that this study is unique in its focus on understanding the EMNE's cross-border partial acquisitions in developed countries from a target's viewpoint. It expands a previous conceptual paper from Buckley, Elia, and Kafauros (2010) on the determinants of post-acquisition target performance in EMNE's acquisitions of firms in advanced countries, by providing relevant empirical examination. 
To the best of my knowledge, this study is the first empirical investigation on the sources of value creation for target firms in the "South-North" cross-border partial acquisition context. From a practical perspective, it provides useful insights for executives of prospective target firms in high-income economies in strategically evaluating bids from prospective EMNE acquirers, based on a sophisticated cultural lens, often used by the acquirer but rarely discussed from the perspective of the target.

\section{LITERATURE REVIEW}

This essay views EMNE’s acquisitions in developed economies from a target's perspective. Most M\&A studies have been based on a more traditional view of corporate acquisitions, in which the acquiring firm is perceived as the key decision maker, and the target firm is relatively weak and unimportant. The target firm often views the acquisition as an organizational death, and hence focuses its effort on maximizing takeover premiums (Graebner \& Eisenhardt, 2004). While this view may be quite applicable when the target is a low-performing company with only tangible resources, it is certainly of limited value when the target is a high-performing company with embedded tacit knowledge resources (Graebner, Eisenhardt, \& Roundy, 2010), such as targeted firms in EMNE's acquisitions in developed economies. In the latter case, it is more reasonable to view the acquirer-target relationship as more of a "courtship” rather than a takeover, where both acquiring and target firms are key decision makers who are equally strong and important (Graebner \& Eisenhardt, 2004).

Through this lens an acquisition is not viewed as a process where target firms are simply reactive and price-driven (Zeng, Douglas \& Wu, 2013), but as a process of mutual 
agreement between acquiring firm and target firm encompassing strategic considerations and cultural fit issues, which are more than just financial consideration (Graebner \& Eisenhardt, 2004). This perspective suggests that the target firm also considers the acquisition as a strategic means to access the acquirer's resources (Inkpen, Sundaram, \& Rockwood, 2000). In partial acquisitions where the acquirer allows the target to retain partial ownership and/or operational autonomy after the acquisition, the target firm's strategic consideration makes even more sense, which in turn influences the target's preferences for a specific acquirer in a way that the target prefers an acquirer who possesses resources needed to make the target successful, even after it is acquired (Dalziel, 2008). While the M\&A research has focused more on acquiring firms than target firms (Haleblian, et al., 2009), several empirical works have examined the postacquisition performance of target firms. These studies have focused on several target performance indicators, including profit and productive efficiency (Bertrand \& Zitouna, 2008), failure rate (Li \& Guisinger, 1991), survival rate (Shaver, 1998; Vermeulen \& Barkema, 2001), and cumulative abnormal returns (Harris \& Ravenscraft, 1991; Kang, 1993; Mann \& Kohli, 2011). Target shareholders generally benefitted and often experienced significant positive returns (Datta, Pinches, \& Narayanan, 1992).

Among studies that have closely examined aspects of target firm survival or failure, Capron, Dussauge, and Mitchell (1998) show that targets and acquirers frequently redeploy resources following horizontal acquisitions, especially resources that frequently face market failure. Other works have focused on determinants of firms' survival, which include greater business scale and scope (Bercovitz \& Mitchell, 2007) and the founding conditions of the target firm (Geroski, Mata, \& Portugal, 2010). Li (1995) shows a higher 
exit rate for foreign acquisitions and joint ventures than subsidiaries established through greenfield investments. The results also indicate a higher exit rate for subsidiaries that diversify than for those that stay in the parent firm's main product areas.

\section{EMNEs' cross-border acquisitions and North American markets for corporate control}

From a target firm's perspective, the partial sale of ownership shares to an EMNE acquirer opens access to acquirer's home market and, possibly, acquirer's regional markets. Foreign direct investment (FDI) inflow to developing economies rose significantly from $\$ 34.7$ billion in 1990 to $\$ 714.1$ billion in 2016 , substantially increasing its share in world's total FDI from 16.9 percent to 40.9 percent for the same period (UNCTAD, 2017). The sizable and fast growing emerging markets have become hot destinations for FDI of multinational enterprises (MNE) from developed economies.

Traditionally, multinational enterprises (MNE) from developed economies enter emerging markets by exploiting their superior ownership advantage in brand, technology, and managerial know-how (Hymer, 1976). In addition to greenfield investment and wholly-owned acquisition, many MNEs enter emerging markets via a hybrid approach by forming an international joint venture with local firms or by partially acquiring local firms in the host countries (Chen \& Hennart, 2004) to reduce risks and offset liabilities of foreignness (Zaheer, 1995). Accordingly, for a prospective target firm in a developed economy, the partial sale of its shares to an EMNE acquirer provides another avenue to tap the large and rapidly growing emerging markets via a hybrid approach, suggesting the decision of a firm in a developed economy to be acquired by an EMNE might be strategic 
rather just purely financial based on the highest bid price. This is especially true in partial acquisitions where the target original shareholders still retain partial ownership after the acquisition is completed.

Despite the phenomenal acquisition activities of EMNEs in the last two decades, very few studies have empirically examined the sources of value creation for the target firms in the context of EMNE's international acquisitions in developed economies. There are notable exceptions. Based on case study and interview data from Chinese acquisitions of German firms in the machinery and equipment industry, Knoerich (2010) argued that the German firms are willing to be acquired by Chinese acquirers because they can gain substantially from the deal due to complementarities in the acquisition motives of both parties (i.e., market-seeking versus strategic-asset-seeking), as well as the underlying strategic needs of both firms. Using an organizational learning perspective, Rabiosi, Elia, and Batoni (2012) found that EMNEs enter developed markets incrementally in order to offset liability of foreignness and choose whether to pursue exploratory or exploitive acquisition, but the study did not examine the performance implication of the strategic choices the EMNEs make.

Based on a sample from acquisitions of publicly-listed firms in the United States between 1979 and 2006, Chen (2011) found acquisitions made by EMNEs tend to increase target profitability, but decease target sales, employment and labor productivity, compared with those made by domestic acquirers or acquirers from other developed economies. Similarly, using a sample from acquisitions of publicly-listed U.S, firms from 1980 to 2006, Chari, Chen and Dominguez (2012) showed the profitability of U.S. firms acquired by EMNE increases, but sales and employment decline in the years following 
the acquisitions, compared with those of matched non-acquired U.S. firms. Both Chen (2011) and Chari et al. (2012), however, stopped short of cross-sectionally examining the sources of target value creation. Utilizing the resource-based theory, Buckley et al. (2010) proposed that both the resources of the target firm in the developed economy and the resources of the EMNE acquirer influence post-acquisition target performance. They further theorized for several determinants of post-acquisition target performance, but performed no empirical test.

In this essay, I focus my empirical investigation on EMNE's partial acquisitions of firms in the United States and Canada. I define an EMNE as a firm whose ultimate parent has a headquarters located in a developing economy. From an empirical standpoint, EMNE's acquisitions in a relatively homogenous North American market provide a unique research setting for examining post-acquisition target firm's value creation. Many EMNEs preserve the identity of foreign firms they have taken over by not operationally integrating them into the parent companies (Kale, Singh, \& Raman, 2009), so data on the target firms are more publicly available compared to cases where firms immediately integrate their acquired targets. I will develop my hypotheses in the next section before discussing my methodology in the subsequent section.

\section{THEORETICAL DEVELOPMENT AND HYPOTHESES}

In Essay 1 I proposed the Dynamic Socio-cultural Model (DSCM) as a generalized perspective on cultural change and creation. The DSCM views an organization as a form of social system. Every social system has cultural resources whose elements include knowledge, values, norms, beliefs, custom, law, language, art, concepts of good and evil, 
tools, technologies, and artifacts (Japperson \& Swidler, 1994). When an EMNE acquires a target firm in a developed country, the DSCM views it as a cultural event comparable to a "marriage" between two firms, in which two social systems bring their distinctive cultural resources and are interacting with each other (Habermas, 1979). Such cultural events involve uncertainty, and the social systems have to reorganize their rules for dealing with uncertainty to survive (Eder, 1999). In modern times uncertainty is inherent in any social system, and interacting individuals within social systems must continuously and collectively learn new rules to survive (Beck, 1992; Sabatier \& Jenkin-Smith, 1993). When an EMNE takes over a target in a developed country, the contacts between the EMNE and the host country, and between the EMNE and the acquired target, change social interactions and bring about uncertainties to the EMNE as well as the acquired target. These uncertainties yield not only risks, but also opportunities for creating new shared cultures for the EMNE and the acquired target, because these risks incentivize the interacting social systems for further collective learning, which generates new shared culture and modifies the cultural resources of the acquirer and the target's organizations.

From a DSCM perspective, the collective learning process modifies existing shared knowledge resources of the interacting social systems, producing novel knowledge in both the EMNE acquirer and the acquired target. Eder (1999) argued that there are two types of collective learning process that yield two different types of shared knowledge, namely, substantive learning and social rule learning. At an organizational level, the concepts of substantive learning and social rule learning are comparable to the idea of exploitation and exploration in the organizational learning literature. Exploitation is a learning process that refines and extends the organization's existing competencies, 
technologies and ways of thinking with relatively proximate, predictable and positive economic returns. This includes activities such as refinement, selection, and/or implementation of existing techniques, choice, production methods, efficiency, etc. Exploration, on the other hand, is a learning process that involves experimentation with new alternatives characterized by relatively uncertain, distant and (often) negative economic returns, which includes activities such as searching for novel ideas, markets, relations, etc. (March, 1991).

All organizational activities always involve some learning, even in mere replication of past actions (Yelle, 1979). Moreover, learning always involves the twin processes of exploration and exploitation (Gupta, Smith, \& Shalley, 2006). To survive and succeed, organizations rely on organizational ambidexterity, which is a dynamic capability to simultaneously and synchronously pursue both exploitation and exploration, with the actual composition between the two possibly different across cases and over time (Benner \& Tushman, 2003). As argued in Essay 2, EMNE’s investment interests in developed economies are more exploration-oriented. By contrast, the target firm’s investment interests in the EMNE's home market are more exploitation-oriented, because target firms in developed economies typically have firm-specific advantages (FSA) relative to their EMNE acquirers in terms of superior technologies, brand and managerial know-how. Thus, it is reasonable to expect that EMNE's collective learning activities in advanced economies are more likely to be exploration-dominant while the target firm's collective learning activities in the EMNE acquirer's home market are more likely to be exploitation-dominant. 


\section{Post-acquisition target performance}

In EMNEs’ partial acquisitions of firms in developed economies, original target shareholders are likely to enjoy a positive return after the acquisition. The domestic M\&A finance literature suggests that the target's shareholders enjoy a positive return after the acquisition (Datta, Narayanan, \& Pinches, 1992). Similarly, general cross-border acquisition literature shows a positive post-acquisition target performance (e.g., Cebenoyan, Papaioannou, \& Travlos, 1992; Danbolt, 2004; Danbolt \& Maciver, 2012). Rare studies with "South-North” cross-border acquisitions context also found that acquisitions of U.S. target firms by EMNEs generate positive returns for target shareholders (Chari et al. (2012) and Chen (2011). There are certain advantages unique to the "South-North" international acquisition context that lead to a more enhanced value creation for the original target shareholders in advanced countries.

First, given the target firm's investment interest in developing economies is likely to be exploitation-dominant, the EMNE acquirer's large and rapidly growing home markets provide more lucrative exploitation opportunities for the target firms, compared with the relatively slow growing domestic or other developed markets. This is especially true if target firms' product and services have matured or saturated in their home or other sophisticated high-income markets, eroding target firms' profitability. The access to the huge and expanding home markets brought by the acquiring EMNE is a unique advantage that target firms in developed countries do not enjoy when they are acquired by purely domestic or non-EMNE foreign firms (Knoerich, 2010).

Secondly, the extensive operation and experience the EMNE acquirers have in their own sizable and fast-growing home markets, and perhaps also in other developing 
economies (Rugman, 2009), are a distinctive advantage possessed by EMNEs often neglected in analyses. EMNEs' particular advantages in these emerging markets include deep understanding of customer needs, ability to operate in difficult business environments, and ability to make products and services at ultra-low costs (CuervoCazurra \& Genc, 2008; Govindarajan \& Ramamurti, 2011; Guillen \& Garcia-Canal, 2009). When EMNEs engage in partial acquisitions of firms in developed countries, target firms view these advantages as valuable resources and capabilities they can tap for penetrating the EMNE's home markets. After being partially acquired, the target firms in developed economies can indeed exploit their technologies, brand, and managerial knowhow in EMNE’s home and regional markets (Ramamurti, 2012), generating more synergistic benefits, compared with those found in pure domestic or cross-border acquisitions involving non-EMNE acquirers. I thus posit

Hypothesis 1: In EMNEs' partial acquisitions of firms in developed economies, the mean of post-acquisition target performance is positive.

\section{Target's prior presence in acquirer's home market}

Target firm's lack of operational presence in its EMNE acquirer's home market prior to the acquisition creates value for the target, because the acquisition allows the target firm to expand into previously inaccessible market segments and production cost structures (Knoerich, 2010). When a target firm from an advanced economy is partially acquired by an EMNE, the target joins a superior network of resources and capabilities that the EMNE uniquely possesses in its home market. The value created from the EMNE acquirer's home country's network is especially substantial when the target had no such 
unique network before the acquisition (Buckley et al., 2010), because the partial sale of ownership to the EMNE acquirer enables the target firm to utilize tangible as well as intangible resources that it did not previously own or control (Capron, 1999; Uhlenbruck, 2004)

While the target firm clearly owns sustainable advantages in technology, brand and management, its EMNE acquirer has a distinctive advantage in the understanding of its own market as a system of relationships among customers, suppliers, competitors and private and public support agencies (Coviello \& Munro, 1995). Historical exposure to their home markets enables the EMNE to accumulate a unique and hard-to-imitate expertise based on its experiential network knowledge. This type of knowledge is rich in detail and contains both codified and non-codified pieces of knowledge as well as cognitive and affective pieces of knowledge (Hohenthal, Johanson, \& Johanson, 2014), generating a value-creating network effect for the target firm. In more concrete terms, the locally-knowledgeable EMNE acquirer can help the target firm to learn faster how to operate successful in the EMNE's home market (and perhaps also the EMNE's regional markets). Similarly, the EMNE acquirer can help the target firm set up production facilities in the EMNE's home market to reduce cost and broaden market segments (Knoerich, 2010; Knoerich, 2016).

While the prior experience in acquirer's home market may make post-acquisition integration easier, in partial-acquisition cases the need for post-acquisition integration is not as critical as in full-acquisition cases. This is especially true in the "South-North" international partial acquisition context, where the investment interest of the target firms in the acquirer's home market is primarily exploitation-dominant, leveraging their 
superior technologies, brand and management, which probably may be maturing in their home bases, but still growing in the acquirer's home markets. Thus, in EMNE's acquisitions of firms in developed economies, the benefit from target's prior experience in the acquirer's home market is outweighed by the benefit that the target enjoys from entering for the first time a completely new and fast growing market, which is large and far from being saturated. I thus posit

Hypothesis 2: In an EMNE's partial acquisition of a firm in a developed economy, the target firm's operational non-presence in the acquirer's home market prior to the acquisition is positively related to post-acquisition target performance.

\section{Target's post-acquisition control}

When a firm in an advanced economy is partially acquired by an EMNE, retaining a controlling majority in the target ownership after the acquisition creates value for target shareholders. As discussed earlier, all organizational activities always involve learning, and all learning is simultaneously composed of some amount of exploitation and exploration processes (Gupta, Smith, \& Shalley, 2006). While EMNEs’ investment interest in the advanced economy is likely to be exploration-dominant, the target firm's interest in the EMNE acquirer's home market is likely to be exploitation-dominant. There are benefits associated with target shareholders maintaining post-acquisition majority ownership, which are indeed conducive for exploitation-dominant investment. Retaining a controlling majority interest after the acquisition allows the target to have the upperhand in the process of combining common procedures, common goals and common 
governance between the acquirer and the target (Hapeslagh \& Jemison, 1991), to ensure that the appropriation of value created by the efficiency in the overhead cost is consistent with the target's exploitation-dominant interest in the EMNE acquirer's home market. Furthermore, maintaining post-acquisition majority ownership provides the target with voting power and maximized benefits from the growth of the acquired company.

Results from Essay 2 suggest that EMNE's non-controlling minority acquisitions of targets in advanced countries induce more cooperative attitude from acquired targets' original owners, top management teams and employees (Madhok \& Keyhani, 2012) that facilitates a more effective transfer of tacit knowledge (Ranft \& Lord, 2002), which EMNEs desperately need from their acquired targets for their exploration-dominant investment in developed economies. EMNEs' non-controlling minority interest after the acquisition implies the target's post-acquisition controlling majority interest, suggesting a high level of complementarity in EMNEs' acquisition of firms in developed economies. I thus posit

Hypothesis 3: In an EMNE's partial acquisition of a firm in a developed economy, the target firm's post-acquisition control is positively related to postacquisition target performance.

\section{Target's international experience}

In an EMNE's partial acquisition of a firm in a developed country, the target firm's operational experience in international market(s) prior to the acquisition, even when it is not in the acquirer's home country or other emerging markets, creates value for the target firm. From a DSCM perspective, such international experience brings more repertoires to 
the cultural resources of targets, from which the targets can select and combine differing pieces to attain their goals, as they enter and operate in the acquirers' home and/or regional markets after the acquisition.

The dramaturgy idea outlined in Essay 1 suggests “back-stage” activities prepare actors for role playing in the "front-stage.” The international experience the target had before the acquisition provided the target with an opportunity for a "back-stage" rehearsal that helps bring improved performance in many areas of its operation, as the target enters the EMNE acquirer's home market. Although the EMNE acquirer's home country may not be institutionally and economically similar to the countries where the target operated prior to the acquisition, the resources and capabilities that the target was able to accumulate in these countries can come in handy and be redeployed to their "active cultural resources" when necessary during the target's future operation in the acquirer's home country.

Although these prior international operations might not be held in the acquirer's home market, the target experience in exploiting its firm-specific advantages (FSAs) outside its home-country setting should still prove valuable for its post-acquisition exploitation-dominant investment in the EMNE acquirer's home country. Concrete exploitation-related benefits from target's general international operation that can somewhat be extended, replicated, and/or redeployed by the target to the specific EMNE acquirer's home market include: economies of scale and scope (Caves, 1996), revenue source diversification to lower risks from revenue fluctuations (Kim, Hwang, Burgers, 1993), and lower costs and higher revenues through increased market power over suppliers, distributors, and customers (Kogut, 1985). From a DSCM view, the target's 
prior experience in various diverse international markets expand the target's cultural resources and provides the target with more possibilities for recombination and reconfiguration of locational-specific advantages of these countries (e.g., country-specific factor endowments, market share and familiarity) with the resources of the EMNE acquirer's home country (e.g., natural resources/raw materials, low labor costs) for future exploitation in the EMNE acquirer's home market as well as other emerging markets (Altaf \& Shah, 2015; Lu \& Beamish, 2004). I thus posit Hypothesis 4: In an EMNE's partial acquisition of a firm in a developed economy, the target firm's international experience is positively related to postacquisition target performance.

\section{EMNE acquirer's state-owned status}

In EMNE's partial acquisitions of firms in developed economies, being acquired by a state-owned EMNE is likely to destroy target firm's value after the acquisition. From a DSCM perspective, a partial acquisition causes the two social systems (i.e., the acquirer and the target) to engage in adaptive interaction and collective learning to create a new shared culture that will expand the cultural resources in each of the two organizations. This collective learning creates value for both the target firms and their EMNE acquirers, but it requires a cooperative attitude from both the acquirer and the target. For the target firm, investment in EMNE's emerging home market is likely to be more exploitationdominant where EMNE's familiarity with local customers and local suppliers of low-cost production factors (e.g., labor, raw materials, energy, etc.) are valuable and could provide the target with synergistic benefits. However, a state-owned EMNE may lack the 
incentive for a cooperative attitude with its target, hampering the value creation for the target, especially in the partial acquisition context where the original target shareholders still retain partial ownership after the acquisition.

The state-owned EMNE's disincentive to wholeheartedly cooperate with its target primarily stems from the “Principal-Principal” problem (Lien, Piesse, Strange, \& Filatotchev, 2005) where conflicts of interest occur between principal shareholders after the acquisition (i.e., the state-owned EMNE and the original target shareholders). In going international, the state-owned EMNE acquirer might be more interested in less concrete non-business objectives, rather than improving firm performance through business activities that create economic value, as typically demonstrated by private sector companies. For instance, many state-owned enterprises in emerging economies carry a mandate from their government to achieve economic security goals whose economic viability often have to be measured by social returns rather than private returns (Chen \& Young, 2010). Others are driven purely by country nationalism and pride that does not make economic sense at all (Cuervo-Cazurra, Inkpen, Musacchio, \& Ramaswamy, 2014). Some state-owned EMNE acquirers with post-acquisition majority shares in their targets might also over-explore and end up “milking” the targets by bringing home strategic resources while abandoning their acquired targets in the developed economies (Bebenroth \& Hemmert, 2013).

The state-owned status of the EMNE might also lead to a value destruction for the target when it becomes a source of illegitimacy in the target’s home country. In fact, state-owned EMNE acquirers may be discriminated against by the host government and society in general. The EMNE's link to their home governments may be perceived as a 
threat to the hosts' national security and interests, especially when they acquire firms in strategic industries such as natural resources, utilities, infrastructure, and so forth (Globerman \& Shapiro, 2009), where acquisitions by foreign state-owned firm are often viewed as an instrument of another government aiming to exercise control in the host country economy (Cuervo-Cazurra, et al., 2014). This negative sentiment could escalate and might disrupt target firms’ relationships with their existing suppliers and customers in their home countries.

EMNE's state-owned status could also be detrimental to post-acquisition target performance due to the EMNE's lack of good governance and accounting transparency (Jory \& Ngo, 2014), making adaptive interaction and collective learning on the acquirer's home market rather challenging. Traditionally, state-owned enterprises have been viewed as inefficient, bureaucratic organizations that strategically mismanage their resources (Megginson \& Netter, 2001; Arocena\&Oliveros, 2012), where post-acquisition valuedestuctive interference from government patrons can be frequent (Uhlenbruck \& de Castro, 2000). Moreover, state-owned enterprises are often associated with a lack of accounting transparency, characterized by window dressing and unreliable data (Jory \& Ngo 2014). While the target firm's collective learning activity on the EMNE acquirer's home market is exploitation-dominant rather than exploration-dominant, involving more codified rather than tacit knowledge, the adaptive interaction remains challenging in the absence of good governance and accounting transparency within the state-owned EMNE acquirer's organization.

Some research has argued that EMNEs with strong connection to their home country governments create value for their targets based on the following reasons. First, 
state-owned EMNEs are more likely to pay higher acquisition premiums, especially in exploration-oriented acquisitions such as in their partial acquisitions of targets in advanced economies (Bass \& Chakrabarbarty, 2014). Second, the host country’s institutional void is something that target firms from advanced economies face in emerging markets (Khanna \& Palepu, 1997), and therefore, sharing ownership with a state-owned or government-related EMNE can reduce some of the risk and uncertainties associated with the institutional void (Okhmatovskiy, 2010) by providing the target firms with opportunities for influencing regulatory policies in acquirers' home markets (Hillman, Keim, \& Schuler, 2004), enhancing firms’ legitimacy (Baum \& Oliver, 1991), benefiting from preferential treatment (Fisman, 2001; Johnson and Mitton, 2003), and from receiving exclusive information regarding state policies (Lester, Hillman, Zardkoohi, \& Cannella, 2008).

Third, being acquired by a state-owned EMNE may facilitate targets' access to valuable resources controlled by the state (Xin \& Pearce, 1996), which include unique assets that the government is reluctant to privatize such as communication and transportation networks, natural resources, and so forth (Okhmatovskiy, 2010). Finally, in many developing countries, state-owned enterprises act as large customers that purchase products and services from privately owned businesses (Toninelli, 2000). Nonetheless, I argue that overall in the long-run these potential state-ownership advantages will be more than offset by the costs that came from the acquirer's less cooperative attitude, acquirer's lack of legitimacy in host advanced market, and acquirer's lack of transparency and good governance, as previously discussed. I thus posit 
Hypothesis 5: In an EMNE's partial acquisition of a firm in a developed economy, the acquirer's state-owned or government-elated status is negatively related to post-acquisition target performance

\section{Industry relatedness}

In EMNEs' partial acquisitions of firms in developed economies, the relatedness between the acquirer's industry and the target's industry positively influences post-acquisition target performance. Related acquisitions are associated with enhanced economies of scale, economies, scope and market power (Dutz, 1989; Capron, Dussauge, \& Mitchell, 1998), while unrelated acquisitions are known to generate diverse new resources that allow involved firms to access routines that can improve post-acquisition performance through a higher level of synergies among resources (Morosini, Shane, \& Singh, 1998). Unlike EMNE's investment in advanced economies that are likely to be explorationdominant characterized by a strategic-asset-seeking motive, the target firms' interest in their acquirer's home markets are likely to be exploitation-dominant characterized by a market-seeking motive, which is also more compatible with related acquisitions and has the potential to create value for the targets.

For instance, EMNE acquirer and target in a developed economy that are operating in the same industries may share a similar corporate culture and management styles, which in turn may help the target in recombining their resources with those of the acquirer to achieve economies of scale and economies of scope, and reap the benefits from vertical integration and expanded market power through reduced post-acquisition conflicts and frictions (Chatterjee, Lubatkin, Schweiger, \& Weber, 1992; Datta et al., 
1992). While unrelated acquisition may generate benefits to exploration-dominant learning, in target's exploitation-dominant learning, these benefits are likely to be outweighed by the gains from related acquisitions (Buckley et al, 2010; Singh \& Montgomery, 1987; Ramaswamy, 1997). I thus posit

Hypothesis 6: In an EMNE's partial acquisition of a firm in a developed economy, the industry relatedness between the acquirer and the target firm is positively related to post-acquisition target performance.

\section{Moderation effects}

In EMNE's partial acquisition of a firm in a developed economy, the target firm's prior experience in international markets other than acquirer's home market prior can help attenuate the negative effect that the cultural distance may exert on post-acquisition target performance. The negative effective effect of cultural distance (CD) on post-acquisition target performance is well-established (e.g., Buono, Bowditch, \& Lewis 1985; Jemison \& Sitkin, 1986; Datta, 1991; Chatterjee et al., 1992; Cartwright and Cooper, 1993;

Berkema, Bell, \& Pennings, 1996; Weber, Shenkar, \& Raveh, 1996; Krug \& Hegarty, 2001). The negative effect of CD on post-acquisition target performance primarily stems from poor communication quality and lack of mutual trust between the target and the acquirer, which makes collective learning more difficult and impedes the post-acquisition integration process (Li, Li, \& Wang, 2016). Although high CD between target's and acquirer's home countries may provide potential learning-related benefits such as more routines and repertoires that can lead to more creative decision-making and problemsolving (Morosini, et al., 1998; Reus \& Lamont, 2009), these benefits are more relevant 
in exploration-dominant ventures and are less useful in the exploitation-dominant interest that firms from developed economies have in their EMNE acquirers' home markets, where the targets are primarily looking to exploit existing firm-specific advantages.

As discussed earlier, from a DSCM perspective, target firms' international experience bring more repertoires to the cultural resources of targets, even when this international experience was not obtained in the EMNE acquirer's home country. The larger the cultural resources, the more diverse the cultural elements are, and that implies a larger target firms' collective learning capacity, as there is a higher probability for one or more of the cultural elements within the target firms' cultural resources to be complementary with those of the EMNE acquirer's cultural resources, making it more likely for successful collective learning between the EMNE acquirer and the target firm. For example, if a U.S. target firm had an international experience somewhere else before being acquired by a Chinese EMNE, even if that experience was in another developed country, that experience will still be helpful for the target in its future collective learning with its Chinese partner to produce new shared culture, since the process of role redefinitions and role playing within the U.S, firm will be less challenging and more time-efficient than if it had no previous international experience at all.

Target firms' larger collective learning capacity may then offset the initial negative effect of the $\mathrm{CD}$ on post-acquisition target performance. As the partially acquired target firm continues to interact adaptively with its EMNE partner and the EMNE's home market, the CD actually experienced by the target is expected to decrease, because the collective learning between the two organizations will lead to growing shared 
cultural resources over time, and will further offset the negative effect of CD on postacquisition target performance. I thus posit

Hypothesis 7a: In an EMNE's partial acquisition of a firm in a developed economy, the cultural distance between the target home and the acquirer's home countries is negatively related to post-acquisition target performance.

Hypothesis 7b: In an EMNE's partial acquisition of a firm in a developed economy, the target firm's international experience prior to the acquisition positively moderates the negative effect of the cultural distance between the target and the acquirer's home countries on post-acquisition target performance.

By contrast, the negative effect of cultural distance on post-acquisition target performance could be amplified when the acquirer is a state-owned EMNE. While the DSCM perspective suggests that over time the cultural distance the target faces in the acquirer's home country can be somewhat mitigated through continuous adaptive interaction and collective learning processes between the target and its acquirer, the collective learning process itself requires a cooperative attitude from both the acquirer and the target. As argued earlier, however, state-owned EMNE acquirers may have a limited incentive to engage in a cooperative attitude, due to their conflict of interests with original target shareholders (e.g., non-business objectives, national pride and protectionism, etc.).

Cooperation could also become more challenging because many state-owned EMNE acquirers do not possess good governance and transparency. Similarly, state- 
owned EMNE acquirers’ potential lack of legitimacy in targets' home countries may affect targets’ capabilities to exploit their firm-specific advantages in the EMNE acquirers' home countries, as the acquirer's lack of legitimacy may lead to negatively

altered or even disrupted target firms' supply chain systems in their home countries (e.g., suppliers, customers, regulators, etc.), making collective learning less rich and more challenging. The reduced collective learning capacity may then aggravate the initial negative effect of $\mathrm{CD}$ on post-acquisition target performance. As the partially acquired target firm continues to interact with its state-owned EMNE partner, the CD actually experienced by the target firm is expected to worsen, because the impeded collective learning will hamper the growth of shared cultural resources over time and further worsen the negative effect of $\mathrm{CD}$ on post-acquisition target performance. I thus posit Hypothesis 7c: In an EMNE's partial acquisition of a firm in a developed economy, the acquirer's state-owned or government-related status negatively moderates the negative effect of the cultural distance between the target and the acquirer's home countries on post-acquisition target performance.

\section{METHODS AND DATA}

\section{Analytical model}

My testable hypotheses are represented by the diagrams in Figure 12. I utilized the event study method (McWilliams \& Siegel, 1997) to test Hypothesis 1 and applied the ordinary least squares (OLS) regression method for testing the rest of the hypotheses. The use of the OLS technique for a cross-sectional examination of value creation sources is straightforward and consistent with a number of recent studies related to acquisition 
performance (e.g., Bhagat, Malhotra, \& Zhu, 2011; Gaur, Malhotra, \& Zhu, 2013; Ning,

Kuo, Strange, \& Wang, 2014).

Figure 12. Analytical model
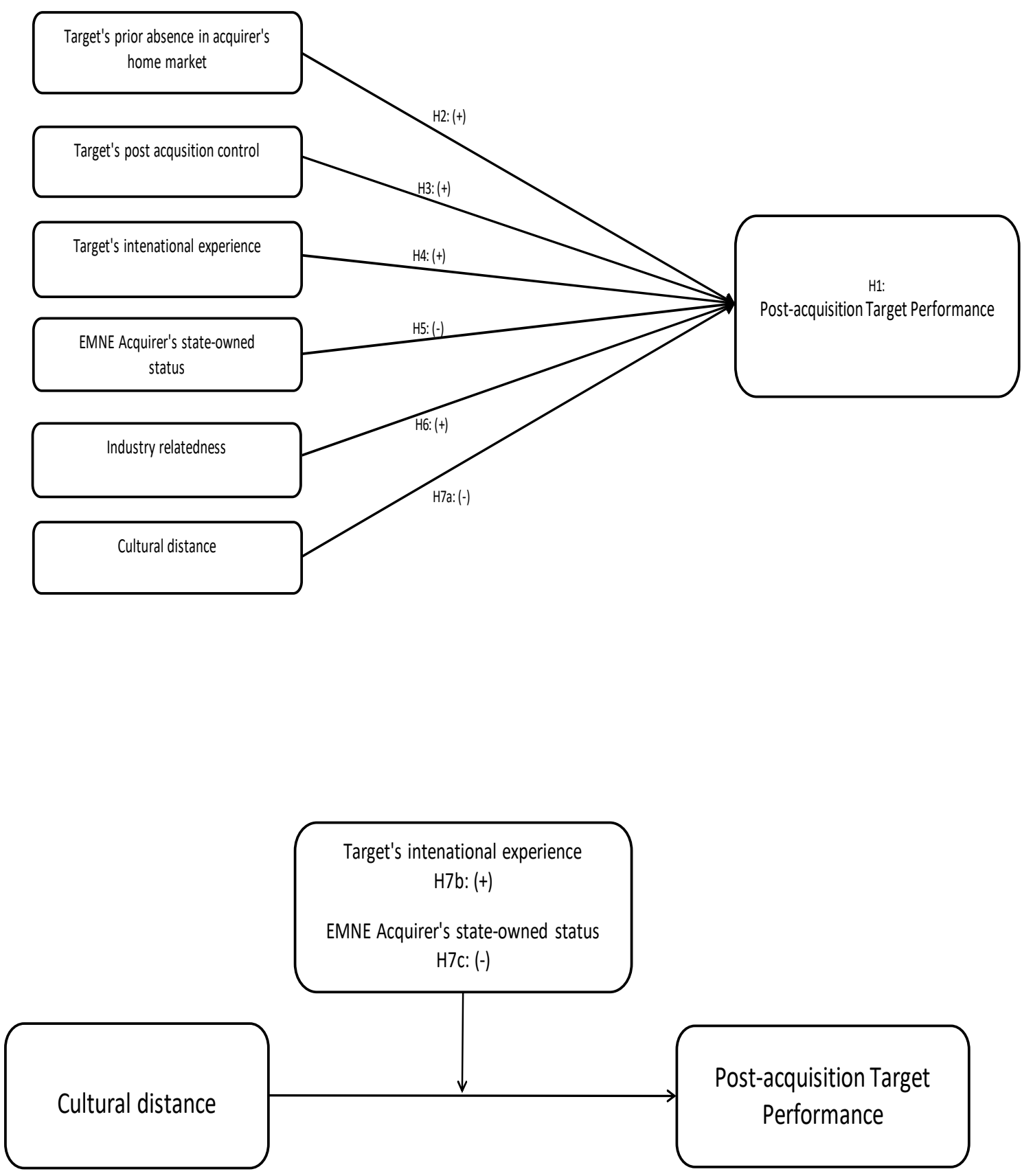


\section{Sample and data collection}

To test the hypotheses, I collected from Thomson One M\&A database a sample of 193 completed cross-border partial acquisitions of publicly listed target firms in the United States and Canada by firms from fifteen major emerging economies ${ }^{8}$ from January 1 , 2000 to December 31, 2015. A partial acquisition is defined as an acquisition where the acquirer holds less than 100 percent ownership of the target firm after the acquisition. I confine my analysis to target firms from North America because it is the world's region where EMNE’s acquisitions in high-income economies have mostly occurred. Besides, the U.S. and Canadian markets for corporate control are relatively homogenous, which is particularly important, since this study focuses on the targets' event-induced stock market reaction, and therefore potential differences in market efficiency characteristics across countries must reasonably be controlled for. Moreover, the year 2000 is selected as the start of the sample period because that was the approximate time when EMNEs began to aggressively acquire firms in developed economies. Most emerging economies started to deregulate their economies around the early 1990s (Bhagat, et al., 2011), which arguably provided an impetus for those economies to engage in outward greenfield and acquisition FDI a decade later.

The data on international acquisitions that were obtained from Thomson One M\&A database also include basic information on deal characteristics, and financial and institutional characteristics of the acquirer and the target's. The event study method requires stock price data for the target firms around acquisition announcement dates, so I retrieved the stock price data from Datastream database. I also collected additional target

\footnotetext{
${ }^{8}$ The fifteen major emerging economies are Brazil, Russia, India, China (including Hong Kong), South Africa, Mexico, Indonesia, Turkey, Colombia, Vietnam, Egypt, Malaysia, Thailand, and the Philippines.
} 
financial data from the Mergent Online database and company annual reports. Countrylevel cultural distance (CD) data are from datasets provided by Berry, Guillen and Zhou (2010). Since their CD data are dynamic yearly data, I performed a linear extrapolation to fill missing values, particularly for the few later year observations.

I excluded from the initial sample observations that contain U.S. or Canadian target firms with material news releases (unrelated to the acquisition activity) around the announcement time to better isolate the effect of the acquisition on the target stock prices. I used the announcement date of the deal as the cut-off date for the event, which is an important element of any event study. This date is the date that a bid announcement first appears in electronic databases. After cleaning for missing or incomplete stock price and financial data, inaccurate entries, and entry duplications, I obtained a final sample size of 167 observations.

In the final sample, 56.9 percent (95) of the targets were Canadian firms and 43.1 percent (72) were U.S. firms. It involved eleven acquirers' country of origins. Around 52.1 percent (87) of acquirers were from China (including Hong Kong), followed by 12 percent (20) from Mexico, 11.4 percent (19) from India, 9 percent (15) from Russia, 4.8 percent (8) from Brazil, 4.8 percent (8) from South Africa, and 5.9 percent (10) from Colombia, Malaysia, Nigeria, the Philippines and Turkey, collectively. About 55.7 percent (93) of the deals involved targets in the energy and resource industry, 22.8 percent (38) in the manufacturing industry, 19.2 percent (32) in the service industry, and 2.4 percent (4) in the financial industry. Around 24 percent (40) of the acquired targets were firms in high-technology industries. 48.5 percent (81) of the acquirers were publicly-listed firms, while 51.5 percent (86) were private firms. About 70.7 percent 
(118) of acquisition deals were privately negotiated purchases, as opposed to tender offer purchases.

\section{Measures}

\section{Dependent variable: target cumulative abnormal returns}

Post-acquisition target performance is represented by target cumulative abnormal returns (CAR) surrounding the public announcement of the acquisition, measured by utilizing the event study method (Brown \& Warner, 1985). I estimated the target CAR for each transaction. The event study method assumes that the market is efficient and, on balance, can accurately discern the value of the announced transaction. This approach has emerged as a popular method for valuing the effects of various unanticipated economically relevant factors in the market for corporate control (e.g., Caves, 1989; Desai, Kroll, \& Wright, 2005; Lubatkin \& Shrieves, 1986; Wright, Ferris, Hiller, \& Kroll, 1995).

To construct CAR for each target firm, I first calculated daily abnormal returns for each target firm $j$ during various event windows between $t_{-2}$ to $t_{+2}$ (i.e., two days before and after the announcement date) by using the market return model (Brown \& Werner, 1985), as follows:

$$
A R_{j, t}=R_{j, t}-\left(\propto+\beta \times R_{m, t}\right),
$$

where $A R_{j, t}$ is the abnormal return, $R_{j, t}$ is the target firm's daily stock return, and $R_{m, t}$ is the daily stock market return (for the market on which the target firm is listed). A short event window can capture the significant effect of an event more effectively. Dann, Mayers, and Raab (1977) demonstrated that transmission of information can be very 
quick in the capital market. A stock price can fully adjust within fifteen minutes of the release of firm-specific information. In fact, a longer event window implies a higher risk for a contamination from confounding events. The parameters $\alpha_{j}$ and $\beta_{j}$ in the market return model were estimated based on a 200-day estimation window before the announcement date, which is consistent with McWilliams and Siegel's (1997) suggestion.

I then summed the daily abnormal returns to measure the CAR of the target firm for various lengths of event window during the five-day period surrounding the acquisition announcement to account for potential leakage or slow transmission of information (McWilliams \& Siegel, 1997). In the regression for the cross-sectional examination of the value creation sources, I used a 1-day $(0,+1)$ event window, in which the target CAR was calculated by using the following formula:

$$
C A R_{j}=\sum_{t=0}^{+1} A R_{j, t}
$$

Given the cross-border nature of the announcement in EMNE's acquisitions of targets in developed economies and the relatively efficient North American capital markets, it is arguably reasonable to use the 1-day $(0,1)$ event window for the target CAR in my regression model. A very short event window is indeed recommended to avoid potential confounding effects from other events (Mitchell \&Netter, 1989). However, I also checked for robustness of the results by testing other CARs with various lengths of event windows within the five-day period as the dependent variable. The use of a five-day period surrounding the acquisition announcement is consistent with other studies in this area (e.g., Fuller, Netter, \& Stegemoller, 2002; Masulis, Wang, \& Xie, 2009). Daily stock 
market return and targets’ return data for estimating market parameters and calculating the target CAR were all obtained from Datastream database.

\section{Independent variables}

Target prior presence in the acquirer's home market is a binary variable, coded 1 , if the target or its ultimate parent had no subsidiary operation in the acquirer's home market before the acquisition announcement. Information about target subsidiaries' geographic locations was provided by target company's annual report for the year before the acquisitions was announced.

Target post-acquisition control is a binary variable, coded 1, if the target original shareholders retained greater than 50 percent (controlling majority) ownership after the acquisition is completed. Information about post-acquisition target ownership was available in Thomson One M\&A database.

Target international experience is a binary variable, coded 1 , if before an acquisition the target firm had operational experience in international markets other than its acquirer's home country or regional markets. Information about international experience was available in target company’s annual report for the year before the acquisition was announced.

EMNE acquirer's state-owned status is a binary variable that has a value of 1 if an EMNE acquirer and/or its ultimate parent was fully or partially owned by its home country government. Information on state-owned status was given in Thomson One M\&A database. 
Industry relatedness is a binary variable, coded 1 , if the target firm operated in the same industry as the acquirer or the acquirer's ultimate parent company. The industry classification is based on Thomson Reuters' 85 mid-level industry categories and was available in Thomson One M\&A database.

Cultural distance is a continuous variable that represents the difference of cultural index scores between he target's home country and the acquirer's home country, which was computed using the Mahalanobis distance formula (1936). The country-level cultural distance index data are yearly data which were obtained from Berry et al. (2010). They were derived from the longitudinal World Values Survey (WVS) questions that measure four different dimensions of culture parallel to Hofstede’s original dimensions of culture, namely power distance, uncertainty avoidance, individualism, and masculinity (1980). I performed a linear extrapolation to obtain scores for missing values in the last few years of the observation period.

\section{Control variables}

Based on extant literature in post-acquisition target performance, I included several control variables, for they are likely to have effects on post-acquisition target performance. First, there were three control variables for target firms' characteristics. Target's prior performance represents target firm's return on assets (in percentage) for the 3-year period prior to the acquisition announcement (Akhigbe, Madura, \& Spencer, 2004). Target's firm size refers to the target firm's total assets (in million U.S. dollars) in the year prior to the acquisition announcement year (Akhigbe, Martin \& Whyte, 2007). Target's prior regional presence was a binary variable, which was coded 1 if the target 
firm or the target's ultimate parent had no subsidiary operation in the acquirer's regional market (other than the acquirer's own home market) prior to the acquisition announcement year (Danbolt \& Maciver, 2012).

Second, there were two control variables for the acquirers' characteristics. Acquirer's target pre-ownership represents the acquirer's shareholding of the target firm prior to the acquisition, which was coded 1 if the acquirer had shares of the target firm prior to the acquisition announcement. (Akhigbe et al., 2004; Danbolt, 2004). Acquirer's sought shares refers to the percentage of the target firm's total shares that were sought by the acquirer in the acquisition (Amoako-Adu \& Smith, 1993).

Third, I included two deal-specific control variables. Acquisition method is a dichotomous variable, which was coded 1 if an acquisition was privately negotiated (or block-purchased), as opposed to a tender offer (Amoako-Adu \& Smith, 1993). Attitude was operationalized using a dummy variable, which was coded 1 if an acquisition involved both friendly acquirer and target (Chen \& Cornu, 2002; Schwert, 2000).

Fourth, I controlled for three industry-level variables. Target industry dummies are dummy variables to capture the effect of target firms' industries on post-acquisition target value creation, while Acquirer industry dummies are dummy variables to account for the effect of acquirer's industries on post-acquisition target value creation. Thomson Reuters' industry group classification was used to define whether firms operated in manufacturing, finance, energy and natural resources, or the service industry (Cebenoyan, Papaioannou, \& Tavlos, 1992, Danbolt \& Maciver, 2012). High-technology target was a binary variable, which was coded 1 if the target firm was in the high-technology industry, based on Thomson Reuters’3-digit classification (Graebner, 2004). 
Table 6. Variable definitions and data sources

\begin{tabular}{|c|c|c|}
\hline Variable & Definition & Source \\
\hline \multicolumn{3}{|l|}{$\underline{\text { Dependent variable }}$} \\
\hline $\begin{array}{l}\text { Target cumulative abnormal } \\
\text { return (CAR) }\end{array}$ & $\begin{array}{l}\text { Target's cumulative daily abnormal log return over a 1-day }(0,0), 2 \text {-day } \\
(0,+1), 3 \text {-day }(-1,+1) \text {, or } 5 \text {-day }(-2,+2) \text { event window, calculated } \\
\text { using the event study method based on the market return model } \\
\text { (Brown \& Werner, 1985) with parameter estimates obtained based on } \\
\text { an OLS regression with a 200-day estimation window. }\end{array}$ & $\begin{array}{l}\text { Thomson One, } \\
\text { Datastream }\end{array}$ \\
\hline \multicolumn{3}{|l|}{ Independent variables } \\
\hline $\begin{array}{l}\text { Target's prior presence in acquirer's } \\
\text { home market }\end{array}$ & $\begin{array}{l}\text { If target or target ultimate parent's had no subsidiary operation in the } \\
\text { acquirer's home market prior to the acquisition announcement year, } \\
\text { it was coded } 1 \text {; otherwise } 0 .\end{array}$ & Company Annual Reports \\
\hline Target's post-acquisition control & $\begin{array}{l}\text { If target original shareholders retained greater than } 50 \% \text { (majority) } \\
\text { ownership after the acquisition, it was coded } 1 \text {; otherwise } 0 .\end{array}$ & Thomson One \\
\hline Target's International experience & $\begin{array}{l}\text { If target or target ultimate parent's had international operation in } \\
\text { countr(ies) other than the acquirer's home country or region prior to } \\
\text { the acquisition announcement year, it was coded } 1 \text {; otherwise } 0 \text {. }\end{array}$ & Company Annual Reports \\
\hline Acquirer's state-owned status & $\begin{array}{l}\text { If the acquirer or acquirer ultimate parent was fully or partially owned } \\
\text { by home country's government, it was coded 1; otherwise } 0 .\end{array}$ & Thomson One \\
\hline Industry relatedness & $\begin{array}{l}\text { If target or target ultimate parent's operated in the same industry as the } \\
\text { acquirer or acquirer ultimate parent (based on Thomson Reuters' } 85 \\
\text { mid-level industry classifications), it was coded 1; otherwise } 0 .\end{array}$ & Thomson One \\
\hline Cultural distance & $\begin{array}{l}\text { Country-level Mahalanobis cultural distance index, derived from World } \\
\text { Values Survey (WVS) questions for four Hofstede (1980)'s original } \\
\text { cultural dimensions. }\end{array}$ & Berry, Guillen and Zhou (2010) \\
\hline \multicolumn{3}{|l|}{ Control variables } \\
\hline Target's prior performance & $\begin{array}{l}\text { Target's return on asset for the } 3 \text {-year period prior to the acquisition } \\
\text { announcement year in } \%\end{array}$ & Mergent Online \\
\hline Target’s firm size & $\begin{array}{l}\text { Target's total asset in the year prior to the acquisition announcement } \\
\text { year (in million US\$) }\end{array}$ & Thomson One \\
\hline Target’s prior regional presence & $\begin{array}{l}\text { If target or target ultimate parent's had no subsidiary operation in the } \\
\text { acquirer's regional market (other than the acquirer's own home } \\
\text { market) in the year prior to the acquisition announcement year, it was } \\
\text { coded } 1 \text {; otherwise } 0 \text {. }\end{array}$ & Company Annual Reports \\
\hline Acquirer’s target pre-ownership & $\begin{array}{l}\text { If acquirer was a target shareholder in the year prior to the acquisition } \\
\text { announcement, it was coded } 1 \text {; otherwise } 0 .\end{array}$ & Thomson One \\
\hline Acquirer's sought shares & Target share ownership sought by acquirer (in \% of total shares) & Thomson One \\
\hline Acquisition method & $\begin{array}{l}\text { If an acquisition was privately negotiated (or block-purchased), it was } \\
\text { coded } 1 \text {; otherwise } 0 .\end{array}$ & Thomson One \\
\hline Attitude & $\begin{array}{l}\text { If acquisition involved both friendly acquirer and target, it was coded } 1 \text {; } \\
\text { otherwise } 0 \text { (base attitude: non-friendly) }\end{array}$ & Thomson One \\
\hline Target industry dummies & $\begin{array}{l}\text { Categorical variables for target industries. Industry categories are based } \\
\text { on Thomson Reuters' industry group classification (manufacturing, } \\
\text { finance, energy \& natural resources, service). Base target industry: } \\
\text { manufacturing. }\end{array}$ & Thomson One \\
\hline Acquirer industry dummies & $\begin{array}{l}\text { Categorical variables for acquirer industries. Industry categories are } \\
\text { based on Thomson Reuters’ industry group classification } \\
\text { (manufacturing, finance, energy \& natural resources, service). Base } \\
\text { target industry: manufacturing. }\end{array}$ & Thomson One \\
\hline High-technology target & $\begin{array}{l}\text { If target was in high technology industry (based on Thomson Reuters' } 3 \text { - } \\
\text { digit classification), it was coded } 1 \text {; otherwise } 0 .\end{array}$ & Thomson One \\
\hline Knowledge Distance & $\begin{array}{l}\text { Country-level Mahalanobis knowledge distance index, derived from } \\
\text { \# of patents filed and \# of scientific articles published in a country. }\end{array}$ & Berry, Guillen and Zhou (2010) \\
\hline Target country dummy & $\begin{array}{l}\text { If target company was headquartered in Canada, it was coded 1; } \\
\text { otherwise } 0 . \text { Base target country: the United States. }\end{array}$ & Thomson One \\
\hline Year dummy & $\begin{array}{l}\text { If the acquisition was announced in } 2008,2009,2010,2011,2012 \text {, } \\
2013,2014 \text {, or } 2015 \text {, it was coded } 1 \text {; otherwise } 0 .\end{array}$ & Thomson One \\
\hline
\end{tabular}


Finally, I also controlled for three country-level and time control variables, namely knowledge distance, target country, and year of acquisition. Knowledge distance is a continuous variable, measured with the Mahalanobis distance formula 1936). It represents the difference of knowledge index scores between the target home country and the acquirer's home country. The yearly country-level scores were obtained from Berry et al. (2010). The scores had been derived from two data components, namely the number of patents and the number of scientific articles published in a country. I used a linear extrapolation to obtain scores for missing values in the last few years of the observation period. Target country dummy is a binary variable to capture heterogeneity in institutional characteristics, macroeconomic conditions, and corporate control market efficiencies in target home countries, namely United States and Canada. It was coded as 1 if the target firm was headquartered in Canada.

Year dummy captures the effect of the global Great Recession that started with the housing bubble burst in the United States and severely affected the performance of firms in most parts of the world, but particularly in North America. It was coded 1 if the acquisition was announced between 2008 and 2015 (inclusive), and was coded 0 for any other year.

A complete description of all variables included in the empirical model is provided in Table 6 along with sources from which data for the variables were obtained.

\section{RESULTS AND DISCUSSION}

To test hypothesis 1 , I used the event study method to measure the effect of acquisition announcements on the value of the target firms. Using 167 EMNE's acquisitions of 
publicly listed firms in the United States and Canada, I performed an event study for various lengths of event window with the five-day period surrounding the day acquisitions were announced.

The effectiveness of the event study method in measuring post-acquisition value creation is based on the assumptions that the stock market is efficient and all stock prices incorporate all relevant information that is available to market traders in an instantaneous manner (Bromiley, Govekar, \& Marcus, 1988), the acquisition announcement is an unanticipated event, and the acquisition announcement is an isolated event with no other events with potential confounding effects (McWilliams \& Siegel, 1997).

Table 7 reports the cumulative average abnormal returns (CAAR) for the target firms during the 1-day 2-day, 3-day and 5-day event windows. For all event windows, the mean CAARs range from 6.12 percent to 9.14 percent and are all statistically significant $(p<0.01)$ under various parametric and non-parametric tests. The results support

Table 7. Target CAR around the acquisition announcement days

\begin{tabular}{|c|c|c|c|c|c|c|c|c|}
\hline $\begin{array}{c}\text { Event } \\
\text { window }\end{array}$ & $\mathrm{N}$ & $\begin{array}{c}\text { Mean } \\
\text { CAAR } \\
(\%)\end{array}$ & $\begin{array}{l}\text { Positive: } \\
\text { negative }\end{array}$ & $\%$ Positive & Patell Z & $\begin{array}{c}\text { Boehmer } \\
\text { et al. }\end{array}$ & $\begin{array}{l}\text { Corrado } \\
\text { rank }\end{array}$ & $\begin{array}{l}\text { Cowan } \\
\text { Sign test }\end{array}$ \\
\hline$(0,0)$ & 167 & 6.12 & $106: 61$ & 63 & $11.84 * * *$ & $4.87 * * *$ & $4.65^{* * * *}$ & $3.64 * * *$ \\
\hline$(0,+1)$ & 167 & 8.17 & $111: 56$ & 66 & $10.21 * * *$ & $5.77 * * *$ & $3.90 * * *$ & $4.42 * * *$ \\
\hline$(-1,+1)$ & 167 & 8.94 & $108: 59$ & 65 & $9.09 * * *$ & $4.65 * * *$ & $4.16^{* * * *}$ & $3.95 * * *$ \\
\hline$(-2,+2)$ & 167 & 9.14 & $105: 62$ & 63 & $6.42 * * *$ & $3.89 * * *$ & $2.83^{* * *} *$ & $3.49 * * *$ \\
\hline
\end{tabular}

Hypothesis 1 and confirm that on average EMNE's acquisitions of firms in developed economies yield positive cumulative abnormal returns. The partial sale of target 
ownership to EMNE's acquirers is viewed by the market as a value creating strategy for the targets.

To test the remaining hypotheses, I ran ordinary least-squares (OLS) regressions of the CAR on various theoretically induced variables across observations to examine factors that lead to value creation for the target firms. Highly correlated independent variables can distort the OLS regression results. Accordingly, before running the OLS regressions, I first performed correlation tests on all included variables to ensure there's no significant multicollinearity problem in my model.

Table 8 presents the pair-wise correlation coefficients of all variables included in the model along with summary descriptive statistics for each variable. The majority of the correlations are lower than 0.2 , well below the 0.7 maximum standard typically used in empirical management literature. I also formally computed variance inflation factors (VIFs), which gives a mean value of 2.87 , confirming there is no multicollinearity problem that may detrimentally affect the OLS regression results.

Estimation results from OLS regressions for all tested models are provided in Table 9. Model 1 contains all basic independent and control variables with no interaction effect included in it. Robust standard errors are given in the parentheses, since a prior Breusch-Pagan test for heteroskedasticity in the basic model gave a statistically significant $\chi^{2}$ statistic of 20.94, indicating that the variance in the model was not constant, contrary to the assumption of the basic OLS model. The use of robust standard error (White, 1980) to correct for heteroscedasticity in cross-section OLS regressions of CAAR 
Table 8. Descriptive statistics and correlations $(N=167)$

\begin{tabular}{|c|c|c|c|c|c|c|c|c|c|c|c|c|c|c|c|c|}
\hline & 1 & 2 & 3 & 4 & 5 & 6 & 7 & 8 & 9 & 10 & 11 & 12 & 13 & 14 & 15 & 16 \\
\hline 1. Target’s CAR & 1 & & & & & & & & & & & & & & & \\
\hline $\begin{array}{l}\text { 2. Target prior presence in } \\
\text { acquirer's home market }\end{array}$ & 0.02 & 1 & & & & & & & & & & & & & & \\
\hline $\begin{array}{l}\text { 3. Target post-acquisition } \\
\text { control }\end{array}$ & $0.13^{*}$ & $0.16^{\star \star}$ & 1 & & & & & & & & & & & & & \\
\hline $\begin{array}{l}\text { 4. Target's international } \\
\text { experience }\end{array}$ & $0.16^{\star \star}$ & -0.11 & 0.06 & 1 & & & & & & & & & & & & \\
\hline $\begin{array}{l}\text { 5. Acquirer's state-owned } \\
\text { status }\end{array}$ & -0.11 & 0.11 & 0.05 & 0.12 & 1 & & & & & & & & & & & \\
\hline 6. Industry related ness & 0.12 & $-0.17^{\star \star}$ & -0.08 & -0.07 & 0.02 & 1 & & & & & & & & & & \\
\hline 7. Cultural distance & -0.08 & -0.09 & $-0.15^{*}$ & -0.03 & -0.12 & $0.13^{*}$ & 1 & & & & & & & & & \\
\hline 8. Target’s prior performance & $-0.23^{\star \star \star}$ & 0.08 & $0.15^{*}$ & -0.11 & 0.04 & 0.07 & 0.01 & 1 & & & & & & & & \\
\hline 9. Target’s firm size & -0.01 & -0.10 & 0.05 & 0.11 & $0.20^{\star *}$ & -0.06 & -0.002 & 0.01 & 1 & & & & & & & \\
\hline $\begin{array}{l}\text { 10. Target's prior regional } \\
\text { presence }\end{array}$ & -0.12 & $0.35^{\star \star \star}$ & -0.05 & $-0.21^{\star \star \star}$ & -0.10 & -0.04 & $-0.21^{* \star \star}$ & $0.13^{*}$ & $-0.16^{\star \star}$ & 1 & & & & & & \\
\hline $\begin{array}{l}\text { 11. Acquirer's target pre- } \\
\text { ownership }\end{array}$ & -0.04 & $-0.58^{\star \star *}$ & $-0.14^{\star}$ & -0.12 & -0.11 & 0.11 & 0.12 & 0.05 & -0.03 & -0.005 & 1 & & & & & \\
\hline 12. Acquirer's sought shares & 0.03 & 0.001 & $-0.73^{\star \star *}$ & -0.07 & -0.01 & 0.05 & 0.11 & 0.10 & -0.06 & 0.07 & $-0.19^{\star \star}$ & 1 & & & & \\
\hline 13. Acquisition method & -0.05 & 0.11 & $0.65^{\star \star \star}$ & 0.04 & 0.09 & -0.04 & -0.10 & 0.06 & -0.03 & -0.06 & $-0.53^{\star \star \star}$ & 0.11 & 1 & & & \\
\hline 14. Attitude & -0.01 & 0.01 & -0.12 & -0.03 & -0.11 & 0.01 & -0.08 & -0.04 & 0.04 & -0.10 & -0.02 & $0.15^{\star}$ & $0.19^{\star \star}$ & 1 & & \\
\hline 15. High-technology target & 0.02 & -0.05 & $-0.13^{*}$ & -0.03 & -0.11 & $-0.14^{\star}$ & 0.04 & $-0.13^{*}$ & -0.05 & 0.03 & 0.02 & $0.16^{\star \star}$ & $-0.16^{* \star}$ & -0.05 & 1 & \\
\hline 16. Knowledge distance & -0.04 & -0.09 & $-0.21^{\star \star \star}$ & 0.04 & $-0.16^{\star *}$ & $-0.19^{\star \star}$ & 0.03 & -0.11 & $0.16^{\star \star}$ & -0.08 & -0.05 & $0.21^{\star \star *}$ & $-0.22^{* \star *}$ & -0.04 & $0.44^{\star \star *}$ & 1 \\
\hline Mean & 0.08 & 0.59 & 0.80 & 0.38 & 0.15 & 0.34 & 17.16 & -415.99 & 7937.03 & 0.78 & 0.19 & 23.76 & 0.71 & 0.86 & 0.24 & 13.87 \\
\hline S.D. & 0.22 & 0.49 & 0.40 & 0.49 & 0.36 & 0.49 & 13.41 & 4092.8 & 80985.6 & 0.42 & 0.39 & 20.85 & 0.46 & 0.35 & 0.43 & 8.47 \\
\hline Min & -0.37 & 0 & 0 & 0 & 0 & 2 & 1.96 & -52264.7 & 0 & 0 & 0 & 3.16 & 0 & 0 & 0 & 5.17 \\
\hline Max & 1.54 & 1 & 1 & 1 & 0 & 71 & 140.05 & 37.3 & 1045409 & 1 & 1 & 91.3 & 1 & 1 & 1 & 33.19 \\
\hline
\end{tabular}

Note: $* * * * *$, and $*$ denote statistical significance at $1 \%, 5 \%$ and $10 \%$ levels, respectively. 
Table 9. Results of regressions with Target CAR as the dependent variable

\begin{tabular}{|c|c|c|c|c|c|c|c|}
\hline $\begin{array}{l}\text { Dependent variable: } \\
\text { Target CAR }\end{array}$ & $\begin{array}{c}\text { Model } 1 \\
(0,+1)\end{array}$ & $\begin{array}{c}\text { Model } 2 \\
(0,+1)\end{array}$ & $\begin{array}{c}\text { Model } 3 \\
(0,+1)\end{array}$ & $\begin{array}{c}\text { Model } 4 \\
(0,+1)\end{array}$ & $\begin{array}{c}\text { Model } 5 \\
(0,0)\end{array}$ & $\begin{array}{c}\text { Model } 6 \\
(-1,+1)\end{array}$ & $\begin{array}{c}\text { Model } 7 \\
(-2,+2)\end{array}$ \\
\hline \multicolumn{8}{|l|}{ Independent variables } \\
\hline $\begin{array}{l}\text { Target's prior presence in } \\
\text { acquirer's home market }\end{array}$ & $\begin{array}{r}0.0867 * \\
(0.0518)\end{array}$ & $\begin{array}{l}0.1010 * * \\
(0.0506)\end{array}$ & $\begin{array}{c}0.0780 \\
(0.0528)\end{array}$ & $\begin{array}{r}0.0925 * \\
(0.0519)\end{array}$ & $\begin{array}{c}0.0477 \\
(0.0440)\end{array}$ & $\begin{array}{r}0.0945 * \\
(0.0500)\end{array}$ & $\begin{array}{c}0.0602 \\
(0.0607)\end{array}$ \\
\hline $\begin{array}{l}\text { Target's post-acquisition } \\
\text { control }\end{array}$ & $\begin{array}{l}0.2869 * * \\
(0.1150)\end{array}$ & $\begin{array}{l}0.2870 * * \\
(0.1149)\end{array}$ & $\begin{array}{l}0.2826^{* *} \\
(0.1159)\end{array}$ & $\begin{array}{l}0.2830 * * \\
(0.1159)\end{array}$ & $\begin{array}{l}0.1522 * * * \\
(0.0462)\end{array}$ & $\begin{array}{l}0.2884 * * \\
(0.1258)\end{array}$ & $\begin{array}{l}0.3473 * \\
(0.1854)\end{array}$ \\
\hline $\begin{array}{l}\text { Target's international } \\
\text { experience }\end{array}$ & $\begin{array}{c}0.0802 * \\
(0.0440)\end{array}$ & $\begin{array}{l}-0.1547 \\
(0.1306)\end{array}$ & $\begin{array}{r}0.0837 * \\
(0.0441)\end{array}$ & $\begin{array}{l}-0.1485 \\
(0.1313)\end{array}$ & $\begin{array}{l}-0.1304 \\
(0.1023)\end{array}$ & $\begin{array}{l}-0.1332 \\
(0.1202)\end{array}$ & $\begin{array}{l}-0.0648 \\
(0.1460)\end{array}$ \\
\hline $\begin{array}{l}\text { Acquirer's state-owned } \\
\text { status }\end{array}$ & $\begin{array}{l}-0.0663^{*} \\
(0.0396)\end{array}$ & $\begin{array}{l}-0.0474 \\
(0.0395)\end{array}$ & $\begin{array}{c}0.3674 \\
(0.2780)\end{array}$ & $\begin{array}{c}0.3636 \\
(0.2645)\end{array}$ & $\begin{array}{r}0.3492 * \\
(0.2002)\end{array}$ & $\begin{array}{r}0.5481 * \\
(0.2884)\end{array}$ & $\begin{array}{l}0.5490 * \\
(0.3075)\end{array}$ \\
\hline Industry relatedness & $\begin{array}{l}0.1003 * * \\
(0.0400)\end{array}$ & $\begin{array}{l}0.1208 * * * \\
(0.0380)\end{array}$ & $\begin{array}{l}0.0942 * * \\
(0.0425)\end{array}$ & $\begin{array}{l}0.1148 * * * \\
(0.0404\end{array}$ & $\begin{array}{r}0.0710^{*} \\
(0.0384)\end{array}$ & $\begin{array}{l}0.1505 * * * \\
(0.0436)\end{array}$ & $\begin{array}{l}0.1383 * * * \\
(0.0505)\end{array}$ \\
\hline Cultural distance (CD) & $\begin{array}{l}-0.0019 * * * \\
(0.0007)\end{array}$ & $\begin{array}{l}-0.0024 * * * \\
(0.0006)\end{array}$ & $\begin{array}{l}-0.0019 * * * \\
(0.0007)\end{array}$ & $\begin{array}{l}-0.0023 * * * \\
(0.0006)\end{array}$ & $\begin{array}{l}-0.0012 * * \\
(0.0005)\end{array}$ & $\begin{array}{l}-0.0020 * * * \\
(0.0007)\end{array}$ & $\begin{array}{l}-0.0019^{*} \\
(0.0010)\end{array}$ \\
\hline $\begin{array}{l}\mathrm{CD} \times \text { International } \\
\text { Experience }\end{array}$ & & $\begin{array}{l}0.0143^{* *} \\
(0.0071\end{array}$ & & $\begin{array}{l}0.0141^{* *} \\
(0.0072)\end{array}$ & $\begin{array}{r}0.0113^{*} \\
(0.0064)\end{array}$ & $\begin{array}{l}0.0128 * * \\
(0.0060)\end{array}$ & $\begin{array}{c}0.0079 \\
(0.0068)\end{array}$ \\
\hline $\begin{array}{l}\mathrm{CD} \times \text { Acquirer's state- } \\
\text { owned status }\end{array}$ & & & $\begin{array}{l}-0.0329 * \\
(0.0191)\end{array}$ & $\begin{array}{l}-0.0312 * \\
(0.0184)\end{array}$ & $\begin{array}{l}-0.0264 * \\
(0.0141)\end{array}$ & $\begin{array}{l}-0.0444 * * \\
(0.0207)\end{array}$ & $\begin{array}{l}.-0.0479 * * \\
(0.0221)\end{array}$ \\
\hline \multicolumn{8}{|l|}{$\underline{\text { Control variables }}$} \\
\hline Target's prior performance & $\begin{array}{l}-0.00002 * * * \\
(0.000001)\end{array}$ & $\begin{array}{l}-0.00002 * * * \\
(0.000001)\end{array}$ & $\begin{array}{l}-0.00002 * * * \\
(0.000001)\end{array}$ & $\begin{array}{l}-0.00002 * * * \\
(0.000001)\end{array}$ & $\begin{array}{l}-0.00001 * * * \\
(0.000001)\end{array}$ & $\begin{array}{l}-0.00002 * * * \\
(0.000002)\end{array}$ & $\begin{array}{l}-0.00001 * * * \\
(0.000002)\end{array}$ \\
\hline Target's firm size & $\begin{array}{c}0.0000001 \\
(0.0000001)\end{array}$ & $\begin{array}{c}0.000001 \\
(00000001)\end{array}$ & $\begin{array}{l}0.0000002 * * \\
(0.0000001)\end{array}$ & $\begin{array}{l}0.0000002 * \\
(0.0000001)\end{array}$ & $\begin{array}{c}0.0000002 \\
(0.0000001)\end{array}$ & $\begin{array}{l}0.0000002 * \\
(0.0000001)\end{array}$ & $\begin{array}{l}0.0000004 * * * \\
(0.0000001)\end{array}$ \\
\hline $\begin{array}{l}\text { Target's prior regional } \\
\text { Presence }\end{array}$ & $\begin{array}{l}-0.0541 \\
(0.0519)\end{array}$ & $\begin{array}{l}-0.0536 \\
(0.0475)\end{array}$ & $\begin{array}{l}-0.0500 \\
(0.0521)\end{array}$ & $\begin{array}{l}-0.0497 \\
(0.0478)\end{array}$ & $\begin{array}{l}-0.0437 \\
(0.0400)\end{array}$ & $\begin{array}{l}-0.0046 \\
(0.0464)\end{array}$ & $\begin{array}{c}0.0294 \\
(0.0487)\end{array}$ \\
\hline $\begin{array}{l}\text { Acquirer's target pre- } \\
\text { ownership }\end{array}$ & $\begin{array}{l}0.1314 * * \\
(0.0634)\end{array}$ & $\begin{array}{l}0.1367 * * \\
(0.0624)\end{array}$ & $\begin{array}{l}0.1300 * * \\
(0.0633)\end{array}$ & $\begin{array}{l}0.1353 * * \\
(0.0624\end{array}$ & $\begin{array}{r}0.0898 * \\
(0.0498)\end{array}$ & $\begin{array}{r}0.1208 * \\
(0.0671)\end{array}$ & $\begin{array}{c}0.0718 \\
(0.0787)\end{array}$ \\
\hline Acquirer's sought shares & $\begin{array}{r}0.0035^{*} \\
(0.0018)\end{array}$ & $\begin{array}{r}0.0034 * \\
(0.0018)\end{array}$ & $\begin{array}{r}0.0033^{*} \\
(0.0018)\end{array}$ & $\begin{array}{r}0.0033 * \\
(0.0018)\end{array}$ & $\begin{array}{c}0.0015 \\
(0.0010)\end{array}$ & $\begin{array}{r}0.0032 * \\
(0.0019)\end{array}$ & $\begin{array}{c}0.0033 \\
(0.0026)\end{array}$ \\
\hline Acquisition method & $\begin{array}{l}-0.0990 \\
(0.0739)\end{array}$ & $\begin{array}{l}-0.1036 \\
(0.0710)\end{array}$ & $\begin{array}{l}-0.1037 \\
(0.0736)\end{array}$ & $\begin{array}{l}-0.1080 \\
(0.0708)\end{array}$ & $\begin{array}{l}-0.0544 \\
(0.0395)\end{array}$ & $\begin{array}{l}-0.1324 * \\
(0.0788)\end{array}$ & $\begin{array}{l}-0.2057^{*} \\
(0.1090)\end{array}$ \\
\hline Attitude & $\begin{array}{c}0.0307 \\
(0.0475)\end{array}$ & $\begin{array}{c}0.0325 \\
(0.0481)\end{array}$ & $\begin{array}{c}0.0421 \\
(0.0480)\end{array}$ & $\begin{array}{c}0.0433 \\
(0.0483)\end{array}$ & $\begin{array}{c}0.0333 \\
(0.0319)\end{array}$ & $\begin{array}{c}0.0705 \\
(0.0554)\end{array}$ & $\begin{array}{c}0.0715 \\
(0.0627)\end{array}$ \\
\hline High-technology target & $\begin{array}{l}-0.0385 \\
(0.0621)\end{array}$ & $\begin{array}{l}-0.0388 \\
(0.0584)\end{array}$ & $\begin{array}{l}-0.0449 \\
(0.0624)\end{array}$ & $\begin{array}{l}-0.0449 \\
(0.0587)\end{array}$ & $\begin{array}{l}-0.0322 \\
(0.0609)\end{array}$ & $\begin{array}{l}-0.0218 \\
(0.0594)\end{array}$ & $\begin{array}{l}-0.0207 \\
(0.0522)\end{array}$ \\
\hline Knowledge distance & $\begin{array}{c}0.0042 \\
(0.0051)\end{array}$ & $\begin{array}{c}0.0075 \\
(0.0047)\end{array}$ & $\begin{array}{c}0.0040 \\
(0.0051)\end{array}$ & $\begin{array}{c}0.0072 \\
(0.0048)\end{array}$ & $\begin{array}{c}0.0052 \\
(0.0045)\end{array}$ & $\begin{array}{c}0.0105 * \\
(0.0055)\end{array}$ & $\begin{array}{c}0.0069 \\
(0.0057)\end{array}$ \\
\hline Constant & $\begin{array}{l}-0.3076 \\
(0.2271)\end{array}$ & $\begin{array}{c}-0.4029 * \\
(0.2122)\end{array}$ & $\begin{array}{l}-0.2935 \\
(0.2294)\end{array}$ & $\begin{array}{c}-0.3884 * \\
(0.2147)\end{array}$ & $\begin{array}{l}-0.1580 \\
(0.1314\end{array}$ & $\begin{array}{l}-0.5576^{* *} \\
(0.2376)\end{array}$ & $\begin{array}{l}-0.4852 \\
(0.3189)\end{array}$ \\
\hline Target industry effects & Yes & Yes & Yes & Yes & Yes & Yes & Yes \\
\hline Acquirer industry effects & Yes & Yes & Yes & Yes & Yes & Yes & Yes \\
\hline Target country effects & Yes & Yes & Yes & Yes & Yes & Yes & Yes \\
\hline Year effects & Yes & Yes & Yes & Yes & Yes & Yes & Yes \\
\hline$F$-statistics & $95.51 * * *$ & $279.04 * * *$ & $108.21 * * *$ & 289.68 & $48.45^{* * *}$ & $298.65 * * *$ & $22.31 * * *$ \\
\hline Adjusted $R^{2}$ & 0.2754 & 0.2985 & 0.2810 & 0.3035 & 0.2222 & 0.2932 & 0.2429 \\
\hline Number of observations & 167 & 167 & 167 & 167 & 167 & 167 & 167 \\
\hline
\end{tabular}

Note: $* * *, * *$ and $*$ denote statis tical significance at $1 \%, 5 \%$ and $10 \%$ levels, respectively. Robust standard errors in parentheses. 
is consistent with MacKinlay's suggestion (1997). While my sample of 167 observations may be moderate in terms of size, I expect no violation of the OLS normality assumption, since Werner and Brown (1985) found that in event studies the test statistics converge to the asymptotic distribution rather quickly. It is also worth noting that endogeneity may arise due to the relation between the target firm characteristics and the degree of anticipation of the event, creating a selection bias that leads to misspecification under the OLS estimation model (MacKinlay, 1997). However, Prabhala (1995) demonstrates that even under this condition, the OLS method still remains reliable for statistical inferences.

Model 1 in Table 9 explains 27.5 percent of variations in post-acquisition target performance, as measured by the target CAR. The model is significant $(F$-statistics $=$ $0.2754, p<0.01$ ), indicating that at least one of the independent variables in the specified model has a non-zero effect on post-acquisition target CAR. The coefficient of target's prior presence in acquirer's home market is significantly positive $(\beta=+0.0867, p<0.1)$, thus supporting Hypothesis 2. It implies that with no previous presence in the acquirer's home market, the target is poised to enter a new market and reap the benefits from the large and fast growing emerging market. The target's post-acquisition control also has a statistically significant positive effect on target CAR $(\beta=+0.2869, p<0.05)$, confirming Hypothesis 3. This result suggests that when the target retains majority ownership after the acquisition, it can exploit their firm-specific advantages in the newly entered acquirer's home market more effectively. More synergistic benefits from a complementary acquisition could be generated when the EMNE acquirer's motive is strategic-asset-seeking and thus prefers a non-controlling minority acquisition of the target. 
Model 1 also shows that the effect of the target's international experience on target CAR is significant and positive $(\beta=+0.0802, p<0.1)$. Hypothesis 4 is thus supported. Having previous international experience somewhere else outside the acquirer's home market, even when it was not in another emerging market, may help the target in navigating the acquirer's home market. Furthermore, the coefficient estimate for acquirer's state-owned status is negative and significant $(\beta=-0.0063, p<0.1)$, which implies having a state-owned EMNE as an acquirer negatively influences post-acquisition value creation for the target. This result corroborates Hypothesis 5. By contrast, the effect of industry relatedness on target CAR is significantly positive $(\beta=+0.1003, p<0.05)$, thus supporting Hypothesis 6. Targets are likely to create value when their EMNE acquirers are from the same industry. Finally, the coefficient estimate of cultural distance is significant and negative $(\beta=-0.0019, p<0.01)$, which is in line with previous related studies (e.g., Berkema et al., 1996; Weber et al., 1996; Krug \& Hegarty, 2001) and confirms Hypothesis 7a.

In Model 2, I added an interaction effect between cultural distance (CD) and the target's international experience as an additional predictor of the target CAR to the basic specification in Model 1, following the procedures outlined by Baron and Kenny (1986. Model 2 remains significant $(F$-statistics $=0.2985, p<0.01)$, with the predictive power of the model increased to 28.9 percent. The coefficient of the interaction effect is positive and significant $(\beta=-0.0143, p<0.05)$, which implies that having prior international experience somewhere else outside the acquirer's home country, even if it is in a developed country rather than another emerging market, may lessen the negative effect of CD on target CAR. This result supports Hypothesis $7 \mathrm{~b}$. 
In Model 3, I included an interaction effect between cultural distance (CD) and the acquirer's state-owned status on target CAR. Model 3 is significant $(F$-statistics $=$ $0.2810, p<0.01$ ), and the model predicts 28.1 percent of variations in target CAR. The interaction effect is statistically significant and has a negative influence on target CAR $(\beta$ $=-0.0329, p<0.1)$. Having an EMNE acquirer with a state-owned status may indeed amplify the negative effect of CD on target CAR, supporting Hypothesis 7c.

In Model 4, the two interaction effects from Model 2 and Model 3 were simultaneously incorporated to the basic specification in Model 1. Model 4 remains significant $(F$-statistics $=0.3035, p<0.01)$. The explanatory power of the model increases to 30.4 percent. The coefficient estimates of the CD-international experience and CD-state-owned EMNE acquirer interaction effects are statistically significant $(\beta=$ $0.0141, p<0.05$ and $\beta=-0.0312, p<0.1$, respectively), and the directions of their effects confirm the results obtained in Models 2 and 3 for Hypothesis $7 \mathrm{~b}$ and Hypothesis 7c.

In Models 1-4, I employed a 2-day event window $(0,+1)$ as a basis for computing the target CAR, which is the dependent variable of the models. As a robustness check, I also estimated regression models using target CAR with other lengths of event windows within the five-day period surrounding the announcement days. Models 5, 6 and 7 are similar to Model 4 in terms of specification, but they have target CARs with 1-day, 3day, and 5-day event windows as dependent variables, respectively. The estimation results in models 5, 6 and 7 are broadly similar to those in Model 4, particularly in regard to statistical significance, size and directions of the coefficient estimates for the two interaction effects. Additionally, incorporating a dummy variable for China in the 
specification of Model 4 or Model 1 to capture a potential acquirer's country of origin effect did not alter the results significantly, except for reduced models' explanatory powers. Similarly, when I expanded the estimation window beyond the 200-day period, the main results were largely unaffected.

\section{CONCLUSION}

In this essay, I pivoted my attention to the perspective of the target firms and examined the sources of value creation for target shareholders in EMNE's partial acquisition of firms in developed economies. I extended the idea of collective learning from the dynamic socio-cultural model (DSCM) in Essay 1 and combined it with theoretical insights from organizational learning and the seller's view literature to develop relevant testable hypotheses. Using the event study method on 167 acquisitions in the United States and Canada that were made by acquirers from eleven major emerging economies, I found that EMNE's partial acquisitions generate, on average, a positive post-acquisition target performance, as measured by the targets' cumulative average abnormal returns upon the acquisition announcements. Performing the cross-section ordinary least-squares regression method, I found target's prior presence in acquirer's home market, target's post-acquisition control, target’s international experience, and target-acquirer industry relatedness are all positively related to target cumulative abnormal returns (CAR). I also found that EMNE acquirer's state-owned status and the cultural distance between home and host countries negatively influenced target CAR. Finally, I found that targets with international experience prior to the acquisition announcement may attenuate the negative 
effect of cultural distance on their CAR, while acquirer's state-owned status may exacerbate the negative effect of cultural distance on post-acquisition target performance.

This essay makes several theoretical contributions. First, it responds to Hexter (1968)'s almost half century call for addressing the imbalance between the acquirer's and the target's perspectives in the M\&A literature. Based on insights from the dynamic socio-cultural model developed in Essay 1, a more elaborate and far-reaching target perspective is developed. Parallel to the seller’s view literature (e.g., Dalziel, 2008; Inkpen et al., 2000; Graebner \& Eisenhardt, 2004; Graebner et al., 2010), this essay views EMNE's partial acquisitions of firms in developed economies as "cultural marriages," in which both the acquiring firms and the target firms strategically consider their potential partners' characteristics, as opposed to financially strong firms acquiring low-performing targets.

This study also enriches a growing stream of research in multinational enterprises from the emerging economies, particularly in the context of EMNE's acquisitions of firms in developed economies, by focusing on a target perspective which is often given less attention in the EMNE literature. From an empirical perspective, this essay provides some examination to a pioneering work by Buckley et al. (2010) that presents several theoretical propositions on the determinants of post-acquisition target performance in the context of EMNE's acquisitions of firms in advanced countries. Furthermore, this essay expands previous empirical works by Chen (2011) and Chari et al. (2012) that found positive post-acquisition target performance in their studies of the "South-North" crossborder acquisitions, but stopped short of a cross-sectional examination on the target sources of value creation. 
From a practical perspective, this study provides useful insights for executives of prospective target firms in high-income economies in understanding the likelihood of post-acquisition success, as they strategically consider prospective acquirers from the emerging markets. For example, estimation results from the two specified moderation effects suggest that executives can lessen the inevitable negative effect from cultural distance at the initial stage of the target-acquirer post-acquisition collective learning by leveraging their existing international experience in other countries. On the other hand, more elaborate pre-acquisition due diligence and negotiations may be necessary when the prospective acquirer is a state-owned EMNE to ensure post-acquisition common objectives and consistent implementation.

This essay, however, has several limitations that need to be addressed in future studies. First, from methodological perspective, sample selection bias in the estimates might occur from not including in my sample numerous targets firms that were not acquired by EMNEs, or not even acquired at all in the sample period. The Heckman twostep estimation procedures (Heckman, 1979) may be performed to alleviate this potential problem, but further extensive data collection involving manual search through hundreds, or even thousands, of annual reports for information on certain variables such as the target's prior presence in acquirer's home market and the target's international experience will be necessary.

Secondly, while it has been recognized that the EMNE acquirers' experience in their home markets benefits their partially acquired targets in the developed economies, the experience that the EMNE acquirers may have in other international markets has not been explicitly considered in this study. In particular, EMNE acquirers have extensive 
experience in other emerging markets through their "South-South" investment activities. Chinese EMNEs, for example, have been known to be actively operating not only in other emerging markets near their home country, but also in distant emerging markets in Africa and South America. Indeed, for a target firm from a developed economy, being acquired by an EMNE with internationally diverse operations creates additional synergistic benefits, because the EMNE acquirer's multinational diversity provides the target with access to even larger fast-growing markets beyond the EMNE's home country. In fact, most EMNE had been aggressive regional players with extensive operational experience in emerging markets nearby their home countries before they actively engaged in cross-border acquisitions in developed markets (Rugman, 2009). The network theory perspective defines a market as a system of relationships among customers, suppliers, competitors and private and public support agencies (Coviello \& Munro, 1995), which should prove useful in analyzing the relationship between acquirer's multinational diversity on post-acquisition target performance. The diversity of the national markets in which the EMNE operates confronts it with a broad array of demand characteristics and large variety of such market actors (Abrahamson \& Fombrun, 1994; Miller \& Chen, 1996). Prior exposure to other developing markets has enabled EMNEs to accumulate a unique and hard-to-imitate expertise based on their experiential network knowledge. This type of knowledge is rich in detail and contains both codified and non-codified pieces of knowledge as well as cognitive and affective pieces of knowledge (Hohenthal, Johanson, \& Johanson, 2014). EMNE acquirers' experiencebased network knowledge is valuable for the partially acquired targets in developed 
economies, as they are exploiting their resource advantage in technologies, brand, and managerial know-how in the fast-growing EMNE’s home and regional markets.

Thirdly, the empirical part of this essay has utilized the event study method to generate target CAR to operationalize post-acquisition target performance. Haleblian et al. (2009), however, have argued that while CAR is the most common indicator used in M\&A performance studies, the event study method itself only considers the value of the decision to acquire (or to be acquired) with the assumption that in the post-acquisition implementation stage everything will go as planned, which is not always necessarily the case (Lebedev, Peng, Xie, \& Stevens, 2015). It is worthwhile to consider other measures of post-acquisition target performance and compare their results. Those measures include profitability (e.g., return on asset, return on investment), economic value added, sales growth, market share, etc. (Meglio \& Risberg, 2011; Sirower \& O’Byrne, 1998).

In addition to addressing the above limitations, future research should explore factors that strategically drive target firms from developed economies to choose certain deal and/or acquirer's characteristics in their partial sale of shares to EMNE and how these strategic decision(s) may affect post-acquisition target performance, combining the research questions in international business and strategic management in the same study. These choices include, for example, the target's decision on retaining post-acquisition controlling majority ownership (versus non-controlling minority ownership), the target's choice for a publicly-listed acquirer (versus private acquirer), the target's decision to be acquired by state-owned EMNEs (versus non-state-owned EMNEs). Moreover, it would be interesting for future studies to assess the foreign direct investment (FDI) performance of firms in developed economies under three comparable "North-South" entry modes, 
namely partial sale to EMNEs, joint venture with EMNEs, and partial acquisition of EMNEs.

This essay has empirically investigated several sources of value creation for target firms in the "South-North" cross-border partial acquisition context. It is unique in its focus on understanding the EMNE's cross-border partial acquisitions in developed countries from a target's perspective.

In closing, essays 1, 2 and 3 in this dissertation have collectively contributed to the growing literature of emerging multinational enterprises, and more specifically to multiple other research streams in IB including cross-border M\&As, global strategy of the EMNEs, cultural change, cultural distance and FDI, liabilities of foreignness, equity ownership choice, partial acquisitions, and seller’s view of acquisitions.

\section{REFERENCES}

Abrahamson, E., \& Fombrun, C. J. 1994. Macrocultures: Determinants and consequences. Academy of Management Review, 19(4): 728-755.

Akhigbe, A., Madura, J., \& Spencer, C. 2004. Partial acquisitions, corporate control, and performance. Applied Financial Economics, 14(12): 847-857.

Akhigbe, A., Martin, A. D., \& Whyte, A. M. 2007. Partial acquisitions, the acquisition probability hypothesis, and the abnormal returns to partial targets. Journal of Banking \& Finance, 31(10): 3080-3101.

Altaf, N., \& Shah, F. A. 2015. Internationalization and firm performance of Indian firms: Does product diversity matter? Pacific Science Review B: Humanities and Social Sciences, 1(2): 76-84.

Amoako-Adu, B., \& Smith, B. 1993. Comparative study of complete tender offers and partial acquisitions. Journal of Banking \& Finance, 17(6): 1097-1110. 
Arocena, P., \& Oliveros, D. 2012. The efficiency of state-owned and privatized firms: Does ownership make a difference? International Journal of Production Economics, 140(1): 457-465.

Barkema, H. G., Bell, J. H., \& Pennings, J. M. 1996. Foreign entry, cultural barriers, and learning. Strategic Management Journal, 17(2): 151-166.

Baron, R. M., \& Kenny, D. A. 1986. The moderator-mediator variable distinction in social psychological research: Conceptual, strategic, and statistical considerations. Journal of Personality and Social Psychology, 51(6): 1173.

Bass, A. E., \& Chakrabarty, S. 2014. Resource security: Competition for global resources, strategic intent, and governments as owners. Journal of International Business Studies, 45(8): 961-979.

Baum, J. A., \& Oliver, C. 1991. Institutional linkages and organizational mortality. Administrative Science Quarterly, 36(2): 187-218.

Bebenroth, R., \& Hemmert, M. 2013. Are emerging market multinationals milking their cross border acquisition targets? A study of inbound Japanese and Korean M\&As. Kobe University RIBE Discussion Paper Series, DP2013-06.

Beck, U. 1992. Risk society: Towards a new modernity. London: Sage.

Benner, M. J., \& Tushman, M. L. 2003. Exploitation, exploration, and process management: The productivity dilemma revisited. Academy of Management Review, 28(2): 238-256.

Bercovitz, J., \& Mitchell, W. 2007. When is more better? The impact of business scale and scope on long-term business survival, while controlling for profitability. Strategic Management Journal, 28(1): 61-79.

Berry, H., Guillén, M. F., \& Zhou, N. 2010. An institutional approach to cross-national distance. Journal of International Business Studies, 41(9): 1460-1480.

Bertrand, O., \& Zitouna, H. 2008. Domestic versus cross-border acquisitions: Which impact on the target firms' performance? Applied Economics, 40(17): 2221-2238.

Bhagat, S., Malhotra, S., \& Zhu, P. 2011. Emerging country cross-border acquisitions: Characteristics, acquirer returns and cross-sectional determinants. Emerging Markets Review, 12(3): 250-271.

Bromiley, P., Govekar, M., \& Marcus, A. 1988. On using event-study methodology in strategic management research. Technovation, 8(1-3): 25-42. 
Brown, S. J., \& Warner, J. B. 1985. Using daily stock returns: The case of event studies. Journal of Financial Economics, 14(1): 3-31.

Buckley, P. J., Elia, S., \& Kafouros, M. 2010. Acquisitions from emerging countries: What factors influence the performance of target firms in advanced countries? European Journal of International Management, 4(1-2): 30-47.

Buono, A. F., Bowditch, J. L., \& Lewis III, J. W. 1985. When cultures collide: The anatomy of a merger. Human Relations, 38(5): 477-500.

Capron, L. 1999. The long-term performance of horizontal acquisitions. Strategic Management Journal 20(11): 987-1018

Capron, L., Dussauge, P., \& Mitchell, W. 1998. Resource redeployment following horizontal acquisitions in Europe and North America, 1988-1992. Strategic Management Journal, 19(7): 631-661.

Cartwright, S., \& Cooper, C. L. 1993. The role of culture compatibility in successful organizational marriage. The Academy of Management Executive, 7(2): 57-70.

Caves, R. E. 1989. Mergers, takeovers, and economic efficiency: Foresight vs. hindsight. International Journal of Industrial Organization, 7(1): 151-174.

Caves, R. E. 1996. Multinational enterprise and economic analysis. Cambridge University Press.

Cebenoyan, A. S., Papaioannou, G. J., \& Travlos, N. G. 1992. Foreign takeover activity in the US and wealth effects for target firm shareholders. Financial Management, 21(3): 58-68.

Chari, A., Chen, W., \& Dominguez, K. M. 2012. Foreign ownership and firm performance: Emerging market acquisitions in the United States. IMF Economic Review, 60(1): 1-42.

Chatterjee, S., Lubatkin, M. H., Schweiger, D. M., \& Weber, Y. 1992. Cultural differences and shareholder value in related mergers: Linking equity and human capital. Strategic Management Journal, 13(5): 319-334.

Chen, W. 2011. The effect of investor origin on firm performance: Domestic and foreign direct investment in the United States. Journal of International Economics, 83(2):219-228.

Chen, C., \& Cornu, P. 2002. Managerial performance, bid premiums, and the characteristics of takeover targets. Annals of Economics and Finance, 3(1): 67-84. 
Chen, S. F. S., \& Hennart, J. F. 2004. A hostage theory of joint ventures: why do Japanese investors choose partial over full acquisitions to enter the United States? Journal of Business Research, 57(10): 1126-1134.

Chen, Y. Y., \& Young, M. N. 2010. Cross-border mergers and acquisitions by Chinese listed companies: A principal-principal perspective. Asia Pacific Journal of Management, 27(3): 523-539.

Coviello, N. E., \& Munro, H. J. 1995. Growing the entrepreneurial firm: networking for international market development. European Journal of Marketing, 29(7): 49-61.

Cuervo-Cazurra, A., \& Genc, M. 2008. Transforming disadvantages into advantages: Developing-country MNEs in the least developed countries. Journal of International Business Studies, 39(6): 957-979.

Cuervo-Cazurra, A., Inkpen, A., Musacchio, A., \& Ramaswamy, K. 2014. Governments as owners: State-owned multinational companies. Journal of International Business Studies, 45(8): 919-942.

Dalziel, M. 2008. The seller's perspective on acquisition success: Empirical evidence from the communications equipment industry. Journal of Engineering and Technology Management, 25(3): 168-183.

Danbolt, J. 2004. Target company cross-border effects in acquisitions into the UK. European Financial Management, 10(1): 83-108.

Danbolt, J., \& Maciver, G. 2012. Cross-Border versus Domestic Acquisitions and the Impact on Shareholder Wealth. Journal of Business Finance \& Accounting, 39(78): 1028-1067.

Dann, L. Y., Mayers, D., \& Raab, R. J. 1977. Trading rules, large blocks and the speed of price adjustment. Journal of Financial Economics, 4(1): 3-22.

Datta, D. K. 1991. Organizational fit and acquisition performance: Effects of postacquisition integration. Strategic Management Journal, 12(4): 281-297.

Datta, D. K., Pinches, G. E., \& Narayanan, V. K. 1992. Factors influencing wealth creation from mergers and acquisitions: A meta-analysis. Strategic Management Journal, 13(1): 67-84.

Desai, A., Kroll, M., \& Wright, P. 2005. Outside board monitoring and the economic outcomes of acquisitions: A test of the substitution hypothesis. Journal of Business Research, 58(7): 926-934. 
Dutz, M. A. 1989. Horizontal mergers in declining industries: Theory and evidence. International Journal of Industrial Organization, 7(1): 11-33.

Eder, K. 1999. Societies learn and yet the world is hard to change. European Journal of Social Theory, 2(2): 195-215.

Fisman, R. 2001. Estimating the value of political connections. American Economic Review, 91(4): 1095-1102.

Fuller, K., Netter, J., \& Stegemoller, M. 2002. What do returns to acquiring firms tell us? Evidence from firms that make many acquisitions. The Journal of Finance, 57(4): 1763-1793.

Gaur, A. S., Malhotra, S., \& Zhu, P. 2013. Acquisition announcements and stock market valuations of acquiring firms' rivals: A test of the growth probability hypothesis in China. Strategic Management Journal, 34(2):215-232.

Geroski, P. A., Mata, J., \& Portugal, P. 2010. Founding conditions and the survival of new firms. Strategic Management Journal, 31(5): 510-529.

Globerman, S., \& Shapiro, D. 2009. Economic and strategic considerations surrounding Chinese FDI in the United States. Asia Pacific Journal of Management, 26(1): 163183.

Govindarajan, V., \& Ramamurti, R. 2011) Reverse innovation, emerging markets, and global strategy. Global Strategy Journal, 1(3-4): 191-205.

Graebner, M. E. 2004. Momentum and serendipity: How acquired leaders create value in the integration of technology firms. Strategic Management Journal, 25(8-9): 751777.

Graebner, M. E., \& Eisenhardt, K. M. 2004. The seller's side of the story: Acquisition as courtship and governance as syndicate in entrepreneurial firms. Administrative Science Quarterly, 49(3): 366-403.

Graebner, M. E., Eisenhardt, K. M., \& Roundy, P. T. 2010. Success and failure in technology acquisitions: Lessons for buyers and sellers. The Academy of Management Perspectives, 24(3): 73-92.

Guillén, M. F., \& García-Canal, E. 2009. The American model of the multinational firm and the "new" multinationals from emerging economies. The Academy of Management Perspectives, 23(2): 23-35.

Gupta, A. K., Smith, K. G., \& Shalley, C. E. 2006. The interplay between exploration and exploitation. Academy of Management Journal, 49(4): 693-706. 
Habermas, J. 1979. Historical materialism and the development of normative structures. Communication and the Evolution of Society, 95-129.

Haleblian, J., Devers, C. E., McNamara, G., Carpenter, M. A., \& Davison, R. B. 2009. Taking stock of what we know about mergers and acquisitions: A review and research agenda. Journal of Management, 35(3): 469-502

Harris, R. S., \& Ravenscraft, D. 1991. The role of acquisitions in foreign direct investment: Evidence from the US stock market. The Journal of Finance, 46(3): 825-844.

Haspeslagh, P. C., \& Jemison, D. B. 1991. Managing acquisitions: Creating value through corporate renewal. New York: Free Press.

Heckman, J. 1979. Sample selection bias as a specification error. Econometrica 47, 153162.

Hexter, R. M. 1968. How to sell your company. Harvard Business Review, 46(5): 71-77.

Hillman, A. J., Keim, G. D., \& Schuler, D. 2004. Corporate political activity: A review and research agenda. Journal of Management, 30(6): 837-857.

Hofstede, G. 1980. Culture's consequence: International differences in work-related values. Newbury Park.

Hohenthal, J., Johanson, J., \& Johanson, M. 2014. Network knowledge and businessrelationship value in the foreign market. International Business Review, 23(1): 4-19.

Hymer, S. H. 1976. A study of direct foreign investment. Cambridge, MA: MIT Press.

Inkpen, A. C., Sundaram, A. K., \& Rockwood, K. 2000. Cross-Border Acquisitions of US Technology Assets. California Management Review, 42(3): 51.

Jemison, D. B., \& Sitkin, S. B. 1986. Corporate acquisitions: A process perspective. Academy of Management Review, 11(1): 145-163.

Jepperson, R. L., \& Swidler, A. 1994. What properties of culture should we measure? Poetics, 22(4): 359-371.

Johnson, S., \& Mitton, T. 2003. Cronyism and capital controls: Evidence from Malaysia. Journal of Financial Economics, 67(2): 351-382.

Jory, S.R., \& Ngo, T.N. 2014. Cross-border acquisitions of state-owned enterprises. Journal of International Business Studies 45(9): 1096-1114. 
Kale, P., Singh, H., \& Raman, A. P. 2009. Don’t integrate your acquisitions, partner with them. Harvard Business Review, 87(12): 109-115.

Kang, J. K. 1993. The international market for corporate control: Mergers and acquisitions of US firms by Japanese firms. Journal of Financial Economics, 34(3): 345-371.

Khanna, T., \& Palepu, K. 1997. Why focused strategies may be wrong for emerging markets. Harvard Business Review, 75(4): 41-48.

Kim, W. C., Hwang, P., \& Burgers, W. P. 1993. Multinationals' diversification and the risk-return trade-off. Strategic Management Journal, 14(4): 275-286.

Knoerich, J. 2010. Gaining from the global ambitions of emerging economy enterprises: An analysis of the decision to sell a German firm to a Chinese acquirer. Journal of International Management, 16(2): 177-191.

Knoerich, J. 2016. Why some advanced economy firms prefer to be taken over by Chinese acquirers. Columbia FDI Perspectives, No. 187, November 21, 2016.

Kogut, B. 1985. Designing global strategies: Comparative and competitive value-added chains. Sloan Management Review, 26(4): 15-28.

Krug, J. A., \& Hegarty, W. H. 2001. Predicting who stays and leaves after an acquisition: A study of top managers in multinational firms. Strategic Management Journal, 22(2): 185-196.

Lebedev, S., Peng, M. W., Xie, E., \& Stevens, C. E. 2015. Mergers and acquisitions in and out of emerging economies. Journal of World Business, 50(4): 651-662.

Lester, R. H., Hillman, A., Zardkoohi, A., \& Cannella, A. A. 2008. Former government officials as outside directors: The role of human and social capital. Academy of Management Journal, 51(5): 999-1013.

Li, J. 1995. Foreign entry and survival: Effects of strategic choices on performance in international markets. Strategic Management Journal, 16(5): 333-351.

Li, J., Li, P., \& Wang, B. 2016. Do cross-border acquisitions create value? Evidence from overseas acquisitions by Chinese firms. International Business Review, 25(2): 471483.

Li, J., \& Guisinger, S. 1991. Comparative business failures of foreign-controlled firms in the United States. Journal of International Business Studies, 22(2): 209-224. 
Lien, Y. C., Piesse, J., Strange, R., \& Filatotchev, I. 2005. The role of corporate governance in FDI decisions: Evidence from Taiwan. International Business Review, 14(6): 739-763.

Lu, J. W., \& Beamish, P. W. 2004. International diversification and firm performance: The S-curve hypothesis. Academy of Management Journal, 47(4): 598-609.

Lubatkin, M., \& Shrieves, R. E. 1986. Towards reconciliation of market performance measures to strategic management research. Academy of Management Review, 11(3): 497-512.

MacKinlay, A. C. 1997. Event studies in economics and finance. Journal of Economic Literature, 35(1): 13-39.

Madhok, A., \& Keyhani, M. 2012. Acquisitions as entrepreneurship: asymmetries, opportunities, and the internationalization of multinationals from emerging economies. Global Strategy Journal, 2(1): 26-40.

Mahalanobis, P. C. 1975. On the generalized distance in statistics. Multivariate Statistical Methods: Among-Groups Covariation, 124-130.

Mann, B. J. S., \& Kohli, R. 2011. Target shareholders' wealth creation in domestic and cross-border acquisitions in India. International Journal of Commerce and Management, 21(1): 63-81.

March, J. G. 1991. Exploration and exploitation in organizational learning. Organization Science, 2(1): 71-87.

Masulis, R. W., Wang, C., \& Xie, F. 2009. Agency problems at dual-class companies. The Journal of Finance, 64(4): 1697-1727.

McWilliams, A., \& Siegel, D. 1997. Event studies in management research: Theoretical and empirical issues. Academy of Management Journal, 40(3): 626-657.

Megginson, W. L., \& Netter, J. M. 2001. From state to market: A survey of empirical studies on privatization. Journal of Economic Literature, 39(2): 321-389.

Meglio, O., \& Risberg, A. 2011. The (mis) measurement of M\&A performance-A systematic narrative literature review. Scandinavian Journal of Management, 27(4): 418-433.

Miller, D., \& Chen, M. J. 1996. Nonconformity in competitive repertoires: A sociological view of markets. Social Forces, 74(4): 1209-1234. 
Mitchell, M. L., \& Netter, J. M. 1989. Triggering the 1987 stock market crash: Antitakeover provisions in the proposed house ways and means tax bill? Journal of Financial Economics, 24(1): 37-68.

Morosini, P., Shane, S., \& Singh, H. 1998. National cultural distance and cross-border acquisition performance. Journal of International Business Studies, 29(1): 137-158.

Ning, L., Kuo, J. M., Strange, R., \& Wang, B. (2014). International investors’ reactions to cross-border acquisitions by emerging market multinationals. International Business Review, 23(4): 811-823.

Okhmatovskiy, I. 2010. Performance implications of ties to the government and SOEs: A political embeddedness perspective. Journal of Management Studies, 47(6): 10201047.

Prabhala, N. R. 1997. Conditional methods in event studies and an equilibrium justification for standard event-study procedures. The Review of Financial Studies, 10(1): 1-38.

Rabbiosi, L., Elia, S., \& Bertoni, F. 2012. Acquisitions by EMNCs in developed markets. Management International Review, 52(2): 193-212.

Ramamurti, R. 2012. What is really different about emerging market multinationals? Global Strategy Journal, 2(1): 41-47.

Ramaswamy, K. 1997. The performance impact of strategic similarity in horizontal mergers: Evidence from the US banking industry. Academy of Management Journal, 40(3): 697-715.

Ranft, A. L., \& Lord, M. D. 2002. Acquiring new technologies and capabilities: A grounded model of acquisition implementation. Organization Science, 13(4): 420441.

Reus, T. H., \& Lamont, B. T. 2009. The double-edged sword of cultural distance in international acquisitions. Journal of International Business Studies, 40(8): 12981316.

Rockwell, W. F. 1968. How to acquire a company. Harvard Business Review, 46(5): 121132.

Rugman, A. M. 2009. Theoretical aspects of MNEs from emerging economies. In R. Ramamurti (Ed.), Emerging multinationals in emerging markets: 42-63. Cambridge, UK: Cambridge University Press. 
Sabatier, P. A., \& Jenkins-Smith, H. 1993. Policy change and learning: An advocacy coalition framework. Boulder: Westview.

Shaver, J. M. 1998. Accounting for endogeneity when assessing strategy performance: Does entry mode choice affect FDI survival? Management Science, 44(4): 571-585.

Singh, H., \& Montgomery, C. A. 1987. Corporate acquisition strategies and economic performance. Strategic Management Journal, 8(4): 377-386.

Sirower, M. L., \& O'Byrne, S. F. 1998. The Measurement of Post-Acquisition Performance: Toward a Value-Based Benchmarking Methodology. Journal of Applied Corporate Finance, 11(2): 107-121.

Stucchi, T. 2012. Emerging market firms’ acquisitions in advanced markets: Matching strategy with resource-, institution- and industry-based antecedents. European Management Journal, 30: 278-289.

Toninelli, P. A. 2000. The rise and fall of public enterprise. In P.A. Toninelli (Ed.), The rise and fall of state-owned enterprise in the western world: 3-24. Cambridge, UK: Cambridge University Press.

Uhlenbruck, K., \& De Castro, J. O. 2000. Foreign acquisitions in Central and Eastern Europe: Outcomes of privatization in transitional economies. Academy of Management Journal, 43(3): 381-402.

Uhlenbruck, K. 2004. Developing acquired foreign subsidiaries: The experience of MNEs in transition economies. Journal of International Business Studies, 35(2): 109-123.

UNCTAD. 2017. World investment report 2017: Investment and the digital economy. New York: United Nations.

Vermeulen, F., \& Barkema, H. 2001. Learning through acquisitions. Academy of Management Journal, 44(3): 457-476.

Weber, Y., Shenkar, O., \& Raveh, A. 1996. National and corporate cultural fit in mergers/acquisitions: An exploratory study. Management Science, 42(8): 12151227.

White, H. 1980. A heteroskedasticity-consistent covariance matrix estimator and a direct test for heteroskedasticity. Econometrica: Journal of the Econometric Society, 48(4): 817-838. 
Wright, P., Ferris, S. P., Hiller, J. S., \& Kroll, M. 1995. Competitiveness through management of diversity: Effects on stock price valuation. Academy of Management Journal, 38(1): 272-287.

Xin, K. K., \& Pearce, J. L. 1996. Guanxi: Connections as substitutes for formal institutional support. Academy of Management Journal, 39(6): 1641-1658.

Yelle, L. E. 1979. The learning curve: Historical review and comprehensive survey. Decision Sciences, 10(2): 302-328.

Zaheer, S. 1995. Overcoming the liability of foreignness. Academy of Management Journal, 38(2): 341-363.

Zeng, Y., Douglas, T. J., \& Wu, C. 2013. The Seller's Perspective on Determinants of Acquisition Likelihood: Insights from China's Beer Industry. Journal of Management Studies, 50(4): 673-698. 
VITA

\section{FAISAL R. HARAHAP}

Born, Jakarta, Indonesia

1989-1991

B.S., Economics

Arizona State University

Tempe, Arizona

1991-1993

M.A., in Economics

The University of Oklahoma

Norman, Oklahoma

2009-2012

M.S., Agricultural Economics

The University of British Columbia

Vancouver, British Columbia

2012-2017

Doctoral Candidate, Business Administration

Florida International University

Miami, Florida

\section{PUBLICATIONS \& PRESENTATIONS}

Harahap, F. (1996). State-owned enterprise reform in Indonesia: An overview. In N.C. Yuen, N.J. Freeman, \& F.C. Huynh (Eds.), State-owned enterprise reform in Vietnam: Lessons from Asia. Singapore: ISEAS.

Harahap, F. (2012). Estimating long-run elasticities of rural wage determinants in Indonesia: The Johansen cointegration method. (Master’s thesis, University of British Columbia).

Kim, J. Harahap, F., Zhao, J. (Summer, 2014). Multicultural work teams and individual performance of crew members in the cruise industry. Poster presented at ICHRIE Summer Conference in San Diego, CA.

Liu, Y., Harahap, F., and Von Glinow, M. A. (August, 2014). A structured model toward crosslevel cultural analyses. Paper presented at Academy of Management Conference in Philadelphia, PA.

Liu, Y., Harahap, F., Von Glinow, M. A., and Clarke, L. (Summer, 2014). A structured snowball model approach to cross-level cultural analyses. Paper presented at CLADEA Conference in Barcelona, Spain.

Liu, Y., Harahap, F., \& Von Glinow, M. A. (2014). A structured snowball model toward crosslevel cultural analyses. In Academy of Management Proceedings 2014(1): 14945. 